Columbia Law School

Scholarship Archive

2019

From a "Culture of Unwellness" to Sustainable Advocacy:

Organizational Responses to Mental Health Risks in the Human

Rights Field

Margaret Satterthwaite

Sarah Knuckey

Ria Singh Sawhney

Katie Wightman

Rohini Bagrodia

See next page for additional authors

Follow this and additional works at: https://scholarship.law.columbia.edu/faculty_scholarship

Part of the Human Rights Law Commons, Public Administration Commons, and the Public Policy Commons 
Authors

Margaret Satterthwaite, Sarah Knuckey, Ria Singh Sawhney, Katie Wightman, Rohini Bagrodia, and Adam Brown 


\title{
FROM A "CULTURE OF UNWELLNESS" TO SUSTAINABLE ADVOCACY: ORGANIZATIONAL RESPONSES TO MENTAL HEALTH RISKS IN THE HUMAN RIGHTS FIELD
}

\author{
MARGARET SATTERTHWAITE, NYU SCHOOL OF LAW \\ SARAH KNUCKEY, COLUMBIA LAW SCHOOL \\ RIA SINGH SAWHNEY, HUMAN RIGHTS ADVOCATE, INDIA \\ KATIE WIGHTMAN, NYU SCHOOL OF LAW \\ ROHINI BAGRODIA, THE NEW SCHOOL FOR SOCIAL RESEARCH \\ ADAM BROWN, THE NEW SCHOOL FOR SOCIAL RESEARCH*
}

\section{TABLE OF CONTENTS}

I. INTRODUCTION .

\begin{abstract}
${ }^{*}$ We extend our gratitude to Alexandra Zetes, who was central to the design and orchestration of this study while serving as a Masiyiwa-Bernstein Fellow from 2016 to 2017. Without Alex's creative and tireless work, this study would not have been possible. The authors thank the members of the Advisory Committee established to provide external advice on the project that resulted in this publication: Yvette Alberdingk Thijm, Executive Director, WITNESS; Lucia Nader, Brazilian human rights expert and independent consultant; and Alice Nah, Lecturer, Centre for Applied Human Rights, University of York. Many thanks to Magda Adamowicz, Senior Program Specialist, Open Society Foundations for indefatigable support and clear vision. The authors also thank Nikta Daijavad, Benjamin Hoffman, Sarah Hong, Jennifer Lim, Elisavet Makridis, Amanda McNally, Kezia Paladina, Anjli Parrin, Deborah Popowski, Ignacio Riesco, Marcela Schaefer, and Miguel Zamora for their work as interviewers; Alexia Braun, Fontanne Chu, Ellie Dupler, Estefania Giaccone, Sarah Murphy, Taro Tanaka, and Kalpana Yadav for their work as research assistants; and Judith Bauder, Hana Monica Hutabarat, Alp Ozturk, Mary Margaret Quinn, and Nikki Reisch for their work as translators. Finally, the authors thank the editors and staff of the Southern California Review of Law and Social Justice for their work on this article.
\end{abstract}




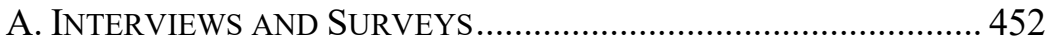

B. PROTOCOL AND ETHICAL CONSIDERATIONS ........................... 452

C. EXPERT INTERVIEW SAMPLE .................................................. 454

D. ORGANIZATIONAL INTERVIEW SAMPLE ................................. 454

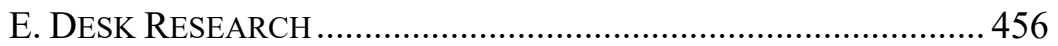

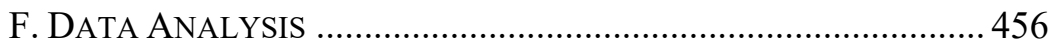

III. STRESS, HARM, AND TRAUMA IN THE HUMAN RIGHTS

FIELD: RESEARCH, EXPOSURE, AND EFFECTS................. 457

A. PRIOR RESEARCH ON STRESS AND TRAUMA IN THE Human

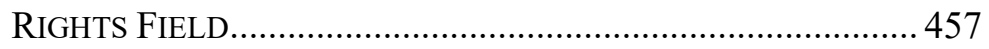

B. Human Rights Advocates' Views ABOUt HaRm, STRESS, AND TRAUMA IN THE HUMAN RIGHTS FIELD ......... 459

1. Vicarious Exposure to Traumatic or Distressing Material 460

2. Direct Trauma Exposure: Witnessing Traumatic or Distressing Incidents 461

3. Direct Trauma Exposure: Threats and Harm to Advocates. 462

4. Discrimination and Bias.................................................. 464

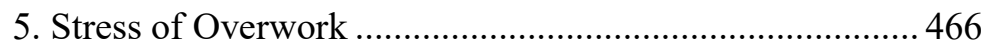

6. Perceived Inefficacy ........................................................... 467

7. Stress of Precarious and Poor Working Conditions.......... 469

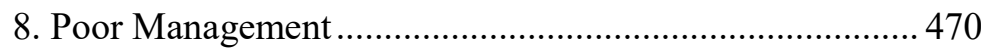

C. Human Rights AdVocates' Views ABOut the EFFECTS OF STRESS AND TRAUMA ....................................................4 470

1. Anxiety, Depression, and Suicide..................................... 471

2. Physical Ailments, Sleep Disturbance, and Substance

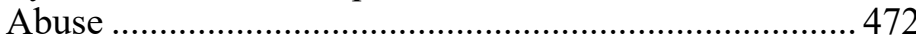

3. Mental Distress and PTSD Symptoms................................. 474

4. Demotivation and Burnout.................................................. 474

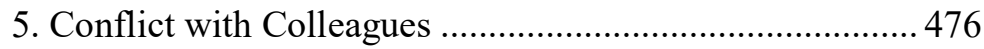

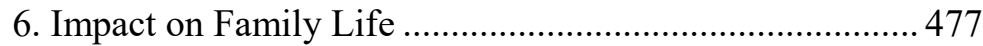

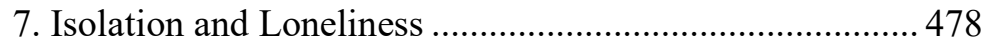

IV. PERCEPTION OF MENTAL HEALTH AND WELL-BEING IN THE HUMAN RIGHTS FIELD .............................................. 478

A. NeGATIVE Perceptions of the State of Mental

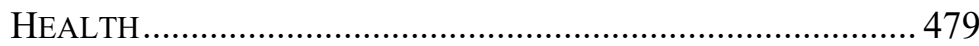

B. Poor Institutional Responses to Mental Health ......... 481

C. Well-Being Pioneers are Creating Space ...................... 483

D. LaCK of Mental Health AND Well-Being Dialogue..... 484 
V. CHALLENGES TO PROMOTING WELL-BEING IN THE HUMAN RIGHTS FIELD. 486

A. INDIVIDUAL BELIEFS AND HUMAN RIGHTS CULTURE: Martyr CUlture, SAVIOR MENTALITy, AND MENTAL HEALTH STIGMA.

B. WorkloAd, "Productivity" Pressure, AND THE MARKETPLACE OF HUMAN RIGHTS 493

C. ORGANIZATIONAL RELIANCE ON INDIVIDUAL "MENTAL HEALTH" AND "SELF-CARE" 495

D. POOR MANAGEMENT AND LEADERSHIP. 497

E. LACK OF MENTAL HEALTH EDUCATION, AwARENESS, AND RESEARCH. 499

F. FUNDING STRUCTURES, LIMITED FUNDING, AND ECONOMIC DISADVANTAGE .502

G. LACK OF ACCESS TO PSYCHOLOGICAL OR PSYCHOSOCIAL SuPPORT OR TAILORED MENTAl HEALth PROGRAMMING . 505

VI. ORGANZATIONAL TACTICS TO PROMOTE WELL-BEING AND RESILIENCE 509

A. ORGANIZATIONAL COMMITMENT AND MANAGEMENT LEADERSHIP 509

B. VIEWING WELL-BEING AS POLITICAL .................................... 513

C. EDUCATION, TRAINING, AND RESOURCES.............................. 516

D. STAFF WORKING GROUPS AND FEEDBACK TO MANAGEMENT ... 518

E. MAINSTREAMING ATTENTION TO WELL-BEING INTO INDIVIDUAL, TEAM, AND ORGANIZATIONAL MEETINGS, PROACTIVE CHECK-INS, AND DEBRIEFS. 519

F. COUNSELING AND PSYCHOLOGICAL SUPPORT ........................ 521

G. PEER SUPPORT AND SOCIALIZING 524

H. MAKING MEANING, AND RECOGNIZING ACHIEVEMENTS

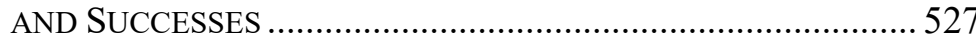

I. SHIFTING TOPIC OR TYPE OF WORK ……................................ 529

J. TRAUMA-AWARE WORKFLOWS ............................................. 531

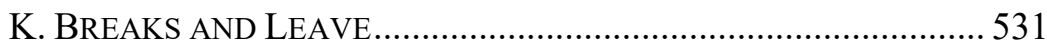

L. REMOTE WORKING AND FLEXIBLE HOURS ........................... 534

M. OfFERING INDIVIDUAL WELL-BEING PRACTICES ................... 535

N. ART, SPIRITUAL, AND RELIGIOUSLY ROOTED HEALING

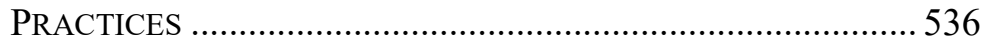

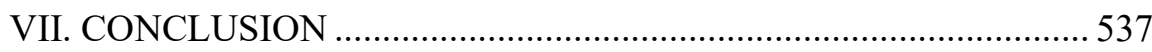

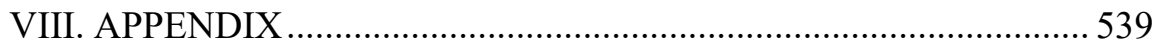


A. CASE Study 1: Paving a Feminist Path TOWARD Well-

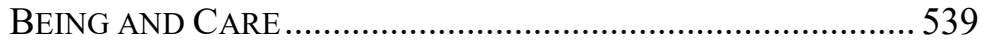

B. CASE STUdy 2: FROM CRISIS TO LEADERSHIP, CONVERSATIONS, AND FUNDING.... 543

C. Case Study 3: Fostering Holistic, Collaborative, AND SUSTAINABLE WELL-BEING 545

D. CASE Study 4: BALANCING Well-Being Practice With EXCESSIVE WORKLOADS 548

E. Case Study 5: CReating An Organizational CUlture THAT VALUES WELL-BEING

\section{INTRODUCTION}

Human rights advocates often experience their advocacy as a source of fulfilment, meaning, strength, joy, friendship, and love. Yet human rights advocacy can also involve exposure to significant stressors and harms of myriad forms. Advocates - whether they are working to counter abuses committed against their own communities or in solidarity with the rights of others, and whether at local, national, or international organizationsengage in a wide array of activities, including investigations, community mobilization, direct action, trainings, advocacy to governments and companies, law reform, lobbying, accompaniment, empowerment, litigation, campaigns, and fundraising. ${ }^{1}$ In doing so, they can face direct and vicarious trauma, organizational stressors, and field-wide systemic harms and obstacles to well-being. ${ }^{2}$ Some forms of exposure seem inherent to any efforts against abuse and injustice. Others are attributable to human rights organizational practices which could, with will and effort, be reformed. There are also field-wide harms and obstacles to well-being that are linked to deeply entrenched human rights cultures or to the socio-economic and political structures in which the human rights field is embedded. These would require major transformations of the human rights field to be overcome.

Advocates working to advance justice frequently interview survivors of horrific abuse, document the harms that perpetrators have inflicted, seek out and analyze evidence of systematic violations, and unearth policies that trap marginalized communities in extreme poverty. ${ }^{3}$ They conduct advocacy by often telling and re-telling their own or others' accounts of

\footnotetext{
${ }^{1}$ Sarah Knuckey, Margaret Satterthwaite, \& Adam Brown, Trauma, Depression, and Burnout in the Human Rights Field: Identifying Barriers to Resilient Advocacy, 49 COLUM. HuM. RTS. L. REV. 267, 269 (2018).

${ }^{2}$ Id. at $269-70$.

${ }^{3}$ Id. at 269.
} 
suffering. Advocates may experience discrimination within organizations and movements, as well as inter-generational trauma resulting from systemic oppression in the broader society. Whether they are working on issues that impact their communities directly or not, advocates may work in insecure environments or be targeted by governments, armed groups, or companies seeking to silence their voices. ${ }^{4}$ Advocates can also face stress from overwork, feel that they are ineffective or can never do enough, experience poor management, and work within organizational cultures that lead advocates to feel undervalued or like a "cog" required to turn out reports for employers or funders. ${ }^{5}$ Some advocates are paid for their work and others work without monetary compensation; either way, many advocates can experience job and economic insecurity. When paid, wages are frequently inadequate, jobs are short-term or precarious, and health care, disability insurance, and retirement savings are often impossible, particularly for individuals working at local or smaller organizations. Advocates based in the global south especially face structural barriers to individual economic security and adequate, or any, organizational funding. Organizations that try to change these dynamics by adopting better pay, benefits, and well-being policies often find themselves stymied by the human rights marketplace. They can be unable to raise sufficient resources from human rights funders, who may be more focused on short-term "outputs" and concrete "impacts," instead of perceived "intangibles," like the well-being of advocates. ${ }^{6}$

These conditions can combine to place intense pressure on the wellbeing and mental health of human rights advocates. While advocates around the world are differently situated in a number of respects and face many different types and levels of harm and stress, recent research suggests that, generally, human rights advocates likely experience elevated levels of posttraumatic stress disorder ("PTSD"), depression, and burnout. ${ }^{7}$ These challenges are experienced not only at the individual level; they also impact and are impacted by organizational, movement-level, and field-wide conditions, structures, and responses. ${ }^{8}$

This Article presents findings from a qualitative study of how individual human rights advocates perceive well-being and mental health issues within the human rights field, and how human rights organizations in

\footnotetext{
${ }^{4}$ See Knuckey, Satterthwaite, \& Brown, supra note 1, at 305.

${ }^{5}$ See Cher Weixia Chen \& Paul C. Gorski, Burnout in Social Justice and Human Rights Activists: Symptoms, Causes and Implications, 7 J. HuM. RTS. PRAC. 366, 376-77 (2015).

${ }^{6}$ Knuckey, Satterthwaite, \& Brown, supra note 1, at 276-78.

${ }^{7}$ Knuckey, Satterthwaite, \& Brown, supra note 1, at 267.

${ }^{8}$ See Chen \& Gorski, supra note 5 (discussing various factors of organizations and human rights culture that affect advocate burnout).
} 
all regions of the world are responding to well-being concerns. The findings are based on an analysis of 110 interviews, which include advocates at 70 human rights organizations from 35 countries and more than three dozen experts; surveys of organizational policies and practices; desk research concerning well-being and mental health; and the experiences of the coauthors working as human rights practitioners with non-governmental organizations ("NGOs") around the world.

After presenting in Part II the methodology used for the study, Part III explores human rights advocates' views about the sources and effects of exposure to harm, trauma, or stress. Advocates reported many sources of stress and cautioned against narrowly focusing on "trauma" when discussing well-being. Advocates perceive wide-ranging mental health effects from exposure to stress and harm. These effects included psychological, interpersonal, and professional impacts. Advocates described concerns about: anxiety, depression, and suicide; physical ailments, substance abuse, and sleep disturbance; PTSD symptoms; demotivation, compassion fatigue, and burnout; conflict with colleagues; family life impacts; and isolation and withdrawal. While these mental health issues are concerns in themselves, the issue of advocacy sustainability also arose: poor well-being harms the sustainability and efficacy of human rights movements, since advocates who are burned out or experiencing depression and anxiety are likely to be less effective in their individual and collective work.

Part IV examines advocates' views about how the field has responded to mental health risks and concerns. Data collected for this study suggests that the human rights field generally has responded poorly to well-being risks. Advocates believe mental health is overlooked and that NGOs are not doing enough to prevent unnecessary exposure to harms, mitigate unavoidable risks, or repair harms once they occur. Most advocates interviewed for this study stated that mental health is a serious challenge in the human rights field. Advocates reported that while some organizations and movements, especially feminist groups, have long had serious discussions about and taken measures to counter the harmful effects of human rights work, inadequate attention has been paid across the field generally to well-being, advocates' needs are under-addressed, and far more needs to be done by organizations. When steps are taken, they are too often single trainings or events, or individualized and de-politicized "self-care" measures, instead of structural changes in the way work is done or deeper shifts in human rights culture or in how organizations and the field itself are organized and constituted. Many also noted that more advocates and organizations have, in recent years, deepened discussion and action to understand and improve mental health. These observations suggest that the field generally appears to be in a period of transition toward improved 
organizational attention to well-being and mental health, but that organizational policies and practices lag behind.

Part $\mathrm{V}$ sets out the many challenges identified by advocates as inhibiting or preventing individuals and organizations from accepting, recognizing, and responding to the mental health and well-being impacts of their work. Advocates frequently discussed a set of overlapping beliefsheld by individual advocates and seen as part of a dominant "human rights culture"-which contribute to poor well-being and impede the steps that could be taken to improve mental health. Advocates described interlinked cultures of martyrdom, in which the human rights field fosters a view among advocates that they should sacrifice themselves for others and the work; a savior or hero mentality, in which advocates view themselves as capable of and duty-bound to "save" others; and a cowboy attitude, where "toughness" and risk-taking are celebrated. Many advocates reported that the sheer volume of human rights abuses, advocates' significant workloads, and organizational and funder pressures to "produce" results in harms to wellbeing and leaves little time to focus on improving well-being. Advocates stressed that the tendency for human rights funders to seek big impacts for small grants, and to fund projects but not core costs have a very real toll on the mental health of advocates. Some advocates noted that organizational well-being efforts that overly focus on steps that individuals can take for their own self-care - rather than viewing well-being politically, holistically, relationally, culturally, and organizationally-could function to inhibit deeper and more structural responses. Human rights advocates also reported that management attitudes and practices could have a significant effect on whether or how organizations respond to well-being needs. Advocates reported that the lack of awareness and training about mental healthincluding among advocates, managers, and human resources personnel-is a significant barrier to reform. Funding is also a pervasive obstacle to organizational improvements, and particularly affects small, local-level, and global south NGOs. And, where staff are also paid very little, their ability to implement well-being strategies can be impeded. The funding model for much human rights work is critical: some advocates reported that donors do not make adequate resources available for things like fair pay, leave and sabbatical time, physical and mental health services, and wellbeing programs. Human rights organizations also face numerous obstacles when seeking psychological or psychosocial support for their staff. Beyond economic inaccessibility, psychological services are sometimes hard to find due to country conditions or may be available but not sufficiently tailored for human rights advocates.

Part VI outlines the tactics human rights organizations have adopted to tackle mental health challenges and to advance well-being. These include: commitment by organizations and leadership by management; viewing 
well-being as political rather than adopting an individualized, medicalized model; providing education, trainings, and resources; creating systems for staff to provide feedback to management about well-being; mainstreaming attention to well-being into meetings; pro-active check-ins and debriefs with staff; providing or facilitating access to therapy; fostering peer-to-peer support mechanisms; creating opportunities for socializing and building advocate bonds; highlighting impacts and achievements; shifting work undertaken; adopting trauma-aware workflows; providing and ensuring breaks and leave; enabling remote working and flexible hours; offering individual well-being practices; and engaging in art, spiritual, and religiously rooted healing practices.

The Article concludes in Part VII by identifying next steps that can support the human rights field to enhance the well-being and resilience of advocates. ${ }^{9}$ Research is needed to evaluate interventions and programming to advance well-being. Support should be provided to enable more knowledge-sharing across organizations and advocates, and tailored educational materials and trainings should be created and offered. Funders play a particularly important role; they can support organizations that want to make structural changes and introduce well-being interventions. Ultimately, change is needed at all levels of the human rights field: from the individual and interpersonal to the organizational, cultural, and the structure of the field as a whole. The conversation has begun; the next steps should broaden commitment and action across the field.

\section{METHODOLOGY}

It is difficult to find sufficiently inclusive, shared, and meaningful terms to name the issues that are the subject of this Article. This Article uses the terms "mental health" and "well-being" relatively interchangeably, casting an inclusive net with the hope of bringing to the human rights field insights from mental health literature that are clarifying and affirming, rather than stigmatizing and pathologizing. We use "well-being" to evoke general living conditions as well as physical, socio-economic, work, and emotional satisfaction. However, it should be noted that the term can also carry negative connotations in some contexts and be linked with expensive, indulgent "self-care" approaches; some advocates reject the term for this reason. The term "mental health" is disfavored by some advocates because of its connotations with pathology, because it can be depoliticized, or

\footnotetext{
${ }^{9}$ This project is continuing beyond this publication, and the authors are working to develop sets of concrete recommendations for funders, NGOs, and others. We have not included the broader set of recommendations in this Article since they were still under development at the time of publication.
} 
because it is linked with specific cultural traditions. Some advocates prefer to use other concepts and frames, such as "healing justice," "care," or "holistic security." 10 When we use the concept "mental health" in this Article, we mean to invoke the rights-based definition advanced by the UN Special Rapporteur on Health, who has explained that:

[T] here is no health without mental health....[G]ood mental health means much more than the absence of a mental impairment. The modern understanding of mental health includes good emotional and social well-being, healthy non-violent relations between individuals and groups, with mutual trust of, tolerance of and respect for the dignity of every person. ${ }^{11}$

The research for this study aims to map what human rights organizations are, and are not, doing to support the mental health and wellbeing needs, broadly understood, of human rights advocates. Building on earlier studies, which focus largely on individual-level responses and experiences, this study examines organizational practices. In an attempt to capture practices used in the global human rights field, we contacted a broad cross-section of organizations to learn about their approaches to well-being (organizational interviews), and we also interviewed a set of individuals identified as experts in this area (expert interviews). For those who participated in organizational interviews, we use the terms "advocate," "activist," and "defender" interchangeably, often guided by how interviewees themselves identified. For those who participated in expert interviews, we generally used the term "expert." Both the organizational interviews and the expert interviews were conducted using a semistructured interview guide. Additionally, we gathered information on organizational practices through a survey administered online and by interview. Finally, the primary research for this study was supplemented by desk research.

This study was carried out over a period of thirty months, from December 2016 to May 2019, which included the development of the study materials, conducting interviews, and the analysis, interpretation, and external review of the results by the Advisory Committee.

\footnotetext{
${ }^{10}$ See infra pp. 514-15, 549.

${ }^{11}$ The Right to Mental Health, Office of the United Nations High Comm'r for Human Rights, https://www.ohchr.org/EN/Issues/Health/Pages/RightToMentalHealth.aspx (last visited Jan. 31, 2019). See also Human Rights Council, United NATions Gen. Assembly, Report of THE SPECIAL RAPPORTEUR ON THE RIGHT OF EVERYONE TO THE ENJOYMENT OF THE HIGHEST AtTAinable Standard of Physical AND MENTAL Health (2017) (discussing challenges and potential changes to promoting mental health in the context of human rights violations).
} 


\section{A. INTERVIEWS AND SURVEY}

The semi-structured interview guides used in this study were developed through an iterative process and guided by findings from prior research identifying high levels of mental health challenges, low utilization of mental health services, a widespread lack of preparation for potentially deleterious mental health impacts of human rights advocacy, and high levels of direct and secondary exposure to traumatic stress. ${ }^{12}$ Through this study, we sought to fill a gap in the knowledge base concerning institutional factors and organizational responses to well-being concerns in human rights advocates. Therefore, the central focus of the study was to map how organizations are responding to these issues by examining whether they had adopted policies and practices to enhance well-being, the challenges organizations face in taking on this work, and the kinds of practices human rights organizations have deployed. This research team has also been involved in discussions and workshops on well-being in human rights advocacy for the past few years. These discussions with advocates, lawyers, and students about this topic informed the questions included in the interview guides. The interview guides were originally written in English, and then translated into multiple languages. Interviews were conducted in person, on the phone, or by video chat, in English, French, Spanish, Portuguese, and Bahasa Indonesian. ${ }^{13}$

In addition to the interviews, we created a structured written questionnaire, which interviewees could fill in themselves online, or, where more feasible, answer during an interview.

\section{B. PRotocol AND ETHICAL CONSIDERATIONS}

The individuals working on this study carried out all documentation and reporting in accordance with the core human rights fact-finding

\footnotetext{
${ }^{12}$ Direct trauma refers to the direct experience of a traumatic event, such as directly experiencing a threat or violent attack. Secondary or indirect exposure to trauma refers to exposure that is vicarious, such as when interviewing direct victims of trauma. Often the greater the amount of indirect or vicarious exposure to traumatic material, the greater the risk of experiencing harmful impacts. See, e.g., Laurie Anne Pearlman \& James Caringi, Living and Working Self-Reflectively to Address Vicarious Trauma, in TREATING COMPLEX TRAUMATIC STRESS DisORDERS: AN EVIDENCE-BASED Guide 202, 202-204 (Christine A. Courtois \& Julian D. Ford eds., 2010); Jason M. Newell \& Gordon A. MacNeil, Professional Burnout, Vicarious Trauma, Secondary Traumatic Stress, and Compassion Fatigue, 6 Best Pracs. Mental Health 57, 60-61 (2010).

${ }^{13}$ We did not use interpreters, and conducted the interviews in English, or another language preferred by the interviewee.
} 
principles of accuracy, confidentiality, sensitivity, impartiality, independence, integrity, and professionalism. ${ }^{14}$

Interviews carried out for this study were conducted or supervised by professors, researchers, advocates, and psychologists experienced in human rights or mental health. Advanced psychology and human rights law students also conducted interviews. ${ }^{15}$ Prior to conducting interviews, the interviewers were trained in the purpose of the research and the interview process.

Prior to commencing the research, this team conducted a detailed rights-based risk assessment. The assessment focused on limiting any privacy, re-traumatization, security, and legal risks related to conducting interviews. ${ }^{16}$ Steps were taken throughout this study to protect the identities of those participating in the research. Researchers applied detailed informed consent guidelines to all interviews. Interviewees chose whether and how they wanted to be identified in this Article and any other public materials. The Article does not include names or other individually identifying information of those interviewed unless requested by the individual concerned. This study was determined by NYU's Institutional Review Board to be exempted from review, as the study was focused on evaluating organizational practices and not on individual experiences. ${ }^{17}$

\footnotetext{
${ }^{14}$ See, e.g., RaOul Wallenberg InSt. Of Hum. RTS. AND Humanitarian Law, Guidelines ON INTERNATIONAL HUMAN RIGHTS FACT-FINDING VISITS AND REPORTS BY NONGOVERNMENTAL ORganisations (The Lund-LONDON Guidelines) 1 (last revised 2015) (creating guidelines to improve human rights factfinding that are based on "accuracy, objectivity, transparency and credibility"); Human Rights Council Res. 5/2, U.N. Doc. A/HRC/RES/5/2 (June 17, 2007) ("[T]he work of the [Human Rights] Council shall be guided by the principles of universality, objectivity, and non-selectivity, constructive international dialogue and cooperation, ..."); INT'L NGO CHARTER OF ACCOUNTABILITY LTD., INTERNATIONAL NON GOVERNMENTAL ORGANISATIONS ACCOUNTABILITY CHARTER (2005) (pledging a commitment to principles that include independence, responsible advocacy, transparency, and professional management).

${ }^{15}$ In all, nineteen researchers were involved in conducting interviews.

${ }^{16}$ In the preparation of this risk assessment, we referred to a range of sources, including: ENRIQUE Eguren \& Marie CaraJ, New Protection Manual For Human Rights DeFEnders ( $3 \mathrm{~d}$ ed., 2009) (providing human rights advocates with a guide to improve their own security and protection as well as run risk-assessments); INT'L ORG. FOR MIGRATION, IOM DATA PROTECTION MANUAL (2010) (providing a guide and principles for protecting personal data that is collected in the process of human rights advocacy); Office of the United Nations High Comm'r for Hum. Rts., Training Manual on Human Rights Monitoring (United Nations 2001) (providing information on effective human rights monitoring in a wide variety of advocacy contexts).

${ }^{17}$ Following submission of the research protocol to the NYU University Committee on Activities Involving Human Subjects, the Committee determined on March 17, 2017 that the study entailed no human subjects research and therefore did not require Institutional Review Board (IRB) review.
} 


\section{EXPERT INTERVIEW SAMPLE}

The research team developed a list of experts through recommendations by individuals who have worked on mental health and well-being issues in the field of human rights; conducting research on wellbeing in the field; and asking experts to recommend others. The study team conducted individual semi-structured interviews with more than three dozen experts from Asia and the Pacific, Sub-Saharan Africa, the Americas (including North, Central and South America), Europe, and the Middle East and North Africa ("MENA"). Insights from the expert interviews helped round out the organizational interviews, providing additional perspective, depth, and nuance.

\section{ORGANIZATIONAL INTERVIEW SAMPLE}

For the organizational interviews, we set out to meet two aims. First, we aimed to conduct a general survey of whether and how human rights organizations across the world are cognizant of, and responding to, the mental health and well-being impacts of human rights work. Second, we aimed to map specific well-being practices employed by human rights organizations.

We had originally planned to construct a multi-stage cluster sample, beginning with a purposive sample of about 300 human rights groups and institutes listed as partners of a key human rights funder, the Ford Foundation; a leading global human rights organization and network, the Féderation International de Droits de l'Homme ("FIDH"); and recognized national human rights mechanisms, the U.N. list of National Human Rights Institutions. We divided that group by region and drew a random sample within each region. We had then planned to create a second sample of human rights organizations that had been identified as having taken notable steps toward improving the well-being of their staff or volunteers.

However, our initial outreach efforts were met with significantly lower than anticipated response rates. In order to overcome this difficulty, we modified our approach significantly, adopting a purposive sampling method to identify the groups and organizations to include in our study. We ultimately included seventy organizations in our study. This group was comprised of organizations that engage in human rights work, and were specifically selected to ensure the diversity of geographical regions, languages used, focuses of the organizations' work, sizes of the organizations, amounts of resources at their disposal, and whether they were identified as having responded to well-being concerns. Therefore, for this sample group, we included no more than four organizations based in any 
single country. ${ }^{18}$ We interviewed between six to eighteen organizations per major geographic region, plus a group of organizations working globally. ${ }^{19}$ Given the initial low response rates, we relied on our professional networks to facilitate contact with the organizations in this sample; this was largely successful. In the end, the sample included a broad range of organizationsfrom very large international non-governmental organizations to regional, national, and local NGOs, to activist groups or collectives that eschew the term "NGO" for various reasons, including that it is seen as too bureaucratized or de-radicalized. The organizations are diverse in their focus. While some work on the entire spectrum of human rights issues, others concentrate on particular issues, including environmental human rights, digital rights, and the rights of specific populations, such as women, LGBTQI persons, persons with disabilities, indigenous peoples, and migrants. Those affiliated with these different organizations and collectives have varying types of organizational affiliation. Some are full-time paid employees; some are part-time employees, consultants, or volunteers; and others are advocates who object to the professionalization of the human rights endeavor. Another form of diversity is reflected in the relationship between the advocates and the rights they champion. Some are geographically, economically, and experientially removed from the communities and/or issues on which they work, while others are community-based advocates working to end the human rights violations that they themselves are experiencing, and some have both experiences across different parts of their identities. Finally, some organizations in the sample are based in conflict, insecure, or isolated environments, while others are based in relatively stable settings; some are based in large urban areas, while others are rural; and across the sample, organizations are based in low, lower-middle, upper-middle, and high-income countries.

\footnotetext{
${ }^{18}$ While advocates from seven organizations were based in the United States, we classed three of these organizations as "international" because they work globally.

${ }^{19}$ To identify groups for this sample, the following steps were undertaken: (1) The research team used their professional networks to create a broad list of organizations by identifying groups from each of the regions and globally that identified as a human rights organization, group, or movement, or would generally be recognized as such by other human rights advocates. (2) A broad-ranging sample was assembled which included, where possible, the following in each region: (a) large, established, well-known NGOs; (b) small organizations, meaning that the organization has a limited budget, small number of staff, one or no offices, etc.; (c) community or movement-based organizations or those made up of mostly volunteers; (d) national or sub-national organizations; (e) organizations from different countries within each region; (f) organizations using a local language; ( $\mathrm{g}$ ) organizations operating in situations where their staff were known to be vulnerable or personally threatened, in the course of their work; (h) organizations which focused on a diverse set of human rights issues; and (i) within each region, organizations identified as having responded in some way to well-being concerns.
} 
Our sampling methodology does not yield a statistically valid representative sample. However, it does represent a broad range of human rights organizations from across the globe. In addition to seeking a broad and diverse sample, we also sought to interview groups seen as leading or innovating well-being (case study interviews). Based on interviews with some of these leading groups, we prepared organization-focused case studies, which are presented in the appendix to this Article.

Overall, 110 interviews were conducted for this study, of which seventy were with representatives of human rights organizations, and more than three dozen with experts. ${ }^{20}$ Organizations in thirty-five countries participated in this study.

\section{E. DESK RESEARCH}

In addition to interviews, this study also drew on analysis of a wide array of other sources, including peer-reviewed publications on mental health, human rights scholarship, news articles, information published by NGOs, and policy guidelines. The data obtained from this research informed the rationale for the study and helped to contextualize the results.

\section{F. DATA ANALYSIS}

The research team developed its approach to analyzing the data gathered for this study in several stages. First, the research team together reviewed the data, and members of the team identified the key themes that emerged in the interviews. Then, the research team conducted a content analysis of the interviews to systematically identify and collate the themes in all interview records. The themes were then reviewed in depth and revised. Each theme was then analyzed and sections of the Article were coauthored by both the human rights and psychology experts on the research team. Drafts of the analysis were reviewed by the members of the Advisory Committee. Each interviewee quoted or cited was provided an opportunity to review how their information was used and to review the material presented for accuracy.

\footnotetext{
${ }^{20}$ Two organizations and two experts participated in second interviews as part of the case study interviews.
} 


\section{STRESS, HARM, AND TRAUMA IN THE HUMAN RIGHTS FIELD: RESEARCH, EXPOSURE, AND EFFECTS}

"This work requires strength. We hear, we hear, and every day we take the stress of others and hold it, and so eventually it comes on us. You can see the manifestations of this in staff-fatigue, stress, insomnia. We accumulate what others tell us. "21

\section{- Lucie Boalo Hayali, Gender Based Violence Specialist, President of the Technical Commission of Projects, Association des Femmes Juristes de Centrafrique (Association of Women Lawyers of the Central African Republic)}

This study examines organizational responses to mental health and well-being concerns among human rights advocates. It builds on an emerging body of research that identifies and analyzes these concerns. This Part begins by briefly summarizing the existing research on human rights advocates' mental health. It then presents findings from the interviews conducted for this study about: (a) the primary sources of stress that advocates see themselves as facing; and (b) the kinds of mental health effects that advocates see resulting from stress and trauma exposure.

\section{A. Prior ReSEARCH on StRESS AND TRAUMA IN the Human RightS FIELD}

Human rights advocates are exposed to a wide variety of stressors and trauma in their work to document harm and advance justice. They can experience direct or indirect exposure to trauma through interviewing rights-holders and witnesses, visiting sites of abuse, reviewing videos or documents containing graphic content, or being threatened or harmed themselves. Advocates can also experience workplace and organizational stressors in the form of challenging working conditions, overwork, poor management, lack of role clarity, competition among staff and across organizations, and insufficient funding.

In order to address advocates' mental health and well-being, it is crucial to identify and understand the specific factors that place advocates at risk for negative mental health impacts. Although stress and vicarious-

\footnotetext{
${ }^{21}$ Interview with Lucie Boalo Hayali, Gender Based Violence Specialist, President of the Technical Commission of Projects, Association des Femmes Juristes de Centrafrique (Association of Women Lawyers of the Central African Republic) (July 19, 2018).
} 
and sometimes direct - exposure to trauma are inherent in human rights advocacy, there has been little research on the mental health of advocates. The limited research that has been carried out is largely focused on the types of stressors and exposures encountered, and on the rates of mental health issues among advocates.

One study found that around $40 \%$ of sampled UN workers were exposed to at least one instance of potentially traumatic material in the year leading up to the survey. ${ }^{22} \mathrm{~A}$ separate survey of 346 human rights advocates found that $34.4 \%$ of respondents "directly witnessed trauma toward others"; " $89.3 \%$ were indirectly exposed to trauma through work with clients, survivors, and witnesses"; and more than $20 \%$ were "themselves ... victims of violence, detention, or threats." 23 Another study examined frontline advocates' experiences of well-being and reported that many "spoke about the challenges of living with pervasive fear and anxiety; of their inability to sleep; of their feelings of powerlessness in the face of oppression; of feeling 'numb' or emotionless; of being in constant 'fight mode'; and of their fatigue, despair, isolation, and stigmatisation."24

One of the first studies that assessed human rights advocates' exposure to traumatic events using a clinical approach studied advocates working in Kosovo and reported that $17.1 \%$ of participants experienced elevated levels of anxiety, $8.6 \%$ had depression, and $7.1 \%$ reported symptoms of PTSD. ${ }^{25}$ A global, cross-sectional survey of human rights advocates was later conducted to further explore rates of negative mental health impacts. ${ }^{26}$ This study found that $19.4 \%$ of those surveyed met criteria for PTSD, $18.8 \%$ for subthreshold PTSD, $14.7 \%$ for depression, and $19 \%$ for burnout. ${ }^{27}$ Similarly, a study of UN personnel found that $17.9 \%$ screened positive for Generalized Anxiety Disorder ("GAD”), 22.8\% for depression, and 19.9\% for PTSD. ${ }^{28}$ Another survey, in which journalists and advocates were asked

\footnotetext{
22 Dubravka Suzic et Al., United Nations High Comm'R For Refugees, Staff WellBEING AND MENTAL HEALTH IN UNHCR 66 (2016), https:/hr.un.org/sites/hr.un.org/files/Staff\%20Wellbeing\%20and\%20Mental\%20Health\%20in\%20UNHCR\%20_0.pdf.

${ }^{23}$ Knuckey, Satterthwaite, \& Brown, supra note 1, at 270.

${ }^{24}$ Alice M. NAH, Univ. of York, Wellbeing, Risk, and Human Rights Practice 2 (2017). Stigmatization is discussed infra in Section V.

${ }^{25}$ Timothy H. Holtz et al., Mental Health Status of Human Rights Workers, Kosovo, June 2000, 15 J. TRAUMATIC StRESS 389, 391 (2002).

${ }^{26}$ Amy Joscelyne et al., Mental Health Functioning in the Human Rights Field: Findings from an International Internet-Based Survey, PLOS One, Dec. 23, 2015, at 2-3.

${ }^{27} \mathrm{Id}$. at 6,8 .

28 United Nations Secretariat, Staff Well-Being Survey Data Report 6 (2017), https:/hr.un.org/sites/hr.un.org/files/Staff\%20wellbeing\%20survey\%20data\%20report_FINAL_2018_ENGLISH_0.pdf.
} 
about the negative impact of workplace exposure to graphic and upsetting online content, found that $40 \%$ of participants reported that this exposure had high "personal adverse effects" and 20\% reported high "professional adverse effects." 29 The duration of human rights work was also associated with adverse mental health impacts. ${ }^{30}$ Another study of advocates found that $60 \%$ of the participants reported living with stress at least some of the time, and $28 \%$ reported experiencing stress all the time. ${ }^{31}$ Among those who reported these levels of stress, concurrent physical or cognitive symptoms, such as muscle pain $(83 \%)$, headaches $(55 \%)$, and inability to concentrate $(50 \%)$ were also noted. ${ }^{32}$

A qualitative study based on interviews with a group of U.S.-based social justice and human rights advocates revealed several factors that advocates identified as contributing to feelings of burnout, including lack of attention to self-care, infighting within the activist community itself, and sensitivities to injustice. ${ }^{33}$ In a similar vein, human rights advocates in another study said they felt "morally obliged to work to the point of physical and emotional exhaustion." 34

\section{B. Human Rights Advocates' Views about HaRm, Stress, AND TRAUMA IN THE HUMAN RigHTS FIELD}

Given the limited research conducted to date on the mental health of human rights advocates, this study sought the views of experts and organizational representatives about the types of harms, stressors, and trauma they believe to be common and significant in the human rights field. Participants reported that advocacy can often involve, or seemingly require, vicarious or direct exposure to human rights abuses, which can be potentially distressing or traumatic. While exposure to trauma was seen as significant, advocates noted the importance of not overly or narrowly focusing on "trauma" when considering stress and well-being issues. In addition to the inherent risks of exposure to human rights abuse, participants also reported numerous human rights organizational, cultural, and field-

\footnotetext{
29 Sam Dubberley et al., Making Secondary Trauma a Primary Issue: A Study of Eyewitness Media AND Vicarious TRAuma on the Digital Frontline 32 (2015), http://eyewitnessmediahub.com/uploads/browser/files/Trauma\%20Report.pdf.

${ }^{30}$ Holtz et al., supra note 25, at 393-94.

${ }^{31}$ Alejandra Burgos et al., Iniciativa Mesoamericana de Defensoras de Derechos Humanos, Traversias Para Pensar y ACtuar: EXPeriencias DE Autocuidado DE DEFENSORAS DE DERECHOS HUMANOS EN MESOAMERICA 98 (2014).

${ }^{32} I d$. at 99.

${ }^{33}$ Chen \& Gorski, supra note 5, at 377.

${ }^{34}$ Kathleen Rodgers, 'Anger is Why We're All Here': Mobilizing and Managing Emotions in a Professional Activist Organization, 9 Soc. Movement STUD. 273, 287 (2010).
} 
wide sources of harm and stress. These included experiencing discrimination and bias within NGOs, the human rights field, and in society more broadly; being overworked, which was often attributed to organizational dysfunction, the pressures of funders, NGO competition, and advocates' beliefs about how much they should work and sacrifice to advance justice; advocates' beliefs about the ineffectiveness of their work; precarious and poor working conditions, explained not only by the broader economic system but also by human rights philanthropy, inequalities between NGOs in the global north and the global south, and internal NGO decisions about how to distribute their funds; and poor NGO management.

\section{Vicarious Exposure to Traumatic or Distressing Material}

Indirect exposure to traumatic or distressing material is an inherent feature of human rights work around the world. Those interviewed for this study explained that advocates review documents, videos, and audio files that contain evidence or allegations of human rights violations; conduct interviews with and advise or represent victims of and witnesses to abuse. They also can have secondary exposure to human rights abuse (which may also constitute direct exposure to distressing material) through handling physical evidence and visiting sites to examine physical evidence of human rights violations (such as mass graves, morgues, and detention centers). ${ }^{35}$ Advocates interviewed for this study underscored that organizations are "bombarded" with raw and graphic imagery, ${ }^{36}$ that secondary exposure is

\footnotetext{
${ }^{35}$ Interview with Advocate (7 Int'l) (Feb. 13, 2018) (“[W]omen are cataloguing the threats, events, the murders, the deaths of women working on the ground as human rights defenders . .."); Interview with Ajeng Larasati, Research and Policy Advocacy Coordinator, LBH Masyarakat (Feb. 13, 2018) ("[M]y colleague worked with a [foreign] client who was tricked into trafficking drugs into Indonesia ..."; "we interviewed women who were on death row."). See also Interview with Ram Kumar Bhandari, Director, National Network of Families of the Disappeared (May 11, 2018) (reporting that advocates get arrested); Interview with Advocate (3 Isr.) (Apr. 24, 2018) (reporting that field workers have seen things, such as "a 5-year old being arrested, or a 10 year old who is being beaten up by the army."); Interview with Andrea Rocca, Deputy Director, Front Line Defenders. (Aug. 3, 2017).

${ }^{36}$ Interview with Alexa Koenig, Executive Director, Human Rights Center, U.C. Berkeley School of Law (Mar. 7, 2018). Interestingly, while this expert acknowledged the beneficial physical protective element of this online work, she also noted that the removal from the physical space of abuse created "a negative psychosocial [effect] where you don't have a sense of camaraderie that comes from being part of a team, or the feeling that you can immediately do triage." See also Interview with Andrea Lampros, Associate Director, Human Rights Center, U.C. Berkeley School of Law (Mar. 7, 2018) (explaining how online information from photographs or social media posts on different platforms has exploded over the last eight years).
} 
omnipresent and hard to disengage from, ${ }^{37}$ and that this kind of exposure represents a significant source of stress. ${ }^{38}$

2. Direct Trauma Exposure: Witnessing Traumatic or Distressing Incidents

Human rights advocates reported that many activists directly witness traumatic events and distressing circumstances. This is particularly true for those who live or work in countries and/or communities experiencing extreme socio-economic disadvantages, state repression, or armed conflict. The advocates interviewed for this study gave examples of the kinds of traumatic experiences that they are exposed to in their work, including witnessing torture, killings, beatings, sexual assault, civil disturbances, armed conflict, unsafe living conditions, extreme poverty, and their family members or colleagues being threatened, detained, or killed. ${ }^{39}$

One advocate explained, "[Y]ou are seeing people killed, you are documenting cases of the worst kind," such as "a case of an old lady who had her head bashed in by the militia," or a massacre in which forty girls were burned to death. ${ }^{40}$ Another human rights advocate noted that such exposure can be part of a "traumatic culture" created by a government that perpetrates "one trauma after another," in which "defenders are affected even harder by the work," sometimes experiencing a "widespread sense of terror." ${ }^{41}$ For example, a targeted break-in at the offices of an NGO "ended up actually taking the lives of the security guards who were guarding the premises at the time of the break-in. ... [S]taff wake up in the morning, go to work, there is a corpse mutilated." 42 An advocate who works to document

${ }^{37}$ Interview with Yana Ziferblat-Knopova, Director, FLOW-Integral Change Center (July 6, 2017). See also Interview with Annabelle Borg, Counselling Psychologist (Mar. 6, 2018) (explaining that advocates are "directly exposed to the narratives of bodies, pictures of bodies, mutilations, torture, rape... These people are seeing the hacking, the marks, they're seeing the tears.").

${ }^{38}$ Interview with Andrea Rocca, supra note 35; Interview with Dominika Bychawska, Board Member, Helsinki Foundation for Human Rights (Sept. 6, 2017) (explaining that human rights work requires "emotional engagement, because you work with people in distressed situations all the time," which has an impact on advocates); Interview with Ajeng Larasati, supra note 35 (describing the difficulty "to regain our spirit after interviewing"). See also Interview with Advocate (7 Int'l), supra note 35.

39 Interview with Advocate (3 Isr.), supra note 35 (describing the shock of witnessing the destruction of a village).

40 Interview with Tabitha Netuwa, Protection and Security Management Manager, DefendDefenders (June 29, 2017).

${ }^{41}$ Interview with Expert (23 Americas) (June 14, 2017).

42 Interview with Yona Wanjala, Executive Director, Defenders Protection Initiative (Sept. 15, 2017). 
extrajudicial executions explained that human rights work requires that advocates find ways to work in the face of horror, and that advocates "cry a lot" when they hear about a new killing, especially the execution of a child or a fellow advocate. ${ }^{43}$ Further, this advocate and others explained that in addition to the witnessing and documentation work of human rights advocacy, advocates must often respond to the emergency needs of victims as well, such as helping victims find safety when they are experiencing acute distress or threats. ${ }^{44}$

\section{Direct Trauma Exposure: Threats and Harm to Advocates}

Advocates can also be direct victims of abuse themselves, whether they are directly targeted for their work or because they live or work in insecure locations. Given the nature of their work, some instances of violence against advocates are specifically targeted to send a message to the human rights organization and its supporters. A recent survey of 346 human rights advocates found that $6.4 \%$ reported having been taken hostage, beaten, or assaulted; $20.2 \%$ had been arrested; and $20.5 \%$ had been directly threatened with violence as a result of their human rights work. ${ }^{45}$

Human rights advocates interviewed for this Article similarly explained that they are also at risk of being threatened, taken hostage, tortured, beaten, sexually assaulted, or detained as a result of their work. ${ }^{46}$ One advocate surmised that "sometimes you put your life in danger if you are advocating for something that the government doesn't want to solve,

\footnotetext{
43 Interview with Renata Trajano \& Raúll Santiago, Members of the Coletivo Papo Reto, \& Priscila Neri, Senior Program Manager, WITNESS (Sept. 19, 2017).

${ }^{4}$ Id.; Associates for Health Rights Uganda, The Impact of Mental Health on the WELLBEING OF LGBTI ACTIVISTS IN UGANDA, AUgUST 2018 (on file with authors); Interview with Douglas Mawadri, former Safety \& Security Officer, Sexual Minorities Uganda ("SMUG"), currently Co-Founder, Associates for Health Rights Uganda (Nov. 27, 2017).

${ }^{45}$ Joscelyne et al., supra note 26 , at 5-6.

${ }^{46}$ Advocates may face attacks. Interview with Advocate (3 Isr.), supra note 35 ("I heard of a case that one of them was shot with a rubber bullet. A rubber bullet isn't made of rubber-it's a regular bullet surrounded by rubber." Additionally, advocates on the front line are "injured by knives and stones ... people get beat up."). Another advocate explained how "the staff in the building were trapped until midnight in the building, and were not able to be rescued by police or to leave the building" due to a group protesting an event held for past human rights abuses. Interview with Ajeng Larasati, supra note 35. See also Interview with Advocate (23 Cambodia) (Mar. 14, 2018) (describing extra-judicial killings); Interview with Expert (26 Americas) (Aug. 24, 2017) (noting an increase in type and number of attacks against human rights defenders, such as the recent death of a journalist, and how this caused an overload of work); Interview with Maria Cappello and Valeria Moscoso, Comisión Mexicana de Defensa y Promoción de los Derechos Humanos ("CMDPDH") (June 19, 2017) (noting the routine violence to which human rights defenders were exposed).
} 
and sometimes you are targeted and you can develop a sense of fear." ${ }^{47}$ One advocate in Haiti suggested that being a human rights defender is "one of the riskiest jobs. There's a lot of persecution, intimidation, and there's no help from the judiciary." ${ }^{48}$ An expert from East Africa noted how constantly living under tense circumstances affected mental well-being. ${ }^{49}$ An expert based in Ireland explained that advocates' families, including their children, are sometimes stigmatized or targeted due to their family member's work; this can be especially difficult for advocates, as they can experience guilt and distress about such attacks. ${ }^{50}$

Many advocates are themselves survivors of abuse, or come from the community on whose behalf they are advocating; as a result, they can face multiple situations that negatively impact their well-being. ${ }^{51}$ As one advocate explained, in some human rights communities "the majority are not defenders by their own choice," but rather they are victims or "mothers of the disappeared who are converted into defenders." 52

\footnotetext{
${ }^{47}$ Interview with Millicent Auma Otieno, Founder, Kiviwosheg (Feb. 28, 2018). See also Interview with Prince Chima Williams, Head of Legal Research \& Democracy Outreach, Environmental Rights Action/Friends of the Earth Nigeria (Nov. 22, 2017) ("The first challenge that we face is fear of reprisals from the actors that we are campaigning against.").

${ }^{48}$ Interview with Nixon Boumba, Member, Mouvement Democratique Populaire (Dec. 11, 2017). Similarly, an advocate based in West Africa explained that "there are lots of cases where the defenders of human rights have been physically or mentally assaulted. This has an effect on their physical health, but also on their mental health, and also that of their family." Interview with Donatien Ndingambaye, Protection and Security Management Officer, West African Human Rights Defenders (June 29, 2017).

${ }^{49}$ Interview with Prince Chima Williams, supra note 47 ("You work daily in that psychologically tense atmosphere, that you don't know what is going to happen next, and because you are bearing the burden of so many people, you are almost always at alert, so that wears out your mental alertness, which affects your mental well-being.”); Interview with Expert (9 Eur.) (Feb. 9, 2018) ("With Human Rights Defenders at Risk, who we work with, in general, it's not in a very good state - people are exposed to threats and risks on a daily basis ...").

${ }^{50}$ Interview with Andrea Rocca, supra note 35.

${ }^{51}$ Interview with Erick Monterrosas, Human Rights Defender (July 10, 2017) ("Human rights communities are typically found within larger communities (neighborhoods, churches, etc.), and this creates a situation where the human rights defender is often re-victimized by the violence reproduced in the community as well as in his or her work.").

52 Interview with Ana María Hernández Cárdenas, Directiva de Consorcio Oaxaca en México (Director of Oaxaca Consortium at Mexico), Coordinator of the Strategy of Self-Care, Collective Care and Healing, Iniciativa Mesoamericana de Mujeres Defensoras de Derechos Humanos (Mesoamerican Initiative of Women Human Rights Defenders) (June 29, 2017). See also Interview with Erick Monterrosas, supra note 51 ("Human rights defenders in Mexico are just normal people who have been placed in situations that convert them into defenders.").
} 


\section{Discrimination and Bias}

Advocates explained that they can face gender, sexuality, race, religion, or other identity-based discrimination and bias-including from within human rights organizations and movements themselves - and that this form of human rights abuse can be highly stressful or traumatic. ${ }^{53}$ One advocate explained that:

[The] gender impact is one example. Women colleagues sometimes face harassment by our own clients, and [they] need to navigate not being seen by the very people we try to assist, or in our court system, which is a very patriarchal construct and atmosphere, or with the corporations we engage with. Race is also an issue. Our white colleagues commonly are deferred to, for example, in dealing with mining companies, compared to our black colleagues who are in the room and more senior. These are intersectional issues for our black women colleagues. This is a part of the wider race dynamics we are dealing with in [our country]. ${ }^{54}$

Female human rights advocates are sometimes "doubly attacked for being defenders and for being women" by the larger community and within human rights organizations. ${ }^{55}$ Individual female advocates are sometimes "attacked as ... bad mother[s]," seen to be "neglecting the role that was imposed on them," 56 and even face "exploitation of the role as a mother" as their children can be threatened. ${ }^{57}$ LGBTQI advocates in many places can also experience intense discrimination. For instance, a Uganda-based organization has stated that, as a result of "contempt and criminalization of all LGBTQI activities" in their country, LGBTQI activists can be "accused of promotion and recruiting into homosexuality," have their residences

\footnotetext{
${ }^{53}$ See Interview with Advocate (13 Austl.) (Feb. 20, 2018) (explaining how indigenous persons in their organization faced intergenerational trauma).

${ }^{54}$ Interview with Lisa Chamberlain, Acting Director, Center for Applied Legal Studies, University of the Witwatersrand (Apr. 11, 2018).

${ }^{55}$ Interview with Ana María Hernández Cárdenas, supra note 52. See also Interview with Isha Khandeklwal, Advocate and Founding Member, Jagdalpur Legal Aid Group ("JagLAG”) (Mar. 19,2018 ) ("[W]orking here as young women is tough, it is so patriarchal . .."); Interview with James Savage, Program Officer, The Fund for Global Human Rights (Sept. 8, 2017) (noting the structures and systems that give rise to stress and pressures around human rights activism, particularly faced by women human rights defenders, such a being harassed and not being taken seriously).

${ }^{56}$ Interview with Expert (23 Americas), supra note 41.

${ }^{57}$ Interview with Ana María Hernández Cárdenas, supra note 52.
} 
attacked or even be evicted upon their landlords learning of their activism, and face rejection by their families. ${ }^{58}$

One advocate described the intense burden of intergenerational trauma faced by indigenous staff. ${ }^{59}$ An expert pointed out that minorities or persons of color experience harms and burdens that other advocates do not shoulder, particularly when working on issues like hate speech or identity-based violence. ${ }^{60}$ The expert explained that "people who might be coming in and working in a space that's not theirs will be affected differently" compared to those working to advance the rights of their own communities. ${ }^{61}$ One expert who conducted research in Kenya drew attention to the sometimes extreme differences of situation and life between national and ex-patriate staff working for international organizations: in their country of residence, ex-patriates often live alone, do not have family responsibilities, and enjoy disposable income, while national staff earn less, may have children, have financial responsibilities to extended families, and have intense non-work schedules. $^{62}$ These inequalities can cause intense disjuncture among staff, leading to friction and sometimes conflict. ${ }^{63}$ The same expert pointed to the connections between inequalities and power differentials within organizations and movements with the "moral problem" of idealizing a specific set of reasons for doing the work:

There needs to be reflection on how that serves a white, privileged, well-educated person from the global north who can cross borders. There has to be far more voice from national staff, in terms of what aid work looks like and how it should be performed and what the motivations are. A broader understanding of what the ramifications are of being committed to this work. In terms of what needs to happen-organizations need to look at who their leaders are, how inclusive is the leadership? How inclusive is the field level? What is happening at a structural [level]? Who has the voice in the space? ${ }^{64}$

\footnotetext{
${ }^{58}$ ASSOCIATES FOR HEALTH Rights UGANDA, supra note 44.

${ }^{59}$ Interview with Advocate (13 Austl.), supra note 53.

${ }^{60}$ Interview with Deepa Iyer, Senior Fellow, Race Forward (Nov. 21, 2017).

${ }^{61} I d$.

${ }^{62}$ Interview with Gemma Houldey, Doctoral Researcher, University of Sussex (June 29, 2018).

${ }^{63} I d$.

${ }^{64}$ Id.
} 


\section{Stress of Overwork}

Human rights advocates report contending often with the stress of persistently high workloads. ${ }^{65}$ As one advocate explained, such working conditions mean "the glass fills and overflows." Another advocate identified overwork as the "number one cause of burnout." ${ }^{67}$ Advocates may struggle to say "no" to additional work in the face of pressing and serious human rights issues, instead over-working to meet a perceived need to "deliver." ${ }^{68}$ They also feel a pressure to meet the demands of their managers and funders. ${ }^{69}$ Across all kinds of human rights and social justice work, advocates reported feeling overworked:

What is impressed upon them is that you need to be there for everything. Everyday. So people feel obligated to work like this. They feel they're doing a disservice to the community if they take a break, if you're not doing something on a regular basis. Capacity is a big issue. Taking on a leadership role that leads to this sense of obligation - that you have to do this and no one else is doing it. ${ }^{70}$

\footnotetext{
${ }^{65}$ Interview with Jannat Fazal, Project Coordinator and Mental Health Practitioner, Digital Rights Foundation (Jan. 4, 2018) ("With my colleagues in the cyber harassment helpline . . people get tense, and this stays with them for a few days. You still have to do calls, and you're unable to take a break."); Interview with Wadih Al-Asmar, President, Lebanese Center for Human Rights (Dec. 11,2017 ) (mentioning that even when there is mandatory leave, "just before these periods, you can feel the tension between the team with high workload."). See also Interview with Advocate (13 Austl.), supra note 53; Interview with Guacira Cesar de Oliveira, Founder, Centro Feminista de Estudos e Assessoria ("CFEMEA") (Apr. 11, 2018); Interview with Muna Baig, Human Rights Advocate (Apr. 28, 2018); Interview with Yana Ziferblat-Knopova, supra note 37; Interview with Dominika Bychawska, supra note 38; Interview with Guus van Zwoll, Coordinator of the E.U. Temporary Relocation Platform, ProtectDefenders.eu (Aug. 7, 2017).

${ }^{66}$ Interview with Ana María Hernández Cárdenas, supra note 52.

${ }^{67}$ Interview with Expert (9 Eur.), supra note 49.

${ }^{68}$ Interview with Expert (2 Eur.) (Oct. 27, 2017). See also Interview with Muna Baig, supra note 65 .

${ }^{69}$ Interview with Cindy Clark, Co-Executive Director, and Shareen Gokal, Director of Special Projects, Association for Women's Rights in Development (Oct. 4, 2018) (“[B]eing a not for profit means that there are limited resources and there are commitments to funders that we need to achieve ..."); Interview with Rupsa Mallik, Director of Programs and Innovation, CREA (Apr. 20, 2018) (" $[\mathrm{A}]$ mongst the big funders there is no idea of the toll that some of the social development work takes on activist[s] - there is no understanding and massive expectation of outcomes and indicators ...."); Interview with Arianna Schindle, Co-Founder, Rhiza Collective (June 4, 2018) (“[P] eople have access to limited resources - they're doing the jobs of 10 peoplethere's management challenges and that all comes into the mix ...").

${ }^{70}$ Interview with Gabrielle Jackson, Mental Wellness Director, Undocublack Network (Oct. 24, 2017).
} 
An expert based in Europe explained that advocates are "essentially overload[ed] and over-burden[ed]; this is exacerbated today by social media, and the fact that we are always 'on' or connected." "Ad Advocates are "working 24/7. Not just working on the computer but being on call or [experiencing] the feeling of never being able to relax."72 Advocates also explained that the corporatization of human rights, and the competitive market for human rights, exacerbate pressures to produce work output. ${ }^{73}$ Some interviewees reported that advocates feel like they are a "cog in a machine."74 Another interviewee indicated that, rather than feeling disposable, the larger problem is that advocates can feel indispensable because of the level of need in this field and, therefore, they struggle to put boundaries around their work. ${ }^{75}$ Advocates said that overwork was not only due to workflows and pressure to be constantly available, but also due to the enormity of the task advocates set for themselves - ending human rights abuses - which means that "there are always more things to do than what you can." 76

\section{Perceived Inefficacy}

Some advocates suggested that stress results from the feeling that no matter how much work is done, the work does not seem effective or sufficient to satisfactorily achieve human rights goals. Advocates expressed concerns about the intangibility of achievements of some long-term human rights work, such as witnessing and seeking justice, rather than the sense of purpose and fulfilment that can be gained when providing direct relief or taking immediate action. As an advocate based in Yemen explained, "In our work we document [with] nothing direct to give these people - we just carry their stories, with nothing to offer in the short term." advocates are extremely aware of the "suffering from the absence of justice, but [they] can only advocate and support, [without] the tools to remedy the

\footnotetext{
${ }^{71}$ Interview with Yana Ziferblat-Knopova, supra note 37.

72 Interview with Wadih Al-Asmar, supra note 65.

${ }^{73}$ Interview with Pramada Menon, Queer Feminist Activist (Jan. 29, 2018).

${ }^{74}$ Interview with Advocate (58 U.K.) (July 12, 2018); Interview with Advocate (55 Int'l) (July 13, 2018).

${ }^{75}$ Interview with Joanna Evans, Legal Director, European Human Rights Advocacy Center (June 7, 2018); Interview with Expert (26 Americas), supra note 46 ("There are cultures [where] if you do not work until a specific time you are not giving all that you can.")

${ }^{76}$ Interview with Joanna Kurosz, former Programme Director for Eurasia, Civil Rights Defenders (Aug. 31, 2017).

${ }^{77}$ Interview with Radhya Al-Mutawakel, Chairperson, Mwatana Organization for Human Rights (May 4, 2018).
} 
injustice directly." "An advocate based in India echoed this sentiment, explaining that for "a lot of our team, stress comes from the feeling that they are not being able to respond and that they need to do something. So when they feel like there is a lack of intervention, that is when the stress builds up.",79

Furthermore, advocates noted that trauma exposure can be more difficult to handle when there are perceptions that human rights advocacy is not making a difference, or where impact is obscured because of the longterm horizon of social change, or because their immediate tasks are separated from the whole. ${ }^{80}$ An advocate from an international human rights organization emphasized how difficult it can be to even conceive of sufficient remedies or impact, given the egregiousness of human rights abuse:

To be completely honest, the realities that we're talking about are so outrageous ... [N]othing can be done for a woman whose precious child has died in agony. There is nothing that can be done. And yet we have to say, "Here is a clear rational explanation for why minister whoever or senator whatever needs to do something about it." We're always offering something that is not enough.... I can crash into your car and I can literally compensate you for the damage - but that's not the case for these kinds of things that are happening to people. ${ }^{81}$

\footnotetext{
${ }^{78}$ Interview with Wadih Al-Asmar, supra note 65 .

${ }^{79}$ Interview with Ditipriya Ghosh, Director of Human Resources Management, \& Pauline Gomes, Manager of Curriculum \& Leadership Development, Breakthrough (Feb. 27, 2018).

${ }^{80}$ See, e.g., Interview with Annabelle Borg, supra note 37 ("[O]ne of the biggest risk[s] of burnout is a sense of helplessness."); Interview with Foromo Frederic Loua, Human Rights Lawyer, Les Mêmes Droits Pour Tous (Dec. 1, 2017) (explaining that advocates "see victim[s] of torture ... female genital mutilation ... those who are being beaten by the police" and feel they "are not able to bring a solution for those type of persons."); Interview with Gasser Abdel-Razek, Executive Director, Egyptian Initiative for Personal Rights (Aug. 1, 2018) (stating that advocates sometimes "become disillusioned" and ask themselves why they are engaging in human rights work, asking why they are "documenting a family, just like ... the month before, and it continues ... and the answers are not self-evident every time," though noting that when a report is published with the information documented by the advocates, "it answered [for] every single staff member ... why we are actually doing the work ..."); Interview with Expert (9 Eur.), supra note 49 ("The changes that human rights defenders are trying to bring take a lot of time and there is a lot of frustrationthese changes will take years of struggle and sometimes you won't see any result, or you will get some results and then it's destroyed.").

${ }^{81}$ Interview with Skye Wheeler, Researcher, Human Rights Watch (July 16, 2018).
} 
Another advocate explained:

There is depression because sometimes [advocates] are facing problems ... that they are not able to solve. You can see the victim of torture, FGM [female genital mutilation] ... those who are being beaten by the police. You have the feeling that you are not able to bring a solution for those type[s] of persons. Sometime[s] you can see detainees in prison who are there for years. ... [Y] ou can do everything to bring them their rights and it can be difficult to face these kind[s] of difficulties. You can have depression, or you can say everything is bad and I have to give up, because they are not understanding the necessity of our work. [Clients] can call five to fifteen times [a] day ... and you cannot do anything [for them.$^{82}$

\section{Stress of Precarious and Poor Working Conditions}

Human rights advocates interviewed for this study identified as a key source of stress their tenuous and poor working conditions, often the result of scarce resources and philanthropic policies that prioritize projects over organizational and staff development. As one expert based in the Americas explained, advocates experience "precarious working conditions: lack of job security, lack of benefits, [and] few outlets to de-stress." 83 Another expert based in Europe explained that "uncertainty when it comes to funding" leads to jobs that "don't have certainty." ${ }^{4}$

Advocates also said that working conditions can even sometimes verge on being exploitative or abusive. An advocate based in Kenya said that "staff struggle to fight for their rights [as workers], and they can't do anything. When they struggle to push [or] lobby for some of the things that need to be done, nobody cares about this. This affects them." 85 Such persistent insecurity can be incredibly stressful over time and can make it harder to take a break when one is needed. This is compounded by

\footnotetext{
${ }^{82}$ Interview with Foromo Frederic Loua, supra note 80. For further elaboration on mental health outcomes, see infra subsection C.

${ }^{83}$ Interview with Ana María Hernández Cárdenas, supra note 52.

${ }^{84}$ Interview with Expert (2 Eur.), supra note 68. See also Interview with Verónica Cruz Sánchez, Director, Las Libres (Apr. 27, 2018) ("There are no guarantees for defenders of anything basic, housing, labor, etc. Defenders are defending others who are even more vulnerable, but [advocates] do not have basic conditions for themselves."); Interview with Marty Huber, Co-Founder and CoWorker, Queer Base (June 19, 2018) (noting that within the network of advocates many work voluntarily but are also in very "precarious life situations").

${ }^{85}$ Interview with Roy Douglas Otieno, Executive Director, Tinada Youth Organization (Apr. 18, 2018).
} 
inequalities among staff. For instance, an expert who conducted field research in Kenya explained that national staff often experience significantly inferior working conditions as compared to ex-patriate staff. ${ }^{86}$

\section{Poor Management}

Human rights advocates underscored that poor management-often resulting from a lack of funding to train or support managers ${ }^{87}$ - and inadequate responses to mental health could have serious impacts on their well-being. Where management is generally poor, advocates reported increased organizational conflict, bullying, role confusion or deficient guidance, reduced mentoring and social support, and more workplace stress. ${ }^{88}$ One advocate at an international organization stated that a "lot of the stress workers face is really about how the organization works and management." ${ }^{" 89}$ Another explained that: "People get burnt out in this work and end up being managers. They're brilliant and very good analysts, but that doesn't necessarily mean they're good managers. $" 90$

Findings in recent psychology research support these concerns. Recent meta-analyses evaluating the impact of poor or destructive leadership found that inadequate leadership was associated with a variety of negative employee outcomes, including counterproductive work behavior, emotional exhaustion, low job satisfaction, withdrawing helping behavior, and reduced commitment to and identification with the organization. ${ }^{91}$

\section{Human Rights Advocates' Views ABOUt the EFFECTS OF STRESS AND TRAUMA}

The human rights advocates interviewed for this study described a wide range of harms that they believe are caused by the stress and trauma

\footnotetext{
${ }^{86}$ Interview with Gemma Houldey, supra note 62.

${ }^{87}$ Interview with Expert (9 Eur.), supra note 49 ("There is never money to do training on management. . . I see a lot of managers who have very poor skills and then when they talk to stressed team members, this creates a lot of mental health issues.").

${ }^{88}$ See, e.g., Interview with Advocate (55 Int'1), supra note 74 (discussing bullying behaviors, and a lack of accountability for abusive managers); Interview with Advocate (50 Int'l) (May 24, 2018); Interview with Expert (9 Eur.), supra note 49 (discussing how one of the barriers to mental health is management structures, and that most organizations are "very hierarchical. ... [Y] ou talk about human rights but you have macho behavior and labor issues.").

${ }^{89}$ Interview with Advocate (55 Int'l), supra note 74.

${ }^{90}$ Interview with Advocate (63 Int'l) (July 16, 2018).

${ }^{91}$ Birgit Schyns \& Jan Schilling, How Bad are the Effects of Bad Leaders? A Meta-Analysis of Destructive Leadership and its Outcomes, 24 LEADERSHIP Q. 138, 147-48 (2013); Yucheng Zhang \& Zhenyu Liao, Consequences of Abusive Supervision: A Meta-Analytic Review, 32 ASIA PACIFIC J. MGMT. 959, 977-78 (2015).
} 
experienced in their work. These effects include psychological, interpersonal, and professional impacts. Advocates described concerns about anxiety, depression, and suicide; physical ailments, substance abuse, and sleep disturbance; PTSD symptoms; demotivation, compassion fatigue, and burnout; conflict with colleagues; family life impacts; and isolation and withdrawal.

While these mental health issues are concerns in themselves, the issue of advocacy sustainability also arises: poor well-being harms the sustainability and efficacy of human rights movements, since advocates who are burned out or experiencing depression and anxiety are likely to be less effective in their individual and collective work. ${ }^{92}$ Some of these concerns, including depression, PTSD, and burnout, have been studied among human rights populations using quantitative and psychology research methods. ${ }^{93}$ Other concerns have not been researched as thoroughly using such methods and would be important areas for future research in the human rights field.

\section{Anxiety, Depression, and Suicide}

Numerous advocates interviewed for this study said that they have observed anxiety, ${ }^{94}$ depression, ${ }^{95}$ and sometimes suicide among colleagues in the human rights field. ${ }^{96}$ An advocate based in Kenya mentioned that

92 See, e.g., Interview with Yvette Alberdingk-Thijm, Executive Director, WITNESS (Oct. 3, 2018) (pointing out that well-being concerns are also sustainability issues for the human rights field).

${ }^{93}$ E.g., Knuckey, Satterthwaite, \& Brown, supra note 1 (analyzing mental health in the human rights field, particularly in the context of trauma, depression, and PTSD).

94 Anxiety (generalized anxiety disorder) is characterized by "excessive, ongoing anxiety and worry that are difficult to control and interfere with day-to-day activities." Generalized Anxiety Disorder, MAYO ClINIC, https://www.mayoclinic.org/diseases-conditions/generalized-anxietydisorder/symptoms-causes/syc-20360803 (last visited Jan. 11, 2019).

95 Depression is a mood disorder characterized by symptoms of depressed mood, irritability, changes in weight and sleep, loss of interest, unexplained aches and pains, difficulty concentrating, feelings of guilt and worthlessness, and thoughts of suicide. Depression (Major Depressive Disorder), MAYO CLINIC, http://www.mayoclinic.org/diseasesconditions/depression/basics/definition/con-20032977 (last visited Jan. 11, 2019).

${ }^{96}$ See, e.g., Interview with Advocate (3 Isr.), supra note 35 (referring to depression faced by those working in the video department); Interview with Sharon Cox, Health and Support Services Manager, Triangle Project (Oct. 27, 2017) ("The rates of depression, burnout, substance abuse are high." Interviewee also discussed suicides and attempts at suicide); Interview with Millicent Auma Otieno, supra note 47 (anxiety); Interview with Peter Ng'ola, Executive Director, Wote Youth Development (Apr. 18, 2018) ("stress, bloodshot eyes, insomnia."); Interview with Alice de Marchi Pereira de Souza, Researcher, Justiça Global (Apr. 25, 2018) ("fear, paranoia, anxiety attacks, panic syndrome"); Interview with Tessa de Ryck, Earth Rights Defenders Coordinator, EarthRights International (Mar. 7, 2017) (“a lot of stress"); Interview with Advocate (50 Int'l), supra note 88 (PTSD, depression); Interview with Joanna Evans, supra note 75 ("very high levels 
when "you hear [about] cases of suicide ... then you realize the magnitude of the problem the person might have been facing." 97 One advocate based in South Africa stated that "the rates of depression, burnout, [and] substance abuse are high. We have had suicides, and probably more attempts at suicide. You name it, we have it." 98 An advocate based in Brazil stated, "I hear overwhelming testimonies from activists that they suffer from panic, anxiety, depression, insomnia, not being able to stop." 99

Feelings of depression were described as linked with advocates feeling unable to right the wrongs they document or to present a solution for victims. For example, an advocate based in Guinea explained that when advocates cannot solve clients' problems, depression sets in. ${ }^{100}$

An advocate based in Africa explained the personal mental toll involved when employees of partner organizations described being attacked and desperately needing support and help. In response to this:

[T] he staff . . . have to listen to their complaints, to their issues, to their concerns. And by listening to all the negative or the challenging situations, there are impacts on the staff at the inner [level] for those who are involved with such a process. And [through] that ... you feel exhausted, you feel broken, [and] you carry it home. ${ }^{101}$

\section{Physical Ailments, Sleep Disturbance, and Substance Abuse}

Some advocates interviewed for the study said the weight of what they carry affects their behavior and can harm them physically. ${ }^{102}$ One advocate

\footnotetext{
of anxiety, high levels of controlling behavior ... a lot of unidentified trauma."); Interview with Advocate (62 Egypt) (July 5, 2018) ("[E]xtreme anxiety, the feeling of lack of security, hopelessness."); Interview with Idil Aydınoğlu, Civil Society in the Penal System, Ceza İnfaz Sisteminde Sivil Toplum Derneği / Türkiye Hapishane Çalışmaları Merkezi ("CISST") (June 22, 2018) (describing anxiety and fear for the future); Interview with Maria LaHood, Deputy Legal Director, Center for Constitutional Rights (June 6, 2018) (referring to feelings of hopelessness and helplessness).

${ }^{97}$ Interview with Millicent Auma Otieno, supra note 47.

${ }^{98}$ Interview with Sharon Cox, supra note 96.

${ }^{99}$ Interview with Guacira Cesar de Oliveira, supra note 65. See also Interview with Gabrielle Jackson, supra note 70 ("The current state of people engaged in the work is that they face very high intensity anxiety and depression. There is a lot of tension.").

${ }^{100}$ Interview with Foromo Frederic Loua, supra note 80.

${ }^{101}$ Interview with Yona Wanjala, supra note 42. See also Interview with Jannat Fazal, supra note 65 ("There is a toll of being frontline defenders. They make it their responsibility to help others, which eventually affects them mentally and physically.").

102 Interview with Advocate (3 Isr.) supra note 35 (noting how a colleague believes pain in the body is "connected with the mental stuff" that is dealt with.). See also Interview with Ram Kumar Bhandari, supra note 35.
} 
based in South Korea explained, "A lot of symptoms are psychosomatic symptoms," in which "you kind of channel...these hundreds of testimonies and you carry them with you and you don't know. Then later, ... [you ask yourself], 'Why do you get sick all the time?'"103 An expert based in the Middle East has noticed that "when people take a few days off, they fall sick." 104

Advocates acknowledged problems with sleeping, as well. As one expert based in the Middle East explained, "People not being able to sleep is one big thing." 105

An expert based in East Africa explained that many human rights defenders connect their trauma to physical symptoms, such as pain and other sensations that they cannot explain. ${ }^{106}$ These symptoms include fatigue, agitation, feeling weak all the time, a racing heartbeat, changes in appetite, and difficulty sleeping. One psychologist interviewed suggested:

For some of them, trauma symptoms give them the impression that they are sick. They go to a hospital, run medical checks, and are told, "You're stressed. Go home and rest." They take that report to the workplace, and they are given a day or two to rest. Even after that day or two to rest they feel the same way-and then they keep asking themselves, "What's wrong with me?"107

Some advocates observed that human rights activists sometimes selfmedicate through alcohol consumption, such that alcoholism can be a major issue in some human rights contexts. ${ }^{108}$

\footnotetext{
${ }^{103}$ Interview by Sarah Hong with Advocate (9 S. Korea) (Nov. 21, 2017). See also Interview with Erick Monterrosas, supra note 51.

${ }^{104}$ Interview with Expert (35 MENA) (May 31, 2018).

${ }^{105}$ Id. See also Interview with Peter Ng'ola, supra note 96; Interview with Gasser Abdel-Razek, supra note 80; Interview with Prince Chima Williams, supra note 47 (noting that insomnia was a problem advocates faced).

${ }^{106}$ Interview with Simon Ndaula, Clinical Psychologist (Aug. 3, 2018). See also Interview with Karen L. Culpepper, Clinical Herbalist and Licensed Massage Therapist, Embracing Rhythm LLC (Dec. 19, 2017) (noting that she was "shocked at the number of folks who had headaches and were constipated and were extremely stressed out" at a healing retreat her organization facilitated).

${ }^{107}$ Interview with Simon Ndaula, supra note 106.

${ }^{108}$ Interview with Matthew Smith, Founder and CEO, and Amy Smith, Founder and Executive Director, Fortify Rights (Oct. 17, 2017). See also Interview with Sharon Cox, supra note 96 (describing high rates of substance abuse); Interview with Advocate (62 Egypt), supra note 96 (discussing alcohol abuse as a response to working in the context of armed conflict).
} 


\section{Mental Distress and PTSD Symptoms}

Some advocates described distress or PTSD symptoms, ${ }^{109}$ including advocates experiencing shock, breakdowns, and nightmares. ${ }^{110}$ For example, an advocate from an organization in the Middle East said that a staff member who witnessed "the destruction of [a] village" and an "attack of settlers" then "entered into a state of shock." 111 Other advocates mentioned mental distress due to indirect exposure to trauma. ${ }^{112}$ An expert based in the Middle East discussed "a complete nervous breakdown of one of my colleagues, who... was working on a report that gathered testimonies of women who were assaulted by the military." 113

\section{Demotivation, Compassion Fatigue, and Burnout}

Many advocates reported that demotivation, compassion fatigue, and burnout are common. ${ }^{114}$ Compassion fatigue is the experience of emotional and physical fatigue felt by an individual, often as a result of frequent experience of helping others who are suffering. ${ }^{115}$ Burnout is a state of emotional, physical, and mental exhaustion in response to chronic emotional and interpersonal stressors. ${ }^{116}$

\footnotetext{
${ }^{109}$ PTSD is a psychological reaction in response to "[e]xposure to actual or threatened death, serious injury, or sexual violence"- through direct experience, witnessing an event, learning that the event occurred to a close friend or family member, or experiencing exposure to details of the event - resulting in significant impairment in social and/or occupational functioning. AM. PSYCHIATRIC ASS'N, Trauma- and Stressor-Related Disorders, in DIAGNOSTIC AND StATISTICAL MANUAL OF MENTAL DisORDERS: DSM-5 265, 271 (5th ed. 2013).

${ }^{110}$ Interview with Wadih Al-Asmar, supra note 65 ("all experiencing PTSD to some degree"); Interview with Tessa de Ryck, supra note 96 ("obvious PTSD"); Interview with Advocate (50 Int'l), supra note 88 (PTSD, depression). See also Interview with Expert (35 MENA), supra note 104 (discussing the occurrences of nightmares and how it can also contribute to sleep issues as well).

${ }^{111}$ Interview with Advocate (3 Isr.), supra note 35.

112 See, e.g., Interview with Sehyek Oh, former Lead Researcher, Transitional Justice Working Group (Apr. 29, 2018).

113 Interview with Expert (35 MENA), supra note 104.

${ }^{114}$ Interview with Advocate (23 Cambodia), supra note 46 (describing people leaving NGO work for the private sector). See also Interview with Douglas Mawadri, supra note 44 (noting that staff are not performing well because they are tired); Interview with Senda Ben Jebara, Tunisian LGBT Activist (June 4, 2018) (noting that young people who joined the movement have left); Interview with Expert (3 Eur.) (June 30, 2017) (noting that advocates have become ineffective or left the field); Interview with Karen L. Culpepper, supra note 106 ("I think a lot of folks really struggle with compassion fatigue.").

${ }^{115}$ See Newell \& MacNeil, supra note 12, at 61.

${ }^{116}$ See Christina Maslach, What Have We Learned About Burnout and Health?, 16 PsYCHOL. \& HEALTH 607, 609-10 (2001).
} 
Feelings of burnout can be experienced after a major adverse political change. One expert based in the Americas described:

A huge frustration $[\ldots$ at] how fast we saw some of the rights that we had believed . . . were already sufficiently guaranteed and enforced [are] dismantling. People are losing the results of many, many years of work and also hope and faith in the institutions that they have been working with for a very long time. ${ }^{117}$

Burnout can occur after intense periods of difficult work or continuous feelings of stress. An expert based in the Middle East explained that an advocate had experienced complete burnout following her work to document executions. ${ }^{118}$ One advocate perceived that female defenders in her area experience a uniquely "high level of burnout because they are always on high alert. Our [precarious] situation causes elevated levels of stress. It is a continuous stress that is accumulated as time goes on."119

Taking time off to mitigate feelings of burnout can also be a source of further negative feelings. One manager observed, "[I]f somebody burns out or collapses in a heap, maybe they are booked off for a few days. But activists generally carry guilt because they feel they should get back to it. ... [Y] ou have collapsed in a heap, and there is a resentfulness that you have time off." 120

An advocate based in Europe emphasized that, while burnout has been a long-standing issue within human rights, it can be exacerbated for those exposed to a lot of online content:

What we continuously see in the fieldwork is that the high level interaction with virtuality (i.e. virtual, online reality) - being deeply inbuilt as part of the work of many advocates - is one of the main contributors to what makes the current burnout situation as catastrophic as it is. The constancy of social and other media exposure causes a range of negative phenomena, including extra exposure to aggression . . . Nowadays, in addition to their own trauma history and the trauma that human rights defenders regularly face in their work as primary and secondary traumatic stress, there is another significant level of trauma exposure derived from the intense interaction with

\footnotetext{
${ }^{117}$ Interview with Expert (19 Americas) (June 27, 2017).

118 Interview with Expert (35 MENA), supra note 104.

${ }^{119}$ Interview with Ana María Hernández Cárdenas, supra note 52.

${ }^{120}$ Interview with Sharon Cox, supra note 96.
} 
virtuality. Given that the human mind is not good at separating what happens in reality with what happens in virtuality, the constant exposure and interaction with virtuality causes significant and rapid fluctuations in the emotional and physical state of advocates. In addition to emotional burnout, this leads to a significant range of physical burnout phenomena among advocates. ${ }^{121}$

\section{Conflict with Colleagues}

Advocates noted that sometimes the toll of the nature and content of the work manifests as hostility, abuse, or even violence in the workplace. ${ }^{122}$ Advocates referred to stress and trauma leading to "tension amongst the members of the movement," who "have difficulty collaborating with each other and doing team work." 123 Further, a lack of clarity in job roles and responsibilities among different staff-or even among different organizations within a joint project - can make collaboration difficult, which, in turn, causes more friction. ${ }^{124}$ One advocate explained that "the worst cases are where people ... become violent. We have had people hospitalized because of that." 125

An expert based in the Americas explained that non-physically violent conflict within movements is common and attributed this to the hostile environments in which many human rights advocates operate. These environments can be reproduced internally within organizations, causing tensions between colleagues, as the expert explained:

Within the organizations or communities, the external context of violence and threats and killings - a lot of these external contexts have direct consequences-people are less flexible, more angry, fearful, [and] closed down. This creates dynamics within the community and within organizations, so even within ... human rights NGOs, during certain peaks of stresses and pressures, the external context is reproduced within the internal setting. And if

\footnotetext{
${ }^{121}$ Interview with Yana Ziferblat-Knopova, supra note 37.

122 Interview with Advocate (13 Austl.), supra note 53.

${ }^{123}$ Interview with Nixon Boumba, supra note 48. See also Interview with Tessa de Ryck, supra note 96 .

124 Interview with Expert (27 Americas) (July 18, 2018).

125 Interview with Tabitha Netuwa, supra note 40.
} 
there is no way to deal with this, it becomes a huge problem. ${ }^{126}$

Such conflicts with colleagues may be harder to endure for human rights advocates who are working overseas or in remote areas, away from friends and family and their usual support networks. One expert reported that internal friction can consume more energy than exposure to the emotionally taxing subject matter of their work, saying:

I was shocked that most [advocates] came back from the most repressive and violent contexts, and we were looking at disappearances and war zones, but we looked at the narratives and what people said impacted people most was the internal friction within the organizations or within the communities - and this was quite striking. People said, "Yes, of course I was affected by detained or killed people, but I spent most energy and frustrations on internal conflicts." 127

One expert perceived that institutions often failed to recognize how external contexts can affect internal dynamics. The expert stated, "Bad practice is not recognizing that this dynamic may happen and that we should not blame ourselves for this." 128

\section{Impact on Family Life}

Advocates emphasized that organizations sometimes fail to account for the diverse needs of people within human rights work, such as the need to balance family life with work. As one advocate said, "I think it's really important to consider the element of being a working parent, particularly in an industry [where] you're expected to put in hours that are much longer than in other industries, and where there is a mental toll on what you're doing." ${ }^{29}$ Several advocates, particularly women, talked about the harmful impact that human rights work had on their ability to have a family life. ${ }^{130}$

\footnotetext{
${ }^{126}$ Interview with Expert (27 Americas), supra note 124.

${ }^{127} \mathrm{Id}$.

${ }^{128} \mathrm{Id}$.

${ }^{129}$ Interview with Advocate (58 U.K.), supra note 74.

${ }^{130}$ See Interview with Muna Baig, supra note 65 (referring to "worry . . . about how the work you do could impact your family."); Interview with Dominika Bychawska, supra note 38 ("I had to cut my travels to become a mother. So there is a family price to pay"); Interview with Advocate (58 U.K.), supra note 74 (noting the difficulty in having a family life); Interview with Advocate (7 Int'1), supra note 35 (noting as a particular source of stress the pressure on young female staffers who have young children).
} 


\title{
7. Isolation and Loneliness
}

Some advocates said that the nature or method of some human rights work leaves them with a sense of loneliness and isolation. ${ }^{131}$ They attributed this to varying factors, including the structure of their work (e.g., working alone rather than in teams), ${ }^{132}$ lack of social support in the workplace, ${ }^{133}$ working among communities where trust is generally low or where there is antagonism toward advocates, ${ }^{134}$ or feeling that their non-human rights advocate friends or families do not understand them or their work. ${ }^{135}$

\section{PERCEPTIONS OF MENTAL HEALTH AND WELL-BEING IN THE HUMAN RIGHTS FIELD}

\author{
"[A]s a field, we have overlooked the mental health and \\ psychosocial components of this work." \\ - Alexa Koenig, Executive Director, Human Rights \\ Center, U.C. Berkeley School of Law ${ }^{136}$ \\ "I think it is more common than not for there to be a \\ culture of unwellness." \\ - Richael Faithful, Folk Healer ${ }^{137}$
}

\footnotetext{
${ }^{131}$ Interview with Alexa Koenig, supra note 36.

132 Id. (explaining that examining traumatic material can lead to "a negative psychosocial [situation]" because there is often an absence of "camaraderie that naturally comes from being part of a team or feeling like you can immediately do triage.").

${ }^{133}$ Interview with Radhya Al-Mutawakel, supra note 77 ("It is easy to talk to people in the center. Field researchers we meet maybe twice a year-so it is not easy to bring them all to Sana'a"). See also Interview with Alexa Koenig, supra note 36 ("I'm often the only woman, and sometimes the guys will get together and they'll say to their other guy friends, 'Let's go grab a beer.' They don't even think about it - and I'm either left out or very much there as an outsider. Certainly not always, but often."); Interview with Advocate (6 Int'l) (Feb. 19, 2018) (noting that advocates experienced a "not authentic understanding" of their work).

134 Interview with Radhya Al-Mutawakel, supra note 77 ("[I]nstead of people being thankful ... people are distrustful of your motive because of the fractious nature of public space in Yemen."). See also Interview with Millicent Auma Otieno, supra note 47 ("“YYou are rejected by the community you want to work in.... A lot of effort is put into being accepted by that community and yet staff are not yet welcome - even though you have the necessary skills.").

${ }^{135}$ Interview with Advocate (3 Isr.), supra note 35 ("If I say something to friends . . . in the good case they'll just ignore it."). See also Interview with Advocate (9 S. Korea), supra note 103 ( "Only human rights advocates can understand the type of pressure we go through.").

${ }^{136}$ Interview with Alexa Koenig, supra note 36; Interview with Maria LaHood, supra note 96 (June 6, 2018).

${ }^{137}$ Interview with Richael Faithful, Folk Healer (Dec. 18, 2017).
} 
Most advocates interviewed for this study stated that mental health is a serious challenge in the human rights field. Advocates used a range of terms - mental health, well-being, resilience, and sustainability-so this section reflects the range of terminology. Advocates reported that while some organizations and movements have long had serious discussions about and taken measures to promote well-being, inadequate attention has been paid across the field generally to well-being, advocates' needs are underaddressed, and far more needs to be done by organizations. ${ }^{138}$ Many also noted that more advocates and organizations have, in recent years, deepened discussions and taken action to understand and improve mental health. These observations suggest that the field generally is in a period of transition toward improved organizational attention to well-being and mental health, but that organizational policies and practices lag behind.

\section{A. Negative Perceptions of the State of Mental Health}

Almost all of the participants interviewed for this study believe that poor mental health is a serious problem for the human rights field. Nearly every advocate who participated in this study painted a bleak picture of the general state of mental health and well-being in the human rights field. For example, an advocate who works with defenders at risk in Africa stated that "all" defenders "are at some level of trauma or depression - they all at some point need professional intervention." 139 One advocate working in Europe

\footnotetext{
138 See, e.g., Interview with Advocate (8 U.K.) (Nov. 17, 2017) (opining that the field does not attend to well-being); Interview with Advocate (9 S. Korea), supra note 103 ("[T] he issue is not discussed ... more emphasis is put on physical security than mental health"); Interview with Expert (14 Int'l) (Aug. 24, 2017) ("In many organizations ... [mental health] is not widely accepted.”); Interview with Jannat Fazal, supra note 65 (noting a lack of action by NGOs); Interview with Simran Sachdev, Justice Program Officer, Nazdeek (Nov. 30, 2017) ("I don't think there is much support ... I don't know any organizations that provide services."); Interview with Matthew Smith \& Amy Smith, supra note 108 ("[M]ental health has not been prioritized in the human rights movement or in organizations."); Interview with Advocate (3 Isr.), supra note 35 (finding that NGOs do not encourage staff to take on well-being issues); Interview with Edeliza Hernandez, Exec. Dir., Med. Action Grp. (Mar. 2, 2018) (noting lack of organizational response); Interview with Nixon Boumba, supra note 48 (expressing unawareness of any organization that has taken action to improve mental health or well-being); Interview with Roy Douglas Otieno, supra note 85 ("[The] majority of the organizations are not focusing on the staff, they are focusing on the beneficiaries."); Interview with Wadih Al-Asmar, supra note 65 (noting that there is not much discussion of this from an organizational standpoint); Interview with Deepa Iyer, supra note 60; Interview with Douglas Mawadri, supra note 114 (noting that organizations have ignored mental health aspects of the work); Interview with Kigongo Ali, Program Officer, Lady Mermaid's Bureau (Feb. 27, 2018) ("[T] here is not much concern, or there are not organizations or donors addressing mental health."); Interview with James Savage, supra note 55("[I]f we surveyed a large number of organizations I would expect to see that NGOs are not really prioritizing mental health.").

${ }^{139}$ Interview with Tabitha Netuwa, supra note 40.
} 
described the overall situation as "shocking," 140 saying that "there are lots of people who are simply not effective anymore." 141 An advocate from the Americas similarly feared that the field was "losing many of [its] most dedicated, capable, best trained, and experienced people." ${ }^{142}$ Experienced advocates noted that concerns about the well-being of advocates are longstanding, and burnout in the community has "always" been present. ${ }^{143}$ Younger people in the field were noted to be at particular risk. ${ }^{144}$

In addition to reporting negative views about the general state of wellbeing among advocates in the human rights field, many interviewees also offered negative assessments about specific populations, countries, situations, issues, and organizations. ${ }^{145}$ For example, an advocate working in the Americas stated, "I think that the majority of woman human rights defenders are impacted physically, mentally and emotionally by gender-

140 Interview with Expert (3 Eur.), supra note 114 (June 30, 2017). See also Interview with Advocate (8 U.K.), supra note 138 (describing the situation as "quite bad.").

${ }^{141}$ Interview with Expert (3 Eur.), supra note 114.

${ }^{142}$ Interview with Alexa Koenig, supra note 36.

${ }^{143}$ Interview with Yana Ziferblat-Knopova, supra note 37 ("This has always been a problem for human rights workers, and we've always seen issues with activists and burnout."); Interview with Sandra Ljubinkovic, Independent Consultant, Expert in Safety \& Holistic Protection of Human Rights Defenders (June 13, 2017) (describing conversations about well-being as having been happening for "over 20 years, but now there is a crack"). See also Interview with Gasser AbdelRazek, supra note 80; Interview with Manon Muti, Training Coordinator / Trainer - Human Rights Defenders \& Security Programme, Justice \& Peace Netherlands (Sept. 19, 2017) ("[M]any defenders we receive are in burnout."); Interview with Expert (9 Eur.), supra note 49 ("I see burnout very frequently -it's often linked to their workload."); Interview with Mikhail Golichenko, Senior Policy Analyst, Canadian HIV/AIDS Legal Network (31 May 2018) (referring to "burnout syndrome").

${ }^{144}$ See Interview with Gasser Abdel-Razek, supra note 80 (noting that the younger people joined the human rights movement in their country "on a high note: and . . it was downhill from there"); Interview with Joanna Evans, supra note 75 (noting that young people are often working with people who are "very burnt out," which prevents them from "question[ing] the impact on [themselves]."); Interview with Advocate (64 Eur.) (June 15, 2018) (noting that he got very little support when he joined a prominent human rights organization as a young advocate); Interview with Marty Huber, supra note 84 (speaking specifically of volunteers, "I noticed that people who are new to this field just don't know where to turn to.").

145 Interview with Tabitha Netuwa, supra note 40 (comparing the kinds of issues faced by advocates across numerous countries in the region); Interview with Expert (2 Eur.), supra note 68 (noting that organizations differ); Interview with Sandra Ljubinkovic, supra note 143 ("There are differences in different movements, and regions. Some organizations are still at the level of 'we need to learn how to take care of ourselves.' Some organizations are further along - they are creating and changing cultures of care."); Interview with Joanna Kurosz, supra note 76 (noting differences among local organizations); Interview with Phil Lynch, Director, International Service for Human Rights (July 6, 2018) (noting that the field was so wide it was difficult to generalize, but that there was increasing awareness of the impact of human rights work); Interview with Mikhail Golichenko, supra note 143 (noting a difference between how lawyers and defenders experience stress, "at least most lawyers would know what to expect—human rights defenders are less equipped to deal with this."). 
based violence.... We see that woman defenders have a high level of burnout because they are always on alert."146

\section{B. Poor Institutional Responses to Mental Health}

Many advocates believe that human rights organizations as a whole are weak in their approaches to mental health. Advocates reported that human rights organizations are focused on the primary human rights harms, not the potential consequences of human rights work, ${ }^{147}$ so they have not made

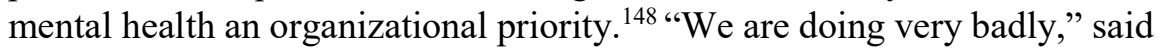

146 Interview with Ana María Hernández Cárdenas, supra note 52. See also Interview with Advocate (3 Isr.), supra note 35 (noting that their organization's field researchers are "exhausted."); Interview with Guacira Cesar de Oliveira, supra note 65 ("How are we doing in this field? People are suffering."); Interview with Sharon Cox, supra note 96 ("The rates of depression, burnout, substance abuse are high. We have had suicides, and probably more attempts at suicide."); Interview with Radhya Al-Mutawakel, supra note 77 (May 4, 2018) (reporting that staff are exposed to a lot of secondary trauma and are under a lot of pressure); Interview with Matthew Smith \& Amy Smith, supra note 108 (describing the state of mental health as "extremely poor"); Interview with Ditipriya Ghosh \& Pauline Gomes, supra note 79 (explaining that there is a lot of trauma and "it is not being addressed"); Interview with Lisa Chamberlain, supra note 54 ("[T]here is poor health and well-being among advocates."); Interview with Erick Monterrosas, supra note 51; Interview with Skye Wheeler, supra note 81 ("I think human rights workers across the board struggle ..."); Interview with Prince Chima Williams, supra note 47 (talking about how mental health is "really poor because people are really exposed" and work daily in a "psychologically tense atmosphere."); Interview with Marty Huber, supra note 84 (noting that "there is a lot of tension" when talking about the LGBTQI rights field).

${ }^{147}$ Interview with Yona Wanjala, supra note 42. See also Interview with Joanna Kurosz, supra note 76 (noting that newer organizations especially are focused on the primary harms they are fighting against, and not their own well-being); Interview with Matthew Smith \& Amy Smith, supra note 108 ("I think that these things tend to get pushed to the wayside. We spend a lot of time looking at traumatized people but not recognizing the effects it has on us."); Interview with Advocate (9 S. Korea), supra note 103.

${ }^{148}$ Interview with Richael Faithful, supra note 137. See also Interview with Advocate (8 U.K.), supra note 138 ("In my experience of working for many different organizations, the organizations don't pay much attention to it or perhaps it's a line in their employee handbook."); Interview with Matthew Smith \& Amy Smith, supra note 108; Interview with Muna Baig, supra note 65 ("In the human rights field [well-being] doesn't come across as something that is considered a concern."); Interview with Ram Kumar Bhandari, supra note 35 (expressing that the issue is neglected within the organization); Interview with Foromo Frederic Loua, supra note 80 (reporting not knowing any organization working to promote advocate well-being); Interview with Muna Baig, supra note 65 (expressing unawareness of any initiatives for mental health in South Asia); Interview with Roy Douglas Otieno, supra note 85 (expressing unawareness of anything being done for mental health of advocates); Interview with Tabitha Netuwa, supra note 40; Interview with Ana María Hernández Cárdenas, supra note 52 ("I dare to say that there is no general practice of NGOs to support mental health and well-being. We still don't see any signs that organizations in [our country] have sustainable practices for dealing with mental health."). 
an advocate working in Lebanon, ${ }^{149}$ summing up the assessments of many. ${ }^{150}$

An advocate based in Egypt said the field has "little respect for the whole idea of well-being," 151 and an expert based in Europe commented that "organizations pay lip service to mental health." 152 An expert in Europe explained that "in general," NGOs do not have mental health on their agendas; ${ }^{153}$ advocates in India and Myanmar echoed this view. ${ }^{154}$ An expert based in the Americas assessed organizational responses to be "relatively poor" overall. ${ }^{155}$ One advocate working in Africa said that the NGOs they observed in Africa have not addressed PTSD "even when it's clear that this is arising." 156 Another expert in Africa explained:

[Y]ou're doing this [human rights work] on a daily, on a weekly basis. It breaks you down, and yet the institution has put no mechanism [in place], no processes of helping you ... to recuperate, of helping you to improve your wellbeing. ${ }^{157}$

An expert working internationally said that mental health issues are "regarded as not really important" by human rights organizations, leading to an environment in which many organizations do not have strategies in place to handle well-being needs. ${ }^{158}$ The expert noted that the responses that

\footnotetext{
${ }^{149}$ Interview with Wadih Al-Asmar, supra note 65;

${ }^{150}$ See Interview with Ditipriya Ghosh \& Pauline Gomes, supra note 79 ("There is no policy or practice that exists within the human rights movement."); Interview with Expert (14 Int'l), supra note 138; Interview with Ram Kumar Bhandari, supra note 35 (describing how the field is responding "badly"); Interview with Sharon Cox, supra note 96 ("The situation sucks-there is no intentional wellness."); Interview with Lisa Chamberlain, supra note 54 (discussing how responses to poor mental health are "usually extremely poor" in the advocate's country).

${ }^{151}$ Interview with Gasser Abdel-Razek, supra note 80. See also Interview with Alice de Marchi Pereira de Souza, supra note 96 ("[T] here is still a lot of resistance in addressing the issue of the impact of activism in mental health.").

${ }^{152}$ Interview with Expert (3 Eur.), supra note 114. See also Interview with Simran Sachdev, supra note 138; Interview with Matthew Smith \& Amy Smith, supra note 108 ("Mental health has not been prioritized in the human rights movement or in organizations."); Interview with Expert (9 Eur.), supra note 49 ("We are doing a lot better than a few years ago - there is more talking about it but we are not yet 'walking the talk."').

${ }^{153}$ Interview with Expert (2 Eur.), supra note 68.

${ }^{154}$ Interview with Simran Sachdev, supra note 138; Interview with Matthew Smith \& Amy Smith, supra note 108 .

${ }^{155}$ Interview with Alexa Koenig, supra note 36.

156 Interview with Tabitha Netuwa, supra note 40.

${ }^{157}$ Interview with Yona Wanjala, supra note 42.

${ }^{158}$ Interview with Expert (14 Int'l), supra note 138; Interview with Jannat Fazal, supra note 65; Interview with Simran Sachdev, supra note 138; Interview with Muna Baig, supra note 65 ("Mental health isn't considered to be a concern in the human rights field.").
} 
do exist are often ad hoc, and not systematized nor made routine. ${ }^{159}$ An expert based in the Americas noted that organizations understand the importance of physical security measures, but they often consider pursuing well-being as "irrelevant." 160

\section{Well-Being Pioneers are Creating Space}

A number of advocates noted some important exceptions to the overall negative assessment of organizational response. Several advocates identified women's organizations and feminist movements as making progress, providing leadership on well-being issues ${ }^{161}$ or opening movement-wide spaces for well-being issues to be discussed. ${ }^{162}$ One advocate said that disability rights and LGBTQI groups were also better at addressing well-being issues. ${ }^{163}$ Another advocate noted that the holistic security training community had become better in recent years at recognizing the importance of mental health. ${ }^{164}$ Organizations in Latin America were perceived by some of the interviewees as being particularly attentive to or creative and pioneering in their approaches to well-being. ${ }^{165}$

${ }^{159}$ Interview with Expert (14 Int'1), supra note 138. See also Interview with Ditipriya Ghosh \& Pauline Gomes, supra note 79.

${ }^{160}$ Interview with Ana María Hernández Cárdenas, supra note 52. See also Interview with Advocate (9 S. Korea), supra note 103 (noting that more emphasis is put on physical security over mental health). One advocate also noted that the humanitarian field seemed to be more proactive than the human rights field concerning well-being issues. Interview with Muna Baig, supra note 65 .

161 Interview with Expert (14 Int'l), supra note 138; Interview with Ana María Hernández Cárdenas, supra note 52; Interview with Expert (19 Americas), supra note 117 (“"TT]he feminist movement has made this an issue - they are in the lead — especially Black feminists - they are the ones who face the most extreme level of institutional violence."); Interview with Manon Muti, supra note 143 ("I think the mental health discourse has nourished itself from the feminist movement.... [T] he feminist movement early on recognized the importance of self-care and mutual care."); Interview with Karen L. Culpepper, supra note 106 ("Reproductive justice organizations give me lots of hope."). But see Interview with Expert (35 MENA), supra note 104 (noting that a feminist organization the interviewee had worked at had failed to address well-being or mental health); Interview with Lucia Nader, Independent Consultant (Aug. 16, 2017) (noting that some feminist organizations prefer other ways of naming and framing the issue - such as "care" or "collective care" - as they try to avoid an overly individualistic interpretation of "wellbeing").

162 Interview with Richael Faithful, supra note 137.

${ }^{163}$ Interview with Ditipriya Ghosh \& Pauline Gomes, supra note 79 ("There are practices within the disability and sexuality field, where people are aware this [work] can be traumatic").

${ }^{164}$ Interview with Manon Muti, supra note 143 ("There has been a shift in thinking, recognizing that security is not only digital and physical but emotional.").

${ }^{165}$ Interview with Lisa Chamberlain, supra note 54; Interview with Advocate (7 Int'1), supra note 35 (noting the presence of coalitions that meet regularly at retreats); Interview with Alice de Marchi Pereira de Souza, supra note 96 (noting the increased interest in well-being, particularly within the feminist movement in Latin America); Interview with Nancy Tapias Torrado, Human 
We provide more detail about tactics and strategies that well-being pioneers have implemented in Part VI, as well as in the case studies included in the appendix to this Article.

\section{Lack of Mental Health and Well-Being Dialogue}

Generally, minimal or inadequate discussion among advocates about mental health was reported. "This is not a topic that comes up a lot," one expert working in Europe explained. ${ }^{166}$ An expert working in the Americas felt similarly, saying, "I don't see this being part of the discussion very much."167 Another expert based in the Americas explained that conversations about well-being did occur in their community, but said that these discussions tended to be informal and among colleagues. ${ }^{168}$ An expert working in Africa reported "barely" meeting any advocates who "know that well-being should be part of their daily work." 169

Many interviewees noted the importance of the interviews conducted for this study, as well-being is an underexplored subject. ${ }^{170}$ An interviewee based in the United States said that her interview for this study "is the most I've ever talked" about mental health in the human rights field; ${ }^{171}$ similar

Rights Lawyer and Doctoral Candidate, Sociology Department, University of Oxford (June 12, 2017) (noting that some groups, including small organizations in the Americas, are taking the issue seriously); Interview with Expert (26 Americas), supra note 46 (noting that efforts were being made to promote spaces where the importance of mental health is valued, including a recent regional forum which had participation of almost the whole South American continent).

${ }^{166}$ Interview with Joanna Kurosz, supra note 76.

${ }^{167}$ Interview with Expert (19 Americas), supra note 117. See also Interview with Advocate (9 S. Korea), supra note 103 (saying that the issue is not discussed, and that it is the "elephant in the room."); Interview with Advocate (58 U.K.), supra note 74 (noting that other than leave policies the impact of trauma was not something "thought about in a really detailed way.").

${ }^{168}$ Interview with Richael Faithful, supra note 137.

${ }^{169}$ Interview with Tabitha Netuwa, supra note 40. See also Interview with Ram Kumar Bhandari, supra note 35 (noting that the members of their organization suffer from trauma but they "forget our self-care and health issues."); Interview with Ajeng Larasati, supra note 35 (stating that advocates in the country "don't pay a lot of attention to their own well-being."); Interview with Sehyek Oh, supra note 112 ("We work for promoting human rights others, but not for ourselves."); Interview with Luis Fondebrider, President, Equipo Argentino de Antropología Forense (the Argentine Forensic Anthropology Team) (May 4, 2018) ("[P]eople don't pay proper attention to it."); Interview with Roy Douglas Otieno, supra note 85 (noting that most organizations do not focus on staff well-being). But see Interview with Phil Lynch, supra note 145 ("[T]here is increasing awareness of and concern regarding implications associated with human rights work").

${ }^{170}$ See Interview with Advocate (9 S. Korea), supra note 103 ("[T] his research is valuable, I never met a donor who asks how are you coping."); Interview with Lisa Chamberlain, supra note 54 ("I'm excited to see this research."); Interview with Advocate (58 U.K.), supra note 74 ("I think your project is really important because it's really underexplored.").

${ }^{171}$ Interview with Kimberly Zieselman, Executive Director, InterAct (June 12, 2018). 
observations were made by participants based in Guinea, India, and Kenya. ${ }^{172}$

Some advocates saw that issues of well-being and mental health were being discussed increasingly. ${ }^{173}$ A number of advocates noted that the field is generally improving and had even reached a point of transition. ${ }^{174}$ Yet some were concerned that increasing conversation is not matched by action, ${ }^{175}$ with one participant noting that the field is "so early on in even beginning to acknowledge that people have issues."176 Interviewees consistently voiced that more work is needed by human rights

172 Interview with Foromo Frederic Loua, supra note 80; Interview with Rupsa Mallik, supra note 69; Interview with Roy Douglas Otieno, supra note 85 ("By the time I was going through the survey I realized there were so many things we were missing.").

173 Interview with Expert (35 MENA), supra note 104 (stating that in the interviewee's country, "it's starting to be one of the things that people think of. But it's not embedded in every organization."); Interview with Alexa Koenig, supra note 36 (observing that there is a "nascent but growing awareness."); Interview with Joanna Kurosz, supra note 76 ("The awareness has grown when it comes to mental health issues.”); Interview with Richael Faithful, supra note 137 ("It is happening very slowly. It is different from ten years ago but it is so slow. There is a growing awareness at all levels."); Interview with Expert (3 Eur.), supra note 114 (observing that efforts are "slowly starting to happen... still not taken as seriously as it needs to be."); Interview with Sandra Ljubinkovic, supra note 143 ("There is more and more. . . Activists are screaming for it."); Interview with Expert (14 Int'1), supra note 138; Interview with Advocate (7 Int'1), supra note 35 (noting increasing awareness among advocates); Interview with Advocate (8 U.K.), supra note 138; Interview with Ajeng Larasati, supra note 35 (noting that advocates in their country have "started to realize that they need to pay more attention to their well-being."); Interview with Kyaw Soe Win, In-charge of Mental Health Assistance Program, Assistance Association for Political Prisoners (Nov. 23, 2017) (noting that international attention to mental health is increasing, but is still poor); Interview with Itzel Silva Monroy, Lawyer, Fundar (May 2, 2018) ("What I appreciate is that I have sixteen years of experience defending human rights. Since I started, there has been a major change."); Interview with Expert (26 Americas), supra note 46 (noting that efforts are being made to promote spaces where the importance of mental health is valued and discussed; the interviewee also noted the increased interest in a "psychosocial approach," a more inclusive perspective, which varies with the experiences and needs of the organization); Interview with Maria Cappello and Valeria Moscoso, supra note 46 ("[O]nly recently have the organizations started paying attention to the issue."); Interview with Expert ( 9 Eur.), supra note 49 ("There is more openness to deal with it in the past few years. . . There has been growing attention to the issue, but we are far from reaching out to the bulk of the group.").

${ }^{174}$ Interview with Alexa Koenig, supra note 36 (noting that the field has reached a "transition point"); Interview with Sandra Ljubinkovic, supra note 143 (describing the current moment as a "crack" and describing growing movements for well-being in the United States); Interview with Lisa Chamberlain, supra note 54 (similar); Interview with Tessa de Ryck, supra note 96 (similar).

${ }^{175}$ Interview with Yana Ziferblat-Knopova, supra note 37. See also Interview with Advocate (13 Austl.), supra note 53 (noting that people in the advocate's legal field were generally aware of mental health, but that putting this into practice can be a real challenge); Interview with Ajeng Larasati, supra note 35 (noting that there is increased attention, but "there is no action or attention to actual practical measures.").

${ }^{176}$ Interview with Alexa Koenig, supra note 36. 
organizations. ${ }^{177}$ In assessing what the human rights field has done for mental health, one interviewee said that on "a scale of 1-10, what has been done is 1.5 in our context." 178

\title{
V. CHALLENGES TO PROMOTING WELL-BEING IN THE HUMAN RIGHTS FIELD
}

\begin{abstract}
"The collective practice of sitting together to talk about care, to move towards practices of caring for each other, that hasn't happened yet. Even though we've talked about it. We can't do it, because our reality is a constant hurricane, and we're in the eye of it the whole time. There is no space in the schedule of our everyday life to reflect on this, amid all the chaos that needs to be resolved."

$$
\begin{gathered}
\text { - Raúll Santiago, Human Rights Defender, Coletivo Papo } \\
\text { Reto, Brazil }{ }^{179}
\end{gathered}
$$
\end{abstract}

Numerous types of challenges can inhibit or prevent individuals and organizations from accepting, recognizing, and responding to the mental health and well-being impacts of their work. Challenges discussed by advocates and experts interviewed for this study ranged from individual beliefs and human rights culture; institutional failures to take responsibility for staff well-being and instead placing the onus on self-care; workload, "productivity" pressure, and the marketplace of human rights; poor management and leadership; lack of mental health education, awareness, research, and resources; limited funding and economic disadvantage; and lack of access to psychological or psychosocial support or tailored mental health programming.

\footnotetext{
177 See, e.g., Interview with Expert (2 Eur.), supra note 68 ("Significantly more is needed."); Interview with Expert (3 Eur.), supra note 114 ("We have still quite far to go"); Interview with Sandra Ljubinkovic, supra note 143 ("We are far"); Interview with Yana Ziferblat-Knopova, supra note 37 ("Much more is needed"); Interview with Expert (14 Int'l), supra note 138 ("More is needed"); Interview with Richael Faithful, supra note 137 ("Significantly more is needed"); Interview with Erick Monterrosas, supra note 51 ("Much more is needed"); Interview with Ana María Hernández Cárdenas, supra note 52 (noting that some things are being done, but there is "a lot lacking"); Interview with Alexa Koenig, supra note 36 ("Significantly more is needed - no question."); Interview with Tabitha Netuwa, supra note 40 ("There is so much more that needs to be done, that should be done, that has to be done."); Interview with Expert (35 MENA), supra note 104 ("Much more needs to be done.").

${ }^{178}$ Interview with Tabitha Netuwa, supra note 40. See also Interview with Advocate (8 U.K.), supra note 138 ("If I had to rate it between 0 and 10, 0 being quite bad at mental health, I think we'd be at 3.").

${ }^{179}$ Interview with Renata Trajano, Raúll Santiago, \& Priscila Neri, supra note 43.
} 


\section{A. INDIVIDUAL BELIEFS AND HUMAN RIGHTS CULTURE: MARTYR Culture, Savior Mentality, and Mental Health Stigma}

Advocates frequently discussed a set of overlapping beliefs - held by individual advocates and seen as part of a dominant "human rights culture" - that contribute to poor well-being and impede the steps that could be taken to improve mental health. Advocates described interlinked cultures of martyrdom, in which the human rights field fostered a view among advocates that they should sacrifice themselves for others and the work; a savior or hero mentality, in which advocates view themselves as capable of and duty-bound to "save" others; and a cowboy attitude, where "toughness" and risk-taking are celebrated. Advocates often see focusing on well-being as a "privilege" or a "luxury," rather than an essential component of human rights work, and they described significant stigma around acknowledging mental health impacts and concerns. Deeply held values of commitment to human rights and to assisting others were seen by interviewees as extraordinarily positive and central to human rights work, but advocates also described extreme views, which they saw as risking or causing harm to individuals and the movement broadly. Advocates explained that these beliefs function to prevent advocates from considering, discussing, or taking mental health seriously; seeking or accessing available resources; or taking time off or pursuing other steps to promote well-being and resilience.

One advocate from the Americas straightforwardly explained a common belief, saying, "If you aren't 'killing' yourself, you aren't doing a good job. ... If you need to stop, 'What's wrong with you?' is what many people think." ${ }^{\prime 180}$ An Argentinian advocate explained:

The main problem is that people mix up doing the work with feeling like you are a militant of human rights. They confuse being committed to human rights with working as hard as possible. And so, they feel guilty to slow down, that this means that they aren't doing enough. The main problem is coming from the people themselves; it is not just their bosses. People don't realize their needs. ${ }^{181}$

Across the field, advocates reported the view that the work is so important that there is little space to take a break or step back. Interviewees said that it was a common view that advocates should make sacrifices for

\footnotetext{
${ }^{180}$ Interview with Nancy Tapias Torrado, supra note 165. See also Interview with Ajeng Larasati, supra note 35; Interview with Manon Muti, supra note 143 ("Many defenders we receive are in burnout because they never stop working because they believe that if they stop others will die. There is a superhero mentality.").

${ }^{181}$ Interview with Luis Fondebrider, supra note 169.
} 
the work, including by not making time for their own or others' wellbeing. ${ }^{182}$ As one advocate from South Asia put it, "People's passion and care for the work can be a hindrance," as advocates focus on the work "instead of taking care of themselves or others within the organization." 183 A senior advocate from an organization in Asia explained that while she encouraged breaks, staff "feel the less they use it, the more it shows that they are committed." 184

Advocates who experience work-related distress tend to ignore or minimize their own suffering by comparing their pain with that of the "primary" victims of human rights violations. The "real suffering" is that of the primary victim or rights-holder; the well-being of the advocate is secondary and even "seen as indulgent and associated with privilege rather than an inherent part of the work or something needed to best serve our communities." 185 In the human rights field, an advocate explained, "there is a guilt around experiencing trauma-how dare we, we are privileged human rights workers-how can I feel badly?" 186 Another advocate similarly expressed:

Particularly if you work with victims, there's a concern that other people have it much worse than you, so why would you seek help if "nothing has really happened to you," if you're just taking in information? There's a lot of that, of thinking, "I've met a lot of people in very dire conditions, so really, I'm probably OK." So a lot of people wouldn't

\footnotetext{
182 See, e.g., Interview with Lisa Chamberlain, supra note 54; Interview with Erick Monterrosas, supra note 51 ("The notions of sacrifice are still very relevant to movements today, especially on the left. It is expected that you make sacrifices if you are part of the movement. It makes it very difficult to deal with well-being."); Interview with Gabrielle Jackson, supra note 70 ("[T]he expectation, what is impressed upon them is that you need to be there for everything. Everyday. So people feel obligated to work like this. They feel they're doing a disservice to the community, if they take a break, if you're not doing something on a regular basis."); Interview with Expert (3 Eur.), supra note 114 (“[T] here is no way to say no-I don't want to work on this."); Interview with Ajeng Larasati, supra note 35 (noting that staff do not want to take breaks and that they "think that they can handle it without taking leave. They think that a casual debriefing discussion or the weekend break is enough. But what I say to them is that 'you might not feel that you need it, but your body and your mind do need it."').

${ }^{183}$ Interview with Simran Sachdev, supra note 138.

${ }^{184}$ Interview with Muna Baig, supra note 65.

${ }^{185}$ Interview with Lisa Chamberlain, supra note 54.

${ }^{186}$ Interview with Expert (3 Eur.), supra note 114. See also Interview with Sondos Shabayek, Project Director, Bussy Project (June 12, 2018) (referring to ongoing feelings of guilt among advocates).
} 
raise that they're feeling a bit off or perhaps aren't feeling like themselves. ${ }^{187}$

Because of how serious and urgent human rights work seems, "[w]ellbeing is seen as a luxury, a taboo issue. Because human rights violations keep happening! Work continues to come up, and [the] recent situation has been getting worse." 188 One advocate working in East Asia explained that funders contributed to this, saying, "We work for promoting human rights for others, but not ourselves.... [I]f we-the human rights advocates - kind of enjoy, or take the services, like mental health care or other things, [funders] would see this as "fancy." "189 One advocate described this type of thinking and why it is important to overcome: "I know this person is suffering so I can't take time for myself. But unless you take a break, you will suffer and a lot of people will suffer because you won't be able to work. Because you will have drained all your energy. People don't understand that." 190

These beliefs can prevent advocates from accessing existing resources that can help. One expert emphasized that even when there is an opportunity to participate in well-being workshops, human rights defenders do not always take advantage of these resources due to feelings of guilt. ${ }^{191}$ This expert described how advocates would rather learn more about helping victims instead of utilizing opportunities to seek counseling. ${ }^{192}$

Some interviewees believed that some advocates' identities were so connected to their human rights advocacy that taking breaks or stepping back posed a serious challenge to their sense of self. One expert stated, "I think saying to someone that they need to stop ... can be threatening to their sense of self and [it] makes them upset." ${ }^{193}$ An expert who runs a healing program for advocates in Eastern Europe echoed this, saying, "I think this is quite logical, because these people really have nothing else but the work, and if you take that away, then there's just this emptiness." 194

\footnotetext{
${ }^{187}$ Interview with Advocate (8 U.K.), supra note 138. See also Interview with Renata Trajano, Raúll Santiago, \& Priscila Neri, supra note 43 ("When there's an opportunity for mental health care, at no time do we think about ourselves. There's opportunity for care? Send the mother of the person who was just murdered, that person should go!").

${ }^{188}$ Interview with Expert (14 Int'1), supra note 138.

${ }^{189}$ Interview with Sehyek Oh, supra note 112.

${ }^{190}$ Interview with Jannat Fazal, supra note 65.

${ }^{191}$ Interview with Expert (14 Int'1), supra note 138. See also Interview with Expert (2 Eur.), supra note 68 (noting that even when there is an awareness of the importance of drawing boundaries and taking time off, there is still the phenomenon of "perhaps workaholic leadership.").

${ }^{192}$ Interview with Expert (14 Int'1), supra note 138.

${ }^{193}$ Interview with Experts (11 Eur.) (Aug. 8, 2017).

${ }^{194}$ Id.
} 
Advocates also discussed how beliefs about themselves as "saviors" contributed to poor mental health. A feminist advocate from Mexico explained:

People think, and we also think, that we are special people, that we can handle everything, and we believe ourselves to be Messiahs or saviors.... [Our] sacrifice is politicized. My risk is taken as part of my activism. This risk is normalized. The exposure to violence is normalized. ${ }^{195}$

One advocate also linked the ideology of the savior model with poor well-being:

Poor well-being is linked with the idea of "missions" to save people. But it shouldn't be about that. It should be about collaboration, with people. The saving people approach is linked with poor mental health. It also affects the people you're working with-because "saving" treats them like they're powerless and weak, and it risks creating dependency. And this also can be bad for well-being. You're not empowering and learning from others. You're looking down at them. This isn't good for the advocate, or the people. If you approach people as "defenseless" or "poor" people, it isn't good, it is disempowering. You should acknowledge and address them as subjects with rights, as agents of change. If you go in "saving," people will reject you. This can affect the advocate's mental health. You won't have fruitful connections with people. ${ }^{196}$

Views about the value of "toughness," fears of appearing "weak," and the attendant professional costs, combined with general societal stigma about mental health, ${ }^{197}$ have resulted in strong stigma in the human rights

\footnotetext{
195 Interview with Verónica Cruz Sánchez, supra note 84. See also Interview with Andrea Rocca, supra note 35 ("There is . . this attitude that people don't take threats seriously, because they just think it's part of the risk of human rights work, but the extended pressure over time really gets to them.").

196 Interview with Nancy Tapias Torrado, supra note 165. See also Interview with Sandra Ljubinkovic, supra note 143 ("The experts' parachute to the global south. But there is a lot of knowledge and capacities and wisdom in local areas. And that has to be supported, in order to sustain movements. These one-off things never work. And it just creates a huge frustration.").

197 See generally Angela M. Parcesepe \& Leopoldo J. Cabassa, Public Stigma of Mental Illness in the United States: A Systematic Literature Review, 40 AdmIn. \& Pol'y Mental Health \& Mental HeALth SERVS. RES. 384 (2013) (revealing that public stigma of mental illness in the United State is widespread); Milton L. Wainberg, et al., Challenges and Opportunities in Global Mental Health: A Research-to-Practice Perspective, 19 CURRENT PSYCHIATRY REP. 28 (2017) (revealing that stigma prevents many individuals from seeking mental health services, and contributes to social exclusion, which can lead to poor recovery outcomes and quality of life).
} 
field. Some interviewees noted that they had seen a reduction in stigma concerning mental health in recent years in their countries, and that this had enabled improved discussion about mental health in the human rights field. However, many advocates reported significant stigma and fear. An advocate based in Ireland explained that "stigma" prevents the field from responding better, "and that's a hard issue to deal with. It's not even really recognized as a 'real' issue - [the perception is] that you need to just get on with your life." 198 An advocate from an international human rights organization described the attitude as, "If it's too hot in the kitchen, then get out." 199 One interviewee described the fear of being seen as "weak" by other advocates:

You don't want to come across as weak or too sensitive.... Even in the office or at work, I can see if someone has that problem. It is again, firstly a lack of wanting to connect it to "mental." The word scares people off, or makes them go on a back foot because you don't want to come across as a weakling, or [be] seen as not being able to do this work. ${ }^{200}$

An advocate based in the Americas explained how these views can prevent advocates from accessing needed support. The advocate stated, "People don't take advantage of hotlines or other things, because they feel that [this means that] they aren't brave enough. We need to refocus the debate - it is about health, not bravery." 201 One advocate saw that the

\footnotetext{
198 Interview with Andrea Rocca, supra note 35. See also Interview with Ram Kumar Bhandari, supra note 35 ("Members suffer from the conflict and post conflict trauma. We forget our selfcare and health issues. Especially [the grassroots organization], family members, and women members, mostly there is big social stigma that most of our members face but they don't speak out [about] how they suffer at a family and personal level; these are practical experiences they have-it's mostly hidden and not spoken out."); Interview with Sandra Ljubinkovic, supra note 143 (noting that connecting to one's own trauma is painful: "It is easier to stay in the head. This is where most activists are. But we must learn how we practice in our skin.").

${ }^{199}$ Interview with Skye Wheeler, supra note 81 (adding that the qualities valued among activists are being "extremely productive and strong and clear and brave.... Not qualities of selfunderstanding and empathy, there is very little space for that.").

${ }^{200}$ Interview with Muna Baig, supra note 65. See also Interview with Tessa de Ryck, supra note 96 ("[Advocates] neglect effects on their psychosocial mental well-being. . . . I think that is partly because of the idea that you're a human rights defender and you're willing to die, and admitting that [the work has] mental impacts [on you] makes you . . . weak.").

${ }^{201}$ Interview with Nancy Tapias Torrado, supra note 165. See also Interview with Maria Cappello \& Valeria Moscoso, supra note 46 ("Faced with this violence, and our work, the profession has a heroic aura. To be 'strong,' you have to repress the negative effects. But the work affects us.").
} 
"tough" attitude harmed mental health by preventing people from releasing and processing their pain. The advocate said:

A dominant framework we see is of having expectations that you must be strong. When you are weak in a context when you are not supported to be weak, it is very dangerous because you don't have spaces to discharge. ... [There] is need to create spaces where people are able to cry and not be destabilizing. There is a problem with the lack of capacity to operate safe spaces, spaces of contextual understanding and restorative process. ${ }^{202}$

General stigma around mental health also makes it difficult for advocates to even open up conversations about it. One said, "I interact with women human rights activists - fighting stigma is very challenging. They don't talk about well-being and mental health, but they hide. They feel it and suffer, but there is no discussion of this." ${ }^{203}$ As one expert from South America noted, "There is a taboo around mental health generally in society. We human rights organizations aren't exempt from this." ${ }^{204}$ Similarly, an advocate from South Korea reported:

Mental health is a stigma here and people hide it, even those who have problems. They don't want to be reported because they fear that they may be fired. Here in South Korea, because of this attitude, people do not discuss these issues. There is no discussion, I have never seen discussion among organizations working on North Korean human rights issues. ${ }^{205}$

\footnotetext{
202 Interview with Erick Monterrosas, supra note 51.

${ }^{203}$ Interview with Ram Kumar Bhandari, supra note 35.

${ }^{204}$ Interview with Nancy Tapias Torrado, supra note 165. See also Interview with Ditipriya Ghosh, \& Pauline Gomes, supra note 79; Interview with Muna Baig, supra note 65; Interview with Gasser Abdel-Razek, supra note 80 ("There is very little respect in many fields . . . but definitely in our field and particularly people within older age ranges. There is very little respect for the whole idea of well-being and the idea of seeking psychological support."); Interview with Ajeng Larasati, supra note 35 (noting that although there was a general perception in their country that "if you see a psychologist you are a crazy person," human rights advocates "do not have the same impression. We understand that it is seeking help to ensure your well-being."); Interview with Manon Muti, supra note 143 ("[I]t can be difficult because for certain cultures, receiving psychosocial help is seen as a weakness, especially for men. It can be stigmatizing. It means you are crazy."); Interview with Maria Cappello \& Valeria Moscoso, supra note 46 ("There is also a lot of stigma about mental health. It is associated with 'weakness,' being 'fearful.' If a person is 'crazy,' he cannot fulfill the job.”); Interview with Expert (9 Eur.), supra note 49 (noting stigma around mental health for defenders, particularly amongst men).

${ }^{205}$ Interview with Advocate (9 S. Korea), supra note 103.
} 
These interviews reflect dynamics observed among other populations and in research in psychology. Mental health stigma is significant in many contexts. ${ }^{206}$ In one cross-national study, perceived stigma was commonly reported, with stigma defined by the presence of both embarrassment and perceived discrimination. ${ }^{207}$ Stigma has repeatedly been shown to be associated with harmful behaviors, including not seeking help when needed. ${ }^{208}$ Many groups have reported that participation in treatment is often avoided so to not receive the "label" of needing psychological help. ${ }^{209}$ Similarly, in the military context, high-ranking participants of one study reported concerns that seeking care could affect perceptions of their leadership abilities, and lower-ranking individuals reported fears of becoming non-deployable or not receiving promotions. ${ }^{210}$ For these reasons, among others, many have refused care or have dropped out of potentially helpful treatments. ${ }^{211}$

\section{B. Workload, "Productivity" Pressure, AND the MarketPlace of HUMAN RIGHTS}

Closely linked with a culture of martyrdom and a savior complex, many advocates reported that the sheer volume of human rights abuses, advocates' significant workloads, management dysfunction, and organizational and funder pressures to "produce" resulted in harms to their well-being and left them little time to focus on improving their well-being.

An advocate from Egypt saw that "self-care is not something that people celebrate. What is being celebrated is when people die of overwork - this is encouraged." ${ }^{212}$ In explaining what contributed to poor well-being, an expert working in Europe stated:

\footnotetext{
${ }^{206}$ Lawrence Hsin Yang et al., Culture and Stigma: Adding Moral Experience to Stigma Theory, 64 SoC. SCI. \& MED. 1524, 1525 (2007); Bernice A. Pescosolido et al., The "Backbone" of Stigma: Identifying the Global Core of Public Prejudice Associated with Mental Illness, 103 AM. J. Pub. HeAlth 853, 858-59 (2013).

${ }^{207}$ Jordi Alonso et al., Association of Perceived Stigma and Mood and Anxiety Disorders: Results from World Health Surveys, 118 ACTA PSYCHIATRICA SCANDINAVICA 305, 309 (2008).

${ }^{208}$ Nicolas Rüsch et al., Mental Illness Stigma: Concepts, Consequences, and Initiatives to Reduce Stigma, 20 EUROPEAN PSYCHIATRY 529, 534 (2005).

${ }^{209} I d$.

${ }^{210}$ Tracy Stecker et al., An Assessment of Beliefs About Mental Health Care Among Veterans Who Served in Iraq, 58 PSYCHIATRIC SERVS. 1358, 1359 (2007).

211 Thomas W. Britt, The Stigma of Psychological Problems in a Work Environment: Evidence from the Screening of Service Members Returning from Bosnia, 30 J. APPLIED SOC. PSYCHOL. 1599, 1614 (2000); Patrick Corrigan, How Stigma Interferes with Mental Health Care, 59 AM. PSYCHOL. 614, 614-15 (2004); Patrick W. Corrigan et al., The Impact of Mental Illness Stigma on Seeking and Participating in Mental Health Care, 15 PSYCHOL. SCI. PUB. INT. 37, 40 (2014).

${ }^{212}$ Interview with Sondos Shabayek, supra note 186.
} 
[F]irst of all it is the workload, which is usually huge. It's work with an emotional engagement, because you work with people in distressed situations all the time, so also it is because of the specific work type. ... Another thing is the travels - usually, we travel a lot. . . For example, I really had to cut my travels to become a mother. So there is a family price to pay, and usually you're quite removed from your family. ${ }^{213}$

An advocate from Brazil further described how workload issues can be gendered, saying:

At the leadership level, there is a lot of overwork. Women assume many responsibilities; they take double and triple burden[s]. They inject gender and racial admonition and they feel very guilty if they do not carry out all of those tasks. They take on a huge responsibility that is not ours. These costs appear more as people's age progresses. I see young women not sleeping, night after night. ${ }^{214}$

Even organizations that are trying to incorporate well-being into their work find it difficult. One interviewee explained:

We are responding to the issue [of well-being], but it is very slow because we don't have a lot of time to discuss and take action. Even working on our core jobs requires working late at night, so it would take even more time to support mental health that we don't necessarily have. ${ }^{215}$

At the organizational level, some advocates experience feeling that "output" and "productivity" are valued more than the well-being of advocates. ${ }^{216}$ An advocate from an international human rights organization described the problem as stemming from a:

pressure to "produce" and a "factory" atmosphere. This affects how you think about taking your breaks, and even how you view your job. You feel like you're in a factory. This really comes from managers. This view has a huge

\footnotetext{
213 Interview with Dominika Bychawska, supra note 38.

${ }^{214}$ Interview with Guacira Cesar de Oliveira, supra note 65.

${ }^{215}$ Interview with Ajeng Larasati, supra note 35; Interview with Expert (26 Americas), supra note 46 ("Often times, the current situation overwhelms the efforts and follow-up required for longterm issues. . . Many times professionals do not have time to systematize the practices.").

${ }^{216}$ Interview with Foromo Frederic Loua, supra note 80. See also Interview with Advocate (55 Int'l), supra note 74 ("The focus at the organization is on productivity, getting as much out as possible, with the least resources.").
} 
impact on morale and how people see their job. This view also leads to bad work-you think of products, not advocacy strategy. ${ }^{217}$

The focus on productivity and getting as much out as possible with the least resources "doesn't leave room for thinking through these well-being issues." 218 Advocates stressed that the roots of this pressure are not only organizational; the tendency for human rights funders to seek big impacts for small grants, and to fund projects but not core costs, have a very real toll. An advocate from South Africa explained that the need for multiple funders created more work and led to less time for well-being efforts:

It's the amount of work, and the nature of the workespecially funding - which adds a whole damn layer to this. Those organizations who are perhaps getting pockets of funding here and there- - because, and precisely because of funders only funding a small piece of core costs-you need to have several funders, which means more reports, more site visits, and more of all the things that take you away from the work. ${ }^{219}$

An advocate based in the United States took the analysis further, explaining:

The model for financial sustainability for our work, because it is still predominantly funder-driven in the human rights world ... for the most part, exacerbates [stressors] and impedes people [from] becoming more resilient. ${ }^{220}$

\section{ORganizational RELIANCE ON INDiVIDUAL "MENTAL HeAlth" AND "SELF-CARE"}

Some advocates noted that organizational well-being efforts that overly focus on steps that individuals can take for their own self-carerather than viewing well-being holistically, relationally, culturally, and organizationally - could function to inhibit further structural and deeper responses. Ideas of "well-being" as primarily individual-focused could also

\footnotetext{
${ }^{217}$ Interview with Advocate (55 Int'l), supra note 74. See also Interview with Expert (9 Eur.), supra note 49.

${ }^{218}$ Interview with Advocate (55 Int'1), supra note 74.

${ }^{219}$ Interview with Sharon Cox, supra note 96.

${ }^{220}$ Interview with Yvette Alberdingk-Thijm, supra note 92.
} 
negatively impact how organizations in some countries respond to the concept. $^{221}$

An interviewee from South Africa stated that "[p]laces like Latin America are streets ahead of South Africa in understanding self-care as acts of political resistance. It's quite individualized [here], rather than situated in a framework of understanding." ${ }^{222}$ Organizations that try to resolve mental health harms by placing the responsibility or burden on the individual advocates, as opposed to changing systems, fail to create a culture of well-being. 233 One advocate noted, "The onus is on the individual - if the individual needs or wants support, they have to make that happen. But that's not easy to do in this environment. Because the environment values certain characteristics, [such as] people who can do a lot of work quickly without any problems." 224 Another advocate similarly cautioned against adopting an approach that places the responsibility on the individual, saying:

Just putting resources in place-there being a phone number that people can call-that is not dealing with mental health. Organizations need to address this issue. They [say], "If you are experiencing problems, you can call this number," instead of saying, "We have these systems in place to prevent these issues, and if you have trouble, we will deal with that." 225

An advocate working for an international organization explained that NGOs should address mental health issues as institutional concerns, which

\footnotetext{
221 Interview with Tessa de Ryck, supra note 96 (noting that well-being conceived in an individualistic way ran counter to how some groups and communities think about these issues). See also Interview with Gasser Abdel-Razek, supra note 80 (critiquing organizations that view well-being as about self-care); Interview with Maria Cappello \& Valeria Moscoso, supra note 46 ("Most organizations treat this subject in individual terms. If someone has a problem, the organization offers him vacations, or to go to the gym. We do not handle the issue structurally.").

${ }^{222}$ Interview with Lisa Chamberlain, supra note 54.

${ }^{223} \mathrm{Id}$. (noting that the idea of self-care placed the burden on the individual advocate to take steps); Interview with Advocate (55 Int'l), supra note 74 (emphasizing that the organization placed the burden on staff to handle mental health impacts of the work instead of seeing it as an organizational issue); Interview with Expert (9 Eur.), supra note 49 (noting that in many partner organizations, there were high levels of stress and addressing it was "left to individual coping mechanisms and strategies.").

${ }^{224}$ Interview with Advocate (55 Int'l), supra note 74.

${ }^{225}$ Interview with Expert (3 Eur.), supra note 114; Interview with Expert (9 Eur.), supra note 49 (noting that the measures proposed for human rights defenders, such as advising them to take time off or relocating them, can exacerbate the reasons for them not doing well, and create other problems, such as the economic impacts of taking time off work, security concerns from being left alone once they "leave the fight," and alienation from the community and loneliness if they are relocated).
} 
may require structural changes to reduce staff stress and advance wellbeing. ${ }^{226}$ An expert based in the United States explained that "spa days once a month [are] not what's going to change the culture."227

\section{POOR MANAGEMENT AND LEADERSHIP}

Human rights advocates reported that management attitudes and practices could have a significant effect on whether or how organizations respond to well-being needs. Dismissive or non-responsive attitudes by leaders to mental health concerns made it challenging for advocates to shift organizational practices and culture, as well as to access resources. ${ }^{228}$ Managers and senior staff play important roles in setting the tone for an organization and modeling good-or perpetuating poor-well-being practices. ${ }^{229}$ Yet, too often, advocates reported that fostering well-being is not a real part of the manager's role and portfolio. ${ }^{230} \mathrm{An}$ advocate from an NGO in Africa explained how a director's behavior affected staff perceptions about their own well-being:

Our director does understand that burnout is real, and sometimes people just need time out, but ... [i]t does not help that we see her burning out and her doing this so totally - she has hardly recovered from the one burnout when she is diving into the other one - and we all feel, who are we to collapse in a heap if she is still going? ${ }^{231}$

One advocate explained that "there was one case of a complete nervous breakdown ... management did not assume any responsibility for that, and they just claimed that she had a mental illness that was not related to work." ${ }^{232}$ Another advocate noted that when a staff member expresses concerns about health, "because of poor management style or leadership, the management will get defensive and will keep on blaming the staff

\footnotetext{
${ }^{226}$ Interview with Advocate (55 Int'l), supra note 74.

${ }^{227}$ Interview with Miriam Zoila Pérez, Activist (Dec. 14, 2017).

228 Interview with Skye Wheeler, supra note 81; Interview with Edeliza Hernandez, supra note 138 ("[I]ndividually we cannot handle it unless the management does not have this kind of sensitivity to the burnout, the stress of the staff."); Interview with James Savage, supra note 55.

${ }^{229}$ See Interview with Gasser Abdel-Razek, supra note 80; Interview with Skye Wheeler, supra note 81; Interview with Advocate (50 Int'l), supra note 88; Interview with Advocate (8 U.K.), supra note 138 .

${ }^{230}$ Interview with Expert (3 Eur.), supra note 114.

${ }^{231}$ Interview with Advocate (42 S.Afr.) (Oct. 27, 2017).

232 Interview with Expert (35 MENA), supra note 104.
} 
instead of supporting the staff . . the staff are shamed publicly." ${ }^{233}$ One advocate who works with an international human rights organization noted that part of the problem was a lack of training for managers. ${ }^{234}$ This advocate saw management as traditionally lacking prioritization, or even understanding, of well-being issues: "Just in the past few years, there has been a realization that [mental health] is a problem. Even just two years ago, we discussed these issues at a meeting, and managers were responding with 'I don't really see what else we could do.",235

An expert saw a generational gap between management and staff on mental health issues, perceiving that older advocates see younger advocates who want more mental health support as "whiny" or less committed. ${ }^{236}$ Some advocates perceive that organizations led by some older men were particularly susceptible to poor management in relation to well-being. One expert from Asia noted that "managers [can] reinforce that [stigma] even further - especially men of a "certain generation." 237 In addition, newer forms of traumatic exposure, such as exposure to user-generated graphic content, may not be well understood by older managers, who may not have had personal experience investigating with such material. ${ }^{238}$ This lack of experience can create serious obstacles to managerial action.

One advocate from an international human rights organization also cautioned against managers adopting a superficial approach to well-being:

We also need to be careful about the fact that concern about mental health has become sort of trendy. You'll get emails from a manager saying "take your vacation" but then the email also contains a list of urgent things the researcher needs to do. We have to be careful about people just paying lip service. ${ }^{239}$

\footnotetext{
${ }^{233}$ Interview with Expert (32 Afr.) (Sept. 15, 2017). See also Interview with Expert (4 Eur.) (Sept. 8,2017 ) (noting "internal pressures" such as divisions and abuse within human rights movements such as bullying and smear tactics).

${ }^{234}$ Interview with Advocate (55 Int'1), supra note 74.

${ }^{235}$ Id.

${ }^{236}$ Interview with Expert (14 Int'1), supra note 138.

${ }^{237}$ Interview with Expert (3 Eur.), supra note 114 (noting that senior staff, especially men, can discount trauma exposure and its effects). See also Interview with Muna Baig, supra note 65.

${ }^{238}$ Sam Dubberley, Margaret Satterthwaite, Sarah Knuckey, \& Adam Brown, Digital Human Rights Investigations: Vicarious Trauma, PTSD, and Tactics for Resilience, in DIGITAL WITNESS: Using Open SOURCe Methods FOR Human Rights InVESTigations, AdvocACy AND ACCountabiLity (Alexa Koenig, Sam Dubberley, \& Daragh Murray eds., forthcoming 2019).

${ }^{239}$ Interview with Advocate (55 Int'1), supra note 74. See also Interview with Deepa Iyer, supra note 60 ("Organizations make it worse when they try to fix one thing [such as burnout] but it's really something else going on [such as too few staff and chronic overwork]."); Interview with
} 
Many studies of other contexts have demonstrated the important role that leaders can have in the mental health of colleagues. ${ }^{240}$ Research has also suggested that proper training for supervisors about mental health is of utmost necessity, given the large role that supervisor attitudes and skills potentially have on the mental health of others. ${ }^{241}$ The literature suggests that if leaders engage in well-being practices and prioritize well-being, employees may similarly better address their own mental health and work balance in their own roles. ${ }^{242} \mathrm{~A}$ recent systematic review, examining fortynine studies conducted over thirty years, evaluated the impact of leaders' stress, behavior, and style on employee stress and affective well-being. ${ }^{243}$ Findings from this review suggest that leaders' stress, ability to provide support, and leadership style were associated with employee stress and affective well-being. ${ }^{244}$

\section{E. Lack of Mental HeAlth EdUCATion, Awareness, AND Research}

Advocates reported that the lack of awareness and training about mental health-including among advocates, managers, and human resources personnel - is a significant barrier to reform. ${ }^{245}$ In the health field

Expert (9 Eur.), supra note 49 ("Too much talking about this can make it worse-sometimes the more you talk about it and the less you do, the worse it is because people get frustrated.").

${ }^{240}$ See, e.g., Kathleen M. Wright et al., Stigma and Barriers to Care in Soldiers Postcombat, 6 PSYCHOL. SERVS. 108, 113-14 (2009); Janne Skakon et al., Are Leaders' Well-Being, Behaviours and Style Associated with the Affective Well-Being of Their Employees? A Systematic Review of Three Decades of Research, 24 WORK \& STRESS 107, 131 (2010). See also Melissa S. Price \& Maureen R. Weiss, Relationships Among Coach Burnout, Coach Behaviours, and Athletes' Psychological Responses, 14 SPORT PSYCHOLOGIST 391, 404 (2000); Lars Glasø \& Ståle Einarsen, Experienced Affects in Leader-Subordinate Relationships, 22 SCANDINAVIAN J. MGMT 49, 65-66 (2006).

${ }^{241}$ Akizumi Tsutsumi, Development of an Evidence-Based Guideline for Supervisor Training in Promoting Mental Health: Literature Review, 53 J. OCCuPATIONAl HeAlth 1, 1, 6 (2011).

${ }^{242}$ See generally AlBERT BANDURA, SOCIAL LEARNING THEORY (1977) (suggesting that in organizational settings, employers who model positive behavior will, by doing so, implicitly encourage employees to perform the same behavior).

243 Skakon et al., supra note 240, at 107-108.

${ }^{244}$ Id. at 131 .

${ }^{245}$ See, e.g., Interview with Advocate (55 Int'1), supra note 74 (explaining that the well-resourced NGO that they worked for offered training for new staff, but it did not include attention to mental health); Interview with Wadih Al-Asmar supra note 65 (explaining that he has heard of NGOs offering training but at an individual level and not regularly; his own organization used to have an external counsellor conduct stress release activities with teams but this has not happened for two years); Interview with Foromo Frederic Loua, supra note 80 (noting that they don't receive training on mental health); Interview with Edeliza Hernandez, supra note 138 ("[W]e have no comprehensive program or training to handle most of their cases. It is just a reactionary program that we have."); Interview with Advocate (15 East Asia) (May 9, 2018) (noting they had a one-off training). 
generally, many studies have been published demonstrating how low health literacy is associated with poorer health outcomes and poorer use of healthcare services. ${ }^{246}$ Similar studies have shown the importance of mental health literacy. ${ }^{247}$ One advocate from MENA, interviewed for this study, explained:

We have bad tools. The key problem when it comes to mental health is that it's so hard for people experiencing mental health issues to detect them. They will call it stress or something else. The people who are working with them or supporting them cannot see it either, because we are not psychologists ... Sometimes in our work you get so caught up that you are able to continue and ignore your warning signs that you are not well. I don't believe that the ... human rights community is assessing their mental health. If I spoke about this with them they would laugh at me. ${ }^{248}$

The lack of awareness of how adverse effects, such as burnout, can develop and can also lead advocates to fail to take preventive steps: "It really takes time to realize you need support, especially if you aren't well-versed in these issues. It just doesn't suddenly dawn on people that they need to slow down and stop, it builds up, it takes time." ${ }^{249}$ Similarly, an advocate based in Israel explained that because they did not have training or resources available, headquarters' staff were sometimes unable to respond appropriately to the difficulties that field staff were experiencing: "What do you say? You don't know what to say. They have seen a five-year-old being arrested, or a 10year-old who is being beaten up by the army. What do you, as an organization, tell the field worker? You don't know what to say." 250

\footnotetext{
${ }^{246}$ E.g., Nancy D. Berkman et al., Low Health Literacy and Health Outcomes: An Updated Systematic Review, 155 ANNALs InTERNAL MED. 97, 103 (2011).

${ }^{247}$ E.g., Anthony F. Jorm, Mental Health Literacy: Empowering the Community to Take Action for Better Mental Health, 67 Am. Psychologist 231, 231 (2012).

${ }^{248}$ Interview with Wadih Al-Asmar, supra note 65. See also Interview with Matthew Smith \& Amy Smith, supra note 108 ("People have a hard time wrapping their heads around it until they experience it directly. It's only people who have been in the dark trenches who realize the importance of it. Otherwise it's not prioritized. Some type of culture shift is required."); Interview with Radhya Al-Mutawakel, supra note 77 ("There is no awareness of this."); Interview with Muna Baig, supra note 65 (noting a lack of awareness of understanding).

${ }^{249}$ Interview with Experts (11 Eur.), supra note 193.

${ }^{250}$ Interview with Advocate (3 Isr.), supra note 35.
} 
Some advocates noted that even where there was training, it was insufficient. An advocate based in Europe stressed the pro forma nature of some training sessions:

Some organizations invite people in to give a talk, but that completely fails to account for turnover of staff, people being promoted, and managers leaving. Having the world's best trauma person from the university in your headquarters' town coming to give a talk once really is a check-the-box experience. ${ }^{251}$

Insufficient research about the causes and effects of the problem was also viewed as inhibiting a response. An advocate from a feminist organization in South Asia attributed the lack of a movement-wide response to well-being to a lack of evidence about the impacts of human rights work: "We've not been able to demonstrate how debilitating [the work] is ... on the activist, who faces burnout, stress, and the feeling that they can't go on." 252 Another advocate, who prioritized well-being in her organization, described trying to research the issue and finding little: "We have looked for books on the topic of mental health for human rights defenders but it's not a large discussion. We think it's strange because we work every day on extreme abuses." ${ }^{253}$ Similarly, an activist from Asia said: "When you look into academic papers or media, you might find a lot of articles or documentaries, but nothing related to issues that human rights activists are facing when they are working with those victims." ${ }^{254}$ An advocate from an international human organization explained the importance of research:

The first thing we need is better information. When I cite the results of [a study of mental health among human rights advocates that found high rates of PTSD and depression] to people, they are shocked. We need to see data about the problem. This will prompt action. We need to better understand the causes of stress. ${ }^{255}$

\footnotetext{
${ }^{251}$ Interview with Expert (3 Eur.), supra note 114.

252 Interview with Rupsa Mallik, supra note 69.

${ }^{253}$ Interview with Matthew Smith \& Amy Smith, supra note 108.

${ }^{254}$ Interview with Advocate (9 S. Korea), supra note 103.

${ }^{255}$ Interview with Advocate (55 Int'l), supra note 74.
} 


\section{F. FUNDING STRUCTURES, LIMITED FUNDING, AND ECONOMIC DISADVANTAGE}

Funding structures, limited resources, and financial constraints are serious obstacles to advancing well-being in the human rights field. In addition to limited funding and economic inequities harming mental health, they also have direct impacts on other economic and social rights. Scarcity appears to limit organizational responses, and where staff are also often paid very little, their ability to implement well-being strategies, adopt different lifestyle choices, and weather challenges can be impeded. The funding model for much human rights work is critical: some advocates reported that donors do not make adequate resources available for things like fair pay, leave and sabbatical time, physical and mental health services, and wellbeing programs. ${ }^{256}$

Many advocates noted that organizations lacked the funding needed to improve their response to well-being concerns. ${ }^{257}$ For example, smaller organizations do not have the resources to adopt specific structures that can address well-being. As an advocate based in Asia explained: "[An] issue is organizational structure. Not many human rights organizations have human resources staff, compared to a corporate company. Therefore, there is no one devoted to staff welfare." 258

Another expert explained that limited organizational resources contribute to high workloads across the organization, hindering attention to well-being:

For example, I need to take leave, but can't because there's so many things going on. If you take off, your work will be added to [the work of] your colleagues. Even when you do take leave, you have emails on your phone. So it's linked

\footnotetext{
${ }^{256}$ See, e.g., Interview with Yvette Alberdingk-Thijm, supra note 92.

${ }^{257}$ See, e.g., Interview with Wadih Al-Asmar, supra note 65; Interview with Ajeng Larasati, supra note 35 (noting that lack of funds meant that NGOs could not have human resources staff who could devote time to well-being); Interview with Expert (26 Americas), supra note 46 (noting that although the "importance [of mental health and well-being is] recognized . . . it [is] difficult to commit and establish practices that endure. Following a plan, dedicating resources and time [is] always a challenge."); Interview with Manon Muti, supra note 143 ("There is a money problem, a financial problem, how to sustain psychological support."); Interview with Maria Cappello \& Valeria Moscoso, supra note 46 ("What prevents us from doing more is the lack of donation funding on the subject.").

${ }^{258}$ Interview with Ajeng Larasati, supra note 35. Another advocate echoed this concern: "The weakness is that we don't have a human resources person. I have been lobbying for this internally." Interview with Tessa de Ryck, supra note 96.
} 
to the structure of human rights organizations, in terms of resources. $^{259}$

While not all mental health initiatives require funding, initiatives like staff training, retreats, counselling, mental health care, and generous leave can require significant funding. Advocates reported difficulty in obtaining from their funders specific financial support for such initiatives, ${ }^{260}$ or the core funding that could provide the organization flexibility to create well-being programming. ${ }^{261}$ Some advocates attributed this to funders and managers seeing "human rights work" as separate from, and more important than, advocate well-being; these attitudes often lead to a dearth of organizational funds for mental health. ${ }^{262}$ One interviewee based in Sub-Saharan Africa explained that:

[F]or local organizations, the main difficult $[\mathrm{y}]$ is the access of resources to pay for such programs ... The government doesn't have any program to assist local organizations. All financing comes from international organizations; we need to apply to international grants, which don't focus on mental health. This can be the main problem which impedes local organizations to have such programs towards their workers. ${ }^{263}$

One advocate working in Asia diagnosed the problem as a systemic one:

I don't know what the funding opportunities are for actually incorporating well-being activities and practices in organizations. What I do think is that-and I don't know why - in some countries, human rights defenders are systematically underpaid. In some cases, management of organizations are to blame by neglecting staff, especially in

\footnotetext{
${ }^{259}$ Interview with Expert (14 Int'l), supra note 138.

${ }^{260}$ Interview with Ram Kumar Bhandari, supra note 35 ("The role of the activists, their health is not considered [by mainstream donors]. I don't see their interest."); Interview with Radhya AlMutawakel, supra note 77 ("[The donors] never responded to things related to insurance . . . For security it is hard to convince them to do something ... . So I can foresee that [obtaining funding for advocate's mental well-being] will be difficult."); Interview with Millicent Auma Otieno, supra note 47 ("There is no funding for mental health.").

${ }^{261}$ Interview with Matthew Smith \& Amy Smith, supra note 108 ("[F]unding for core costs is always an issue. We are always looking for core funding but funders want to support programmatic costs not core costs. We have to pay salaries and health insurance, communication costs.").

${ }^{262}$ Interview with Joanna Kurosz, supra note 76 ("They have an enormous amount of human rights work that they feel they can't afford to put resources, whether time and money into [mental health].").

${ }^{263}$ Interview with Foromo Frederic Loua, supra note 80.
} 
more remote areas. Often per diems and transportation money are used to compensate for the low salaries, lacking accountability and transparency. Donors are maintaining the system and need to increase overhead. Decent salaries, health benefits are important. In international organizations, the overheads are very high. There should be enough money for these things. There is a direct link to well-being, if you have a decent salary. ${ }^{264}$

A prominent advocate working on the rights of intersex persons explained:

My understanding is that it's the way the world works, with individuals doing activism working in the non-profit NGO world ... almost always working with very little resources and the priority for those resources is given to getting the work done and for serving the mission directly. I think for better or for worse, making time and energy and funding available to support the mental health and well-being of the people doing the work, is uniformly a low priority. ${ }^{265}$

Some advocates also emphasized that the recent spate of laws in many countries, which crack down on human rights work by preventing or making external funding very difficult, have harmed efforts to advance the wellbeing of advocates. ${ }^{266}$ These laws deliver a double punch: they stigmatize rights advocates as foreign agents and deprive movements of funding needed to support advocates.

Interviewees also stressed that many human rights advocates, especially at smaller organizations and in the global south, are paid extremely little, if at all. One advocate explained that "neither in international cooperation nor at the level of nations have there been adequate funds dedicated. There is a moralistic, puritanical attitude that believes that defenders must do what they do for love and do it for free. There is no professional respect." 267 Advocates explained that low salaries increase stress:

Funders ... will only fund a part of funding that can go to salaries - and so that has a big impact on us here ... $[\mathrm{u}]$ nless you are paying your staff in line with what is a decent salary in line with the cost of living - that has an awful impact on the well-being of staff. We don't pay staff

\footnotetext{
${ }^{264}$ Interview with Tessa de Ryck, supra note 96.

${ }^{265}$ Interview with Kimberly Zieselman, supra note 172.

${ }^{266}$ Interview with Expert (14 Int'1), supra note 138.

${ }^{267}$ Interview with Verónica Cruz Sánchez, supra note 84.
} 
at a level adequate to live on their own, or own both a car and property - and that really does have an impact. Funders still have not changed their model of funding - they still say a very small percentage needs to go to staff salaries. ${ }^{268}$

This lack of funding results in stressful economic insecurity, as well as minimal resources to pay for counseling, exercise programs, vacations, or other support. Many years in this poorly-paid field can also create long-term stress related to family support, retirement planning, and even end-of-life care. ${ }^{269}$

Despite the lack of funding available for mental health among human rights organizations, funders and organizations have significant incentives to invest in mental health care. Research has shown that employees suffering from depression and anxiety exert a significant cost burden on an employer, including productivity loss, increased absenteeism, high turnover, and suboptimal performance. ${ }^{270}$ Investment in effective treatment has been shown to increase productivity, thereby potentially justifying the costs of the treatments itself. ${ }^{271}$

\section{G. LACK OF ACCESS TO PSYCHOLOGICAL OR PSYCHOSOCIAL SUPPORT OR TAILORED MENTAL HeALTH PROGRAMMING}

Human rights organizations face numerous obstacles when seeking psychological or psychosocial support for their staff. Funding is a pervasive obstacle and particularly affects small, local-level, and global south NGOs. ${ }^{272}$ Beyond economic inaccessibility, psychological services are

\footnotetext{
${ }^{268}$ Interview with Sharon Cox, supra note 96.

269 See, e.g., Interview with Advocate (66 Turk.) (June 22, 2018) (explaining how financial instability in human rights organizations can result in poor staff salaries. This makes it challenging for staff to obtain the financial stability needed to retire which exacerbates mental health problems).

${ }^{270}$ Ron Goetzel et al., The Business Case for Quality Mental Health Services: Why Employers Should Care About the Mental Health and Well-Being of Their Employees, 44 J. OcCUPATIONAL \& ENVTL. MED. 320, 320 (2002).

${ }^{271} I d$. at 322.

272 See, e.g., Interview with Advocate (58 U.K.), supra note 74 (explaining that the organization does not have resources to ensure things like psychological support are available to staff); Interview with Simran Sachdev, supra note 138 ("There are a lack of resources, a lack of funding."); Interview with Matthew Smith \& Amy Smith, supra note 108 (noting that "funding for core costs is always an issue," impeding the ability to address well-being); Interview with Sehyek Oh, supra note 112 ("I know my organization doesn't have the budget for providing ... special services."); Interview with Ajeng Larasati, supra note 35 ("Human rights organizations have very tight budgets which can inhibit responses to well-being concerns."); Interview with Foromo Frederic Loua, supra note 80 ("For local organizations the main difficulty is accessing resources to pay for such programs.").
} 
sometimes hard to find due to country conditions. Sometimes counseling is available, but it is not sufficiently tailored for human rights advocates. Perhaps worst of all, psychologists themselves are sometimes actively hostile or discriminatory toward specific types of advocates.

Finding appropriate mental health resources is particularly challenging for the many organizations that are not in urban areas and western countries. An advocate working in Asia explained, "There are not many mental health professionals in [our country] - there is no mental health department in the ministry of health . . . There are about 200-300 mental [health] providers for 51 million people." ${ }^{273}$ Similarly, an interviewee from East Africa said, "There are eighty-eight psychiatrists in all [in our country]; there is only one who operates in [the west of the country], and this person is now bedridden." 274 An expert from MENA echoed this, saying, "there are not enough resources and therapists, in particular, are very hard to access." 275 Expertise in PTSD and other related concerns can also be hard to find. ${ }^{276}$ One interviewee with an international human rights organization indicated that although she had access to experts, because there were so few with specific expertise in PTSD, those same experts might also be involved in helping the NGO to work with the affected population. ${ }^{277}$ Their relationship as professional colleagues created discomfort in seeing the psychologist for personal counseling. ${ }^{278}$

Even in places where psychological services are available, advocates reported difficulties in locating counselors who understand human rights. An advocate based in one Asian country and working on severe violations in another country explained the discomfort that can come from working with a health provider who is unfamiliar with grave human rights violations, and who thus may not understand or believe what the advocate is going through. ${ }^{279}$ Some advocates perceive that psychologists "look at you as if you were crazy, as if you came from the moon." ${ }^{280}$ Another advocate wished for counselors who understand human rights and have sufficient

\footnotetext{
${ }^{273}$ Interview with Kyaw Soe Win, supra note 173.

${ }^{274}$ Interview with Roy Douglas Otieno, supra note 85.

275 Interview with Advocate (62 Egypt), supra note 96.

${ }^{276}$ Interview with Matthew Smith \& Amy Smith, supra note 108.

${ }^{277}$ Interview with Advocate (50 Int'1), supra note 88.

${ }^{278} \mathrm{Id}$. ("The problem is it is a rather small pool of experts, and you may not want to consult with people you work with.”).

${ }^{279}$ Interview with Advocate (9 S. Korea), supra note 103 (noting that some psychologists "have no idea about human rights crimes committed in other countries ... [t] hey only know the reality [in their own country.]").

${ }^{280} I d$. (noting that if certain psychologists use their own experiences as the benchmark, they may perceive the testimonies of severe human rights violations that advocates hear to be exaggerated or fabricated).
} 
"background knowledge. ... . [to] properly respond" to the psychological needs of advocates who seek their support. ${ }^{281}$ If interactions between counselors and advocates are based on judgment instead of understanding, the result can be harm instead of relief.

An advocate with experience in Latin America but based in the Netherlands discussed how hard it was to find culturally competent psychosocial support for human rights defenders who participated in the advocate's three-month shelter initiative: "a temporary relocation program to provide rest and respite for three months to human rights defenders around the world." 282 Many psychologists engaged in this initiative often had no knowledge of what it was like to be a human rights defender, and "copy-pasted Western approaches." 283 The advocate also noted that while Eye Movement Desensitization and Reprocessing ("EMDR") therapy for $\mathrm{PTSD}^{284}$ had produced good results, "three months was ... a very short time to heal people, so we need to be very careful with the therapists to not open wounds that cannot be addressed in such a short time." 285

Negative interactions with psychologists are especially harmful for advocates who face marginalization or vulnerability in society-for example, on the basis of their sexual orientation, or gender, racial, or ethnic identity. For example, one advocate explained that indigenous advocates have rejected recommendations to use counseling services out of concern that the services were not culturally appropriate or respectful. ${ }^{286}$ An advocate who works on LGBTQI rights explained the harms they had seen:

I've seen a number of mental health practitioners who didn't know anything about LBGTI and who did more harm than good by what they said and what they prescribed ... I don't know whether it was because [of] the fact [that] homosexuality was a 'mental illness' for so long, whether that had an impact on the mental health field, whether they are still biased against the LGBTI community, or whether

\footnotetext{
${ }^{281}$ Interview with Sehyek Oh, supra note 112.

${ }^{282}$ Interview with Manon Muti, supra note 143.

${ }^{283} \mathrm{Id}$. ("There is a complete lack of cultural sensitivity, gender perspective or basic understanding of what it means to be human rights defender.") Muti also noted the lack of psychologists in Honduras who had experience with the violent trauma faced by human rights defenders.

${ }^{284}$ EMDR therapy, first developed in 1989 to treat PTSD, involves recalling the traumatic memory and its associated negative affects while engaging in rapid eye movements by "following the repetitive motion of the therapist's hand." Ulrike Feske, Eye Movement Desensitization and Reprocessing Treatment for Posttraumatic Stress Disorder, 5 CLINICAL PSYCHOL. SCI. \& PRAC. 171, 171 (1998).

${ }^{285}$ Interview with Manon Muti, supra note 143.

${ }^{286}$ Interview with Advocate (13 Austl.), supra note 53.
} 
they're not aware of the LGBTI community . . . they're supposed to be the people who help but sometimes it feels like they're not the best. ${ }^{287}$

An advocate based in East Africa placed the challenge in stark relief: "We have only one counselor who can work with SOGI [sexual orientation and gender identity] members who does not turn it into a prayer and conversion session." 288

The lack of access to appropriate counseling and mental health professionals is alarming. Mental health professionals have become increasingly aware of the important role that culture plays in delivering effective services. Over the last 40 years, "multicultural competence" has emerged as a key theme for the training of mental health providers to ensure that they are prepared to provide effective and tailored services to all patients, especially those from marginalized groups that had previously received unequal treatment and access to care based on race, ethnicity, socioeconomic status, gender, religion, sexual orientation, disability, and other aspects of identity. ${ }^{289}$ While seeing a mental health professional is not needed or appropriate for all, extensive research demonstrates how helpful expert support can be in a variety of circumstances for improving wellbeing. ${ }^{290}$ Research has also examined how poorly-delivered counseling can exacerbate mental health conditions. ${ }^{291}$ Harmful effects can include worsening severity of symptoms, increased concern about current symptoms, and reluctance to seek future treatment. ${ }^{292}$ For example, despite the widespread use of Critical Incident Stress Debriefing ("CISD") - a psychotherapy delivered to groups soon after exposure to a traumatic event to prevent the development of mental health issues - studies have found that this approach may have either no effect or, in some cases, may lead to deleterious outcomes. ${ }^{293}$ Even if extensive research has led to recommendations of specific treatments for specific disorders, individual

${ }^{287}$ Interview with Advocate (60 Fr.) (June 5, 2018).

${ }^{288}$ Interview with Tabitha Netuwa, supra note 40. See also Interview with Kimberly Zieselman, supra note 172 ("It's not easy, there are not many well-informed culturally competent intersex counselors.").

${ }^{289}$ Derald Wing Sue et al., Multicultural Counseling Competencies and Standards: A Call to the Profession, 70 J. Counseling \& DeV. 477, 477 (1992).

290 See generally Derek Griner \& Timothy B. Smith, Culturally Adapted Mental Health Intervention: A Meta-Analytic Review, 43 PSYCHOTHERAPY (2006).

291 See generally Scott O. Lilienfeld, Psychological Treatments that Cause Harm, 2 PERSPECTIVES ON PSYCHOL. SCI. 53 (2007) (reviewing the potential harmful effects of various types of therapy commonly provided, such as attachment therapy and grief counseling).

292 Charles M. Boisvert, Negative Effects in Psychotherapy: Research Findings and Clinical Implications, 15 DiRECTIONS CLINICAL \& COUNSELING PSYCHOL. 37, 37-38 (2003).

${ }^{293}$ Lilienfeld, supra note 291, at 59. 
patient treatment response may vary across factors, such as treatment length, the specific intervention model, or individual environmental circumstances. ${ }^{294}$ For these reasons, it is important that any decision about whether to access or implement counseling is made in light of the local context, and that delivered therapies for human rights advocates are adapted to the relevant cultural context and existing knowledge base.

\section{ORGANIZATIONAL TACTICS TO PROMOTE WELL-BEING AND RESILIENCE}

Human rights organizations are using a variety of tactics in an effort to improve well-being for advocates. While those interviewed for this study generally noted that the field's response has been highly inadequate overall, advocates shared organizational practices that they view as important for supporting well-being and building more resilient advocates and organizations. The practices discussed by advocates have not been independently empirically assessed for their effects within the human rights field, but some have been studied in other fields, and the perspective and experience of advocates as to their benefits provides important knowledge about promising tactics and reforms. Advocates emphasized the importance of high-level organizational commitment to well-being, leadership from management, seeing well-being as political rather than individual and medical, mental health education, offering psychosocial support and wellbeing practices, peer support, and breaks. Advocates also discussed practices such as staff working groups, recognizing achievements, bringing meaning, mainstreaming well-being discussions into regular staff meetings, proactive check-ins, trauma-aware workflows, shifting the types of work undertaken, remote working, flexible hours, and art, spiritual, or religiously rooted practices of care.

\section{A. ORGANIZATIONAL COMMITMENT AND MANAGEMENT LEADERSHIP}

Advocates emphasized the importance of an organization-level response and commitment to well-being, with leadership on these issues from management and senior staff. Advocates interviewed for this study stated that to achieve a shift in human rights well-being culture and to create an enabling environment for well-being, management and the organization itself needed to prioritize well-being, model behavior, and work toward

\footnotetext{
${ }^{294}$ Michael Lambert, Presidential Address: What We Have Learned From a Decade of Research Aimed at Improving Psychotherapy Outcome in Routine Care, 17 PSYCHOTHERAPY RES. 1, 3-4 (2007).
} 
structures and organizational plans for well-being. ${ }^{295}$ An advocate from South Africa explained: "We try to think about collective care over selfcare. It's not just an individualized thing, like one person going to yoga or a therapist. Rather it needs to be an organizational approach to work." 296

Some organizations demonstrated their prioritization of well-being by creating mental health or resilience policies, or by integrating well-being strongly into other organizational policies or strategies. ${ }^{297}$ One organization working in MENA to monitor human rights violations committed during war explained that it is incorporating mental health into its five-year organizational strategy to ensure that mental health would be brought into each project and proposal. ${ }^{298}$ A U.S.-based organization, in which staff are regularly exposed to traumatic imagery, has prioritized resilience by creating a specific "resilience officer" tasked with promoting well-being across the organization. ${ }^{299}$ Another organization adopted a "shared leadership" model, with two executive directors, in recognition of the

\footnotetext{
${ }^{295}$ See, e.g., Interview with Yvette Alberdingk-Thijm, supra note 92 (emphasizing the importance of managers taking on a leadership role in advancing well-being and being supported in this role); Interview with Gasser Abdel-Razek, supra note 80 (emphasizing that management must value employees as people and support them when experiencing emotional difficulties. When employees realize they are valued by management, this improves the dynamics within the organization); Interview with Cindy Clark \& Shareen Gokal, supra note 69 (highlighting the need for leaders to model appropriate behavior due to the resulting "ripple down effect" within the organization).

${ }^{296}$ Interview with Lisa Chamberlain, supra note 54. See also Interview with Maria Cappello \& Valeria Moscoso, supra note 46 ("Within the Commission, we look at the issue under many structures: how to work within the team, how our work affects us collectively, and what ways we handle self-care individually. The two things (collective responses and individual responses) go hand in hand.").

${ }^{297}$ See, e.g., Interview with Advocate (8 U.K.), supra note 138 (describing written guidelines for analysts and lawyers addressing self-care in the context of traumatic imagery review); Interview with Advocate (13 Austl.), supra note 53; Interview with Andrea Lampros, supra note 36 (referring to short written policy and protocols); Interview with Expert (14 Int'1), supra note 138 (discussing plans to create an organizational policy including sections on mental health); Interview with Tabitha Netuwa, supra note 40 (noting that including mental health issues in the human rights resources policy helps); Interview with Lisa Chamberlain, supra note 54 ("We are developing a collective care policy to document what we try to practice. We are grappling with what collective self-care means and how it differs from individual self-care. What has become clear though is the need for a written policy, to give legitimacy across the board [as] opposed to just talking about self-care. The risk is that some people will feel more comfortable with this than others. We are working through how to document this and make it a formal practice. I see collective care as involving greater organizational planning."); Interview with Phil Lynch, supra note 145 (describing a risk assessment policy).

${ }^{298}$ Interview with Radhya Al-Mutawakel, supra note 77. See also Interview with Expert (2 Eur.), supra note 68 (emphasizing importance of putting mental health into project proposals).

${ }^{299}$ Interview with Andrea Lampros, supra note 36.
} 
enormous workload on a sole director, and as part of an effort to promote mental health of staff through structural changes to the organization. ${ }^{300}$

Advocates emphasized the importance of employers creating an "enabling environment" for individual staff to take self-care measures, and of managers themselves understanding well-being issues. ${ }^{301}$ Some managers described trying to create positive work environments by letting staff know that they understand how human rights work can affect wellbeing, signaling the importance of balance, and making clear that support is available. 302 "We want them to [be] successful in work but also be healthy individuals," explained one manager. ${ }^{303}$ Another elaborated:

$[\mathrm{W}]$ hen there is a genuine interest within an organization to make sure the organization is caring for its staff and comfortable for its staff, that gets transmitted to the people working there. If an organization's management is trying ... all the time [to] make the work conditions and culture comfortable for its staff, people know it and feel it. ${ }^{304}$

Psychology research demonstrates that positive and effortful leadership has led staff to report less stigma and fewer barriers to access mental care, ${ }^{305}$ and suggests that proper supervisor mental health training is crucial, given the key role a supervisor's attitudes and skills potentially have on the mental health of subordinates. ${ }^{306}$

A manager from an NGO based in the United States explained efforts to help staff prioritize work to reduce workloads and make time for wellbeing:

One of the things I do with the team is to constantly talk about the things they do to take care of themselves. We talk about obligations: we always have to do things, take up opportunities to speak, or attend things. But we consider: is

\footnotetext{
${ }^{300}$ Interview with Advocate (7 Int'1), supra note 35.

${ }^{301}$ Interview with Advocate (13 Austl.), supra note 53; Interview with Expert (3 Eur.), supra note 114; Interview with Matthew Smith \& Amy Smith, supra note 108 (explaining management promotes a positive working culture); Interview with Gasser Abdel-Razek, supra note 80; Interview with Kimberly Zieselman, supra note 172 (all noting attempts of leadership to model positive mental health practices).

${ }^{302}$ Interview with Matthew Smith \& Amy Smith, supra note 108. But see Interview with Simran Sachdev, supra note 138 (noting the difficulty for managers of achieving work-life balance themselves).

${ }^{303}$ Interview with Matthew Smith \& Amy Smith, supra note 108.

${ }^{304}$ Interview with Gasser Abdel-Razek, supra note 80.

305 Wright et al., supra note 240, at 113.

306 Tsutsumi, supra note 241, at 1-9.
} 
this [a] priority right now, versus being able to get a good night's sleep after a few weeks?

Another manager of an international human rights organization described a concrete way in which workloads were managed, explaining that at planning meetings, staff were instructed to budget and plan for only $90 \%$ of their time, as human rights work requires flexibility in responding to evolving and crisis situations. ${ }^{308}$

Advocates stressed the importance of managers proactively and regularly discussing well-being and burnout with staff ${ }^{309}$ and being very open and available to staff to have conversations about these issues. ${ }^{310} \mathrm{An}$ advocate working in Europe stated how important these kinds of management actions can be for staff: "Knowing that your boss understands goes so far. Just taking five minutes to check in and say 'Are you OK?' is huge. Noticing, reminding employees or students that they need to take a break, step away." 311

Advocates also noted the importance of managers' own behavior at work and said that modeling self-care was important to organizational culture. ${ }^{312}$ Empirical research underlines the importance of management behavior, suggesting that leaders' own stress, ability to provide support, and leadership style are associated with employee stress and well-being. ${ }^{313} \mathrm{~A}$ manager from the Americas explained how senior staff in their organization try to lead by example to improve well-being for all staff:

We also encourage people to have more of a social life and to do things outside of work. And then lead by example. For example, a senior staff member now organizes a

\footnotetext{
${ }^{307}$ Interview with Gabrielle Jackson, supra note 70.

${ }^{308}$ Interview with Phil Lynch, supra note 145.

${ }^{309}$ Interview with Ajeng Larasati, supra note 35; Interview with Andrea Lampros, supra note 36; Interview with Gabrielle Jackson, supra note 70.

${ }^{310}$ Interview with Gabrielle Jackson, supra note 70.

${ }^{311}$ Interview with Expert (3 Eur.), supra note 114. See also Interview with Expert (2 Eur.), supra note 68 .

${ }^{312}$ Interview with Gabrielle Jackson, supra note 70; Interview with Gasser Abdel-Razek, supra note 80; Interview with Kimberly Zieselman, supra note 172; Interview with Phil Lynch, supra note 145 (all noting importance of efforts made by the leadership to model positive mental health practices).

313 Skakon et al., supra note 240, at 131. See also Price \& Weiss, supra note 240, at 403; Glasø \& Einarsen, supra note 240, at 65 .
} 
cinema night every Friday at her house for her friends, to relax and to watch movies and have food. ${ }^{314}$

A number of advocates pointed out that the culture of human rights work needs to change before a real difference can come about and highlighted the important role of managers in shifting workplace cultures. At the extreme end, one expert based in the MENA region explained, "[I]f you see your manager being burnt out completely, and he is not stepping down or even taking a proper break, this is also not giving a good culture to the organization." ${ }^{315}$ An expert based in the Americas summarized the problem this way:

The culture that prevails is that of responsiveness and not prevention. We see many manifestations of stress: muscle pain, migraines, and problems with menstrual cycles. We consider [these symptoms] to be expressing in the body what is not worked out in the mind. It is necessary to incorporate a vision of mental health into the discourse of protection. ${ }^{316}$

An expert based in Europe concurred, explaining that while some organizations have begun to shift the way they talk about well-being and respond to such issues by embracing "cultures of care," this is "the hardest thing to change" because "leaders are often too busy," and well-being work "ends up being an extra load for individuals who are motivated." 317

\section{B. VieWING WeLl-Being as Political}

Some advocates explained that an important approach to improving well-being has been to see and pursue well-being as political, rather than to adopt an overly individualized, medicalized model of mental health. Some organizations and movements have long adopted a politicized, social justice

\footnotetext{
${ }^{314}$ Interview with Luis Fondebrider, supra note 169. See also Interview with Gabrielle Jackson, supra note 70 (discussing how asking leadership constantly what they do to take care of themselves "to incorporate wellness into everything we do.").

${ }^{315}$ Interview with Expert (35 MENA), supra note 104; Interview with Guacira Cesar de Oliveira, supra note 65 ("At the leadership level, there is a lot of overwork."); Interview with Gabrielle Jackson, supra note 70 (explaining how taking on a leadership role leads to a sense of obligation); Interview with Advocate (64 Eur.), supra note 144 (discussing how the culture of overwork is valorized).

${ }^{316}$ Interview with Ana Maria Hernández Cárdenas, supra note 52.

${ }^{317}$ Interview with Sandra Ljubinkovic, supra note 143; Interview with Gasser Abdel-Razek, supra note 80. Similarly, an expert based in Europe explained that sometimes a junior staff member seeks the help of an expert "because the management hasn't listened." Sometimes these external interventions can be crucial and are even seen as "sav[ing] the organization." Interview with Joanna Kurosz, supra note 76.
} 
vision of well-being, highlighting the links between individual emotional well-being, collective care, and the achievement of human rights, captured famously by Audre Lorde: "Caring for myself is not self-indulgence, it is self-preservation, and that is an act of political warfare." 318 Others are more recently seeking to shift away from a pathologizing or depoliticizing view of mental health, moving instead toward improved integration of well-being with their social justice commitments. This is less a "tactic" than a significant structural and cultural shift in how to conceive of advocates' well-being.

An activist from Brazil connected care of self and community with social movement strategies and human rights goals:

Care means looking in a holistic way. It is a fundamental goal of what we want to do in the world. Care among us, among the community we live in. It is also our strategy: if we do not experience caring, [if we] neglect ... ourselves, the careful world we want will not come. Just as we cannot have human rights if we do not give ourselves the right to exert our rights. It is impossible to change the world if we are not doing this carefully among ourselves. The strategy of care is central to our empowerment and survival. For the strengthening and survival of the feminist and anti-racist movement. With all the aggressions we are experiencing today, if we do not have that, we will not survive. ${ }^{319}$

Some advocates have adopted "healing justice" as a framework, ${ }^{320}$ which recognizes how structural forms of oppression, such as racism and xenophobia, harm individuals and communities, as well as those working to dismantle these oppressions. This framework ties collective efforts toward liberation, or human rights enjoyment, together with healing. ${ }^{321}$ An

\footnotetext{
318 AUdRE LORDE, A BURST OF LIGHT: ESSAYs 131 (1989). See also Interview with Manon Muti, supra note 143 ("For the feminist movement in Latin America especially, mental health is a political act. Claiming your rights to self-care is political and an act of rebellion.").

${ }^{319}$ Interview with Guacira Cesar de Oliveira, supra note 65. See also Interview with Gabrielle Jackson, supra note 70 (describing efforts to move away from a medicalized model of well-being).

${ }^{320}$ Interview with Richael Faithful, supra note 137. However, one advocate offered caution about using "healing." See Interview with Cara Page, Activist-in-Residence Fellow, Barnard Ctr. for Research on Women (May 5, 2018) ("I have faced tons of pushback on the use of the word healing. As much as I can't stand the term health because of what/how that has been institutionalized and constructed, I have had disability rights organizers say yes, but healing presumes a wholeness that we all have a whole body, a whole mind, a whole way of being. And that is very ableist. So I was like, oh shoot, we can't use that! So I watched people move into care, or resiliency or sustainability. Which I am finding fascinating. I have leaned more into wellness and well-being."). ${ }^{321}$ Loretta Pyles, Healing Justice: Holistic Self-Care For Change MaKers xviii-xix (2018).
} 
expert who was instrumental in coining the term "healing justice" explained that "individual wellness is integral to our collective survival" and that "integral to political liberation is the understanding that we are well and safe and liberated." 322

Advocates also explained how political activism itself could improve well-being:

I also see that activism is the healing of many people. Activism not only makes us sick, it heals us. For women who have a history of isolation, being able to share their pain, transforming into activism, ha[s] become a relief. This is a good part of the history of the women's movement: many have gone into activism because of the despair of the isolation... solidarity received in the movements and commitment within the struggle ... creates bonds of trust, recognition, etc. When we are alone, we build or feel 'impotent.' When we are part of movements we feel empowered. [This] is curative. ${ }^{323}$

An expert from Europe emphasized that advocates must not lose sight of the fact that, while human rights work can be a source of strain, it is also a source of strength:

We need to not victimize or use the well-being discourse as a way to be so introspective that we cannot see that the reason we do the work is part of the reason our well-being is at risk. On the other hand, I also think we should keep the balance and not think that all we need to do is work on well-being - if we lose the focus on human rights work, we will crack. In my experience, doing human rights work is what gets me out of bed, and makes me resilient-it's your motivation - it's what keeps you healthy. It is a resource to stay well. The focus of our work must stay in our sightswe must not lose our hope. We need to make the space to improve mental well-being without displacing our attention to the human rights work itself. ${ }^{324}$

Some noted that the political approach to well-being was not widespread in their networks. An advocate working in South Africa said that although she

\footnotetext{
322 Interview with Cara Page, supra note 320.

${ }^{323}$ Interview with Guacira Cesar de Oliveira, supra note 65; Interview with Marty Huber, supra note 84 ("The best motivation is to have people that you can really help through their asylum procedure to succeed and get a positive decision.").

${ }^{324}$ Interview with Expert (9 Eur.), supra note 49.
} 
personally viewed "self-care as acts of political resistance," this was not a view shared among many in her organization or field regionally. ${ }^{325}$ This advocate felt that such an approach would help human rights organizations tackle well-being issues, encouraging them to make more resources available. ${ }^{326}$

\section{EducAtion, TRAining, AND RESOURCES}

Prior research has found that advocates often are not well-educated about mental health and human rights: in one survey, $62 \%$ of advocates surveyed had received little to no training on the emotional impacts of human rights advocacy. ${ }^{327}$ As this Article focused on organizations, we examined the types of education and resources provided and found that the amount and frequency of education provided varied widely. ${ }^{328}$ Forms of training or support included induction trainings, periodic or one-off workshops, incorporating mental health education into existing staff meetings or retreats, or providing written guides or tips to advocates.

Some advocates reported initial or induction trainings for new staff which included raising awareness about potential exposure to difficult material in the work and about trauma, vicarious trauma, and self-care. ${ }^{329}$ Practitioners involved in teaching noted that there were increasing numbers of modules or seminars on well-being in university settings where human rights advocacy is taught. ${ }^{330}$ Advocates at NGOs discussed workshops ranging from an hour to a week, sometimes entirely dedicated to well-being or as part of a general training, holistic security training, or staff retreat. ${ }^{331}$

\footnotetext{
${ }^{325}$ Interview with Lisa Chamberlain, supra note 54.

${ }^{326} \mathrm{Id}$.

${ }^{327}$ Knuckey, Satterthwaite, \& Brown, supra note 1, at 270.

${ }^{328}$ In our study, only sixteen organizations (of the sixty-one interviewed) talked about trainings, whether internally or organized by an external organization.

${ }^{329}$ Interview with Advocate (8 U.K.), supra note 138 (describing how an external consultant delivered a workshop on secondary trauma and self-care for all staff members, as well as a presentation explaining that the organization's approach to vicarious trauma is part of the induction program for all new lawyers and analysts); Interview with Advocate (13 Austl.), supra note 53; Interview with Andrea Lampros, supra note 36 (explaining how people new to the work are provided information about what they are likely to encounter, and the range of possible reactions, with the aims of normalization, and helping them to recognize any changes and take preventive steps).

${ }^{330}$ Interview with Expert (3 Eur.), supra note 114.

331 Interview with Matthew Smith \& Amy Smith, supra note 108; Interview with Advocate (23 Cambodia), supra note 46 (describing a training provided on holistic security, including some attention to mental health); Interview with Alexa Koenig, supra note 36; Interview with Expert (14 Int'l), supra note 138; Interview with Expert (2 Eur.), supra note 68; Interview with Yona Wanjala, supra note 42 (noting that the organization began including mental health into general security training two years ago); Interview with Tabitha Netuwa, supra note 40; Interview with
} 
One advocate noted the importance of not just doing one-off training, but also reiterating the materials, checking in with participants, and discussing materials again. ${ }^{332}$ Some organizations have created written resources about well-being, including "tip sheets" of resilience strategies for staff or students, which captured lessons learned. ${ }^{333}$

Some argued that mental health should be brought into all trainings, ${ }^{334}$ or that such trainings should be compulsory to help overcome stigma issues. ${ }^{335}$ One experienced advocate explained why it was important to provide education and training about well-being before problems arose:

The best moment to learn about fighting fires [is] not when your house is on fire - you have to do the fire drill to know what to do when it actually happens. In the moment the person is under enormous amounts of stress because they are facing a threat. This is not the time to learn strategies of resistance and protection. ${ }^{336}$

Some organizations incorporated well-being trainings or awareness-raising into general staff meetings: one organization showed videos about self-care and provided and discussed readings about self-care. ${ }^{337}$ However, one advocate noted that educational efforts were sometimes ineffective. ${ }^{338}$ His organization had facilitated an online well-being program for staff, but staff reported that they were too busy to use it. ${ }^{339}$ This example demonstrates the

\footnotetext{
Sehyek Oh, supra note 112; Interview with Guacira Cesar de Oliveira, supra note 65 (discussing multiple 4-5 day immersive trainings); Interview with Janet Munywoki, Former Director, Legal Research Foundation Trust (Apr. 24, 2018) (describing "education days" where counselors come in and present); Interview with Millicent Auma Otieno, supra note 47 (describing external trainings on trauma healing and conflict management); Interview with Alice de Marchi Pereira de Souza, supra note 96 (discussing how consultants come once a month and talk to the whole group); Interview with Sondos Shabayek, supra note 186 (describing psychoeducation workshops and information in the training manual); Interview with Gasser Abdel-Razek, supra note 80 (describing a one-off training with external psychologist); Interview with Idil Aydınoğlu, supra note 96 (discussing eight group therapy sessions organized by a large human rights organization); Interview with Maria LaHood, supra note 96 (describing how "[a] psychologist who is [an] expert on torture, PTSD, vicarious trauma speaks to the staff from time to time.").

${ }^{332}$ Interview with Andrea Lampros, supra note 36.

333 Interview with Experts (11 Eur.), supra note 193; Interview with Alexa Koenig, supra note 36; Interview with Skye Wheeler, supra note 81 (discussing secondary trauma guidelines).

${ }^{334}$ Interview with Tabitha Netuwa, supra note 40.

${ }^{335}$ Interview with Expert (3 Eur.), supra note 114 (recommending "compulsory training sessions for every member of the staff, and that is how we will change the organizations. A great thing to do would be to do a full audit of the organization and where the problems are, make sure the managers are aware of it.").

${ }^{336}$ Interview with Expert (2 Eur.), supra note 68.

${ }^{337}$ Interview with Advocate (13 Austl.), supra note 53.

${ }^{338}$ Id.

${ }^{339}$ Id.
} 
importance of a holistic approach: specific interventions are likely to be weakened without a broader enabling environment.

Proper psycho-education and training can have dramatic impacts on mental health outcomes. For example, one study conducted with volunteers involved in the disaster relief efforts following the 2011 earthquakes in Japan found that those who received training about mental health prior to their work subsequently had lower levels of PTSD and acute stress. ${ }^{340}$ Such training must be adapted to the human rights culture, however: it has become well accepted in the field of psychology that clinicians with higher levels of cultural sensitivity - those who are able to tailor a treatment to the nuances of the specific population - experience more favorable outcomes with their patients. ${ }^{341}$ Only a small number of initiatives have been created that aim to provide tailored support for human rights advocates, and to our knowledge, there have not been any studies to empirically test the efficacy of these approaches for human rights advocates.

\section{STAFF WORKING GROUPS AND FEEDBACK TO MANAGEMENT}

Some organizations have created systems for staff to provide feedback to management about well-being issues to promote organizational accountability and improve organizational responses. Some advocates explained that their organizations have created working groups or committees of staff who are responsible for leading on well-being, opening conversations, or bringing issues to the attention of management. ${ }^{342}$ One advocate discussed her organization's staff union, which brought up issues and helped secure better working conditions. ${ }^{343}$ Other organizations created surveys or questionnaires so that staff could provide feedback to the organization and promote internal learning and growth. ${ }^{344}$ One advocate explained that this was an important way to "tap into staff experience." 345

\footnotetext{
${ }^{340}$ June Okanoya et al., Psychoeducational Intervention to Prevent Critical Incident Stress Among Disaster Volunteers, 45 KITASATO MED. J. 62, 62-63 (2015).

${ }^{341}$ Hung-Bin Sheu et al., Multicultural Counseling Self-Efficacy Scale-Racial Diversity Form: Factor Structure and Test of a Social Cognitive Model, 22(5) PSYCHOTHERAPY RES. 527, 52728 (2012).

${ }^{342}$ Interview with Advocate (7 Int'1), supra note 35 (staff-led working group); Interview with Expert (14 Int'1), supra note 138 (staff committee); Interview with Skye Wheeler, supra note 81 (staff led working group on stress and resilience) Interview with Lucia Nader, supra note 161. But see Interview with Gasser Abdel-Razek, supra note 80 (explaining that attention to well-being came out of discussions within management).

${ }^{343}$ Interview with Expert (14 Int'l), supra note 138

${ }^{344}$ Interview with Advocate (7 Int'1), supra note 35 (staff questionnaires); Interview with Andrea Lampros, supra note 36 (regular surveys for anonymous feedback).

${ }^{345}$ Interview with Advocate (7 Int'l), supra note 35.
} 
Another advocate said that bringing in external researchers to conduct focus group discussions with the staff and report their findings to management was important in moving the conversation forward on stress and resilience. $^{346}$

\section{E. MAINSTREAming ATtention to Well-Being INTO INDIVIDUAL, TEAm, AND ORganizational MEetings, PROACTIVE CHECK-INS, AND DEBRIEFS}

Some organizations proactively include discussions of wellness in regular staff or team meetings, or create check-in processes or debriefs after distressing work. Discussion of well-being in regular staff meetings can open space to vent harms and stress, and encourage well-being practices. This approach normalizes concerns about mental health and well-being, and allows staff to share good practices with each other. One advocate emphasized the importance of creating an enabling environment for staff to practice self-care. ${ }^{347} \mathrm{He}$ suggested that organizations can utilize self-care videos and literature to help develop a common language to discuss wellbeing issues. ${ }^{348}$

The director of an organization based in MENA described the importance of normalizing conversations around well-being, pointing out that: "[T]here is an environment within [our organization] where everyone is encouraged to discuss how they feel without any shame and when those feelings are expressed, people realize that [these feelings] are not unique to them." 349 The director of an international human rights organization based in Europe discussed how the organization had incorporated "wellness Wednesdays," during which the director adheres to an open door policy and is available to speak with staff about wellness issues for two hours every second Wednesday of the month. ${ }^{350}$

Some organizations have mainstreamed attention to well-being in personnel processes, such as staff evaluations and job descriptions. ${ }^{351}$ For example, one advocate in Africa explained that "at every staff review, at every staff retreat, we talk about well-being. This is a regular part of all of

\footnotetext{
${ }^{346}$ Interview with Skye Wheeler, supra note 81.

${ }^{347}$ Interview with Advocate (13 Austl.), supra note 53.

${ }^{348} \mathrm{Id}$.

${ }^{349}$ Interview with Gasser Abdel-Razek, supra note 80.

${ }^{350}$ Interview with Phil Lynch, supra note 145.

${ }^{351}$ Interview with Expert (27 Americas), supra note 124.
} 
our work." ${ }^{352}$ An advocate working in the Americas explained that her organization has had a difficult time obtaining funding for well-being measures, and the organization has instead adopted a mainstreaming approach:

In our meetings, we separate moments dedicated to care ... . in our last planning retreat, we had a specific time to deal with our overwork, share what we are doing, how we can take better care of ourselves and between us. There were four days of planning and one of those days was entirely dedicated to looking at ourselves, our own care. In shorter meetings, we sometimes do meditation, breathing, seek more centering. Be more attentive to each other's needs. $^{353}$

Some organizations have created processes and spaces for regular well-being and mental health check-ins. An advocate and team leader working in the Americas described how her organization supplemented trainings with regular check-ins. ${ }^{354} \mathrm{~A}$ training on mitigating vicarious trauma for team members exposed to graphic and distressing video and photographic evidence proved to be insufficient on its own. ${ }^{355}$ The supervisors then implemented a "more holistic approach," which included checking in with small groups of team members following some weeks of work with graphic content. ${ }^{356}$

Some organizations use debriefings following research or investigation trips, or following critical security events or especially distressing work. ${ }^{357}$ An advocate working in Asia explained that her organization uses informal debriefing after "a difficult incident," and encourages discussion about stressful work experiences. ${ }^{358}$ An advocate working in Africa described a process following "crisis situations," in which the organization can bring human rights defenders together to discuss the event with counselors, either in the group or in one-on-one discussions. ${ }^{359}$ Debriefing should be used with care, as the results of clinical

\footnotetext{
352 Interview with Tabitha Netuwa, supra note 40. See also Interview with Advocate (13 Austl.), supra note 53 (noting that self-care questions can be effective in regular supervisor/employee meetings and in performance reviews).

${ }^{353}$ Interview with Guacira Cesar de Oliveira, supra note 65.

${ }^{354}$ Interview with Andrea Lampros, supra note 36.

${ }^{355} I d$.

${ }^{356} \mathrm{Id}$.

${ }^{357}$ Interview with Ditipriya Ghosh \& Pauline Gomes, supra note 79.

${ }^{358}$ Interview with Ajeng Larasati, supra note 35.

${ }^{359}$ Interview with Tabitha Netuwa, supra note 40.
} 
trials on debriefing is mixed, and some types of debriefing (e.g., where it is too soon, too short, or insufficiently private) may exacerbate symptoms of distress in some individuals. ${ }^{360}$

\section{F. COUNSELING AND PSYCHOLOGICAL SUPPORT}

Many advocates reported organizational practices of providing or facilitating access to therapy or counseling. Services varied widely-some NGOs had individual and/or group therapy, and many had voluntary access to services, while some had mandatory services. ${ }^{361}$ Some organizations

360 See, e.g., Jonathan I. Bisson et al., Psychological Debriefing for Adults, in EFFECTIVE TREATMENTS FOR PTSD: PRACTICE GUIDELINES FROM THE INTERNATIONAL SOCIETY FOR Traumatic Stress Studies 83, 101 (Edna B. Foa et al. eds., 2d ed. 2010); R. A. Mayou et al., Psychological Debriefing for Road Traffic Accident Victims: Three-Year Follow-Up of a Randomised Controlled Trial, 176 BRITISH J. PSYCHIATRY 589, 592 (2000); Marit Sijbrandij et al., Emotional or Educational Debriefing After Psychological Trauma: Randomised Controlled Trial, 189 BRitish J. PsychiAtry 150, 154-55 (2006); Debbie M. Hawker et al., To Debrief or Not To Debrief Our Heroes: That Is the Question, 18 CLINICAL PSYCHOL. \& PSYCHOTHERAPY 453, 461 (2011); Grant J. Devilly et al., Ready! Fire! Aim! The Status of Psychological Debriefing and Therapeutic Interventions: In the Work Place and After Disasters, 10 REV. GEN. PSYCHOL. 318, 328-45 (2006).

${ }^{361}$ Interview with Wadih Al-Asmar, supra note 65 (describing how two years previously they had sometimes had "capacity building and team building meetings with an external counsellor who came and spent the day with the team trying to do activity to release stress"); Interview with Advocate (3 Isr.), supra note 35 (describing psychology services offered to staff); Interview with Matthew Smith \& Amy Smith, supra note 108 (noting that the organization brought a counselor to a retreat to discuss secondary trauma and to do one on one sessions for staff); Interview with Advocate (13 Austl.), supra note 53 (describing free counseling for staff); Interview with Siti Mazumah, Human Rights Defender and Lawyer, LBH APIK Jakarta (Apr. 20, 2018) (describing access to therapists from an organization which works on trauma healing); Interview with Kyaw Soe Win, supra note 173 (describing a counseling program available to staff; the organization noted that "there is good feedback that counseling helps them understand themselves and helps to control their emotions."); Interview with Luis Fondebrider, supra note 169 (describing access to counselors); Interview with Janet Munywoki, supra note 331 (describing access to a counselor); Interview with Lisa Chamberlain, supra note 54 (explaining that her organization has had psychologists on retainer for the past few year, and staff can access a certain number of sessions per year); Interview with Senda Ben Jebara, supra note 114; Interview with Sondos Shabayek, supra note 186 (describing how staff who facilitated workshops had to work with a consultant psychologist who was on retainer); Interview with Gasser Abdel-Razek, supra note 80 (noting that the NGO covers four assessment sessions with any qualified psychologist); Interview with Advocate (62 Egypt), supra note 96; Interview with Advocate (64 Eur.), supra note 144 (describing how staff on a particular project had mandatory group sessions with a counselor); Interview with Expert (35 MENA), supra note 104 (describing therapy provided to staff); Interview with Experts (11 Eur.), supra note 193 (group therapy); Interview with Yona Wanjala, supra note 42; Interview with Tabitha Netuwa, supra note 40 (describing the hosting of group sessions for defenders after or during crisis situations, and also making individual counseling available); Interview with Millicent Auma Otieno, supra note 47 (describing a weeklong "crash program" in trauma healing); Interview with Marty Huber, supra note 84 ("We have a monthly supervision. There is also the ability to do this one on one, that are paid."). 
made counselors available at the office; ${ }^{362}$ others provided healthcare plans or financial resources for staff to access mental health services independently. ${ }^{363}$ An organization based in a university made sure that campus mental health services were accessible to students exposed to graphic or distressing online content in the course of their advocacy. ${ }^{364}$

Some organizations have regularized, permanent services, ${ }^{365}$ while others had provided access to a psychologist once, ${ }^{366}$ or as needed by any staff, ${ }^{367}$ or in response to a crisis or particularly difficult work and requests from staff. ${ }^{368}$ Some organizations acknowledged that their practices were inconsistent: one MENA NGO, for example, explained that it has previously had psychologists come in to provide staff support and activities aimed at relieving stress, but that it had discontinued the practice. ${ }^{369}$

Organizations also reported connecting staff to counseling resourceseither managers helped staff to locate or connect to counselors, ${ }^{370}$ or the NGO kept a database of counselors and support organizations to which staff could connect. ${ }^{371}$ An advocate noted that the organization also worked with psychologists so that managers could better understand the general wellbeing of staff. ${ }^{372}$

\footnotetext{
${ }^{362}$ Interview with Wadih Al-Asmar, supra note 65 (explaining that psychologists were brought into the NGO offices both for individual sessions with staff and also for a day of de-stress group activities with staff).

${ }^{363}$ Interview with Foromo Frederic Loua, supra note 80 (describing the financial resources that are made available); Interview with Ana María Hernández Cárdenas, supra note 52 (explaining how the organization has a small fund for individual therapy for staff); Interview with Gasser Abdel-Razek, supra note 80 (discussing financial resources to access counselors for four assessment sessions were available); Interview with Itzel Silva Monroy, supra note 173 (explaining how advocate selects counselor and organization funds sessions); Interview with Maria LaHood, supra note 96; Interview with Maria Cappello \& Valeria Moscoso, supra note 46 (explaining how the organization has an agreement with an organization that offers psychotherapeutic treatment, and covers the costs of treatment).

${ }^{364}$ Interview with Andrea Lampros, supra note 36.

${ }^{365}$ Interview with Luis Fondebrider, supra note 169 (reporting seeing an in-house psychologist at some organizations); Interview with Ana María Hernández Cárdenas, supra note 52 (monthly meeting with team and an external psychologist); Interview with Skye Wheeler, supra note 81 (inhouse counselor)

${ }^{366}$ Interview with Ajeng Larasati, supra note 35.

${ }^{367}$ Interview with Verónica Cruz Sánchez, supra note 84.

${ }^{368}$ Interview with Luis Fondebrider, supra note 169.

${ }^{369}$ Interview by Jennifer Lim with Wadih Al-Asmar, supra note 65; Interview by Jennifer Lim with Matthew Smith \& Amy Smith, supra note 108.

${ }^{370}$ Interview with Gabrielle Jackson, supra note 70; Interview with Andrea Lampros, supra note 36 (explaining that university mental health services are referred to student staff managers and lab students, and are also invited to speak to the human rights lab).

${ }^{371}$ Interview with Ditipriya Ghosh \& Pauline Gomes, supra note 79.

${ }^{372}$ Interview with Matthew Smith \& Amy Smith, supra note 108.
} 
Advocates raised concerns about the high cost for organizations of providing such services ${ }^{373}$ and observed that advocates paying for their own healthcare could find it difficult to maintain consistent treatmentespecially where the advocate is the family's main income-earner, making it difficult to prioritize spending money and time on personal well-being over family expenses. ${ }^{374}$ Advocates also raised concerns about whether staff actually availed themselves of the offered services and whether staff working in more remote areas might experience barriers to accessing services. ${ }^{375}$ One advocate discussed how women in Brazil supported other women in a popular housing rights movement by providing childcare support which allowed them to participate in communitarian therapy or other psychosocial support activities. ${ }^{376}$

The importance of access to counseling is clear from extensive psychology research. This research has demonstrated the positive effects of psychotherapy to be significant and constant across most diagnostic conditions. ${ }^{377}$ Furthermore, a growing body of evidence suggests that psychotherapy is associated with improved work functioning, reduced disability, morbidity or mortality, and reduction in general medical costs. ${ }^{378}$ Early treatment is important; research has demonstrated that delayed treatment may allow the "kindling" of symptoms. ${ }^{379}$ In other words, untreated mental health issues can lead to symptoms increasing in intensity and duration until a full depressive (or other) episode occurs. ${ }^{380}$ Psychotherapy research has identified a number of treatments associated with positive mental health outcomes. The effectiveness of evidence-based treatments, such as cognitive behavior therapy, exposure-therapy, interpersonal therapy, and dialectical behavior therapy, highlight the importance of randomized control trials to gauge the impact on mental

\footnotetext{
${ }^{373}$ Interview with Ajeng Larasati, supra note 35.

${ }^{374}$ Interview with Millicent Auma Otieno, supra note 47.

${ }^{375}$ Interview with Advocate (3 Isr.), supra note 35.

${ }^{376}$ Interview with Guacira Cesar de Oliveira, supra note 65.

${ }^{377}$ Am. Psychol. Ass'n, Recognition of Psychotherapy Effectiveness, 50 PSYCHOTHERAPY (CHI., ILL.) 102, 102 (2013).

378 Katherine Dixon-Gordon et al., Psychotherapy for Personality Disorders, 23 INT'L REV. PSYCHIATRY 282, 283 (2011); Am. Psychol. Assoc., supra note 377, at 103.

${ }^{379}$ Fabrice Duval et al., Treatments in Depression, 8 Dialogues Clinical Neuroscience 191, 196 (2006).

${ }^{380}$ Id.
} 
health outcomes. ${ }^{381}$ Other forms, such as mindfulness-based practices ${ }^{382}$ and psychodynamic psychotherapy, ${ }^{383}$ have also shown promise. While this research has demonstrated success in certain communities and contexts, further research is needed to ascertain the efficacy of these interventions in non-western contexts and with specific populations, such as human rights advocates, and to potentially identify less well-researched and novel forms of therapy ${ }^{384}$ that may be beneficial in such settings.

\section{G. PEER SUPPORT AND SOCIALIZING}

One of the most common measures mentioned by interviewees was the use of peer support mechanisms. Advocates described efforts to foster peerto-peer mental health support, as well as more general efforts to create opportunities for socializing and building inter-staff trust and bonds.

Numerous advocates said that opportunities for socializing and discussion among peers are an important form of support for well-being at their organizations. One advocate working in Africa explained that

${ }^{381}$ E.g., Stefan G. Hofmann et al., The Efficacy of Cognitive Behavioral Therapy: A Review of Meta-Analyses, 36 COGNITIVE THERAPY \& RES. 427, 435-36 (2012) (evaluating the effectiveness of cognitive behavioral therapy in treating disorders such as anxiety, depression, and schizophrenia); Mark B. Powers et al., A Meta-Analytic Review of Prolonged Exposure for Posttraumatic Stress Disorder, 30 CliniCAL PSYCHOL. ReV. 635, 639-640 (2010) (finding that prolonged exposure therapy was highly successful in treating PTSD).

382 E.g., Stefan G. Hofmann, et al., The Effect of Mindfulness-Based Therapy on Anxiety and Depression: A Meta-Analytic Review, 78 J. Consulting \& CliniCAL Psychol. 169 (2010) (reviewing studies of mindfulness-based therapy as treatment for anxiety and depression, concluding that it shows promise as a treatment option). See generally Alberto Chiesa \& Alessandro Serretti, Mindfulness-Based Stress Reduction for Stress Management in Healthy People: A Review and Meta-Analysis, 15 J. Alternative \& ComplementARy Med. 593 (2009) (examining the effectiveness of mindfulness-based stress reduction and concluding that it is able to reduce stress levels in healthy individuals); Nancy L. Sin \& Sonja Lyubomirsky, Enhancing Well-Being and Alleviating Depressive Symptoms with Positive Psychology Interventions: A Practice-Friendly Meta-Analysis, 65 J. ClinICAL PSYCHOL. 467 (2009) (evaluating the effectiveness of positive psychology interventions ("PPIs"), which are aimed at cultivating positive feelings and behaviors in patients, in treating depression and enhancing well-being, concluding that PPIs are effective in doing so).

383 See generally Jonathan Shedler, The Efficacy of Psychodynamic Psychotherapy, 65(2) AM. PSYCHOLOGIST 98 (2010) (examining the effectiveness of psychodynamic psychotherapy, finding that its positive effects have continued to last even after treatment ends).

384 See Gerhard Andersson \& Pim Cuijpers, Internet-Based and Other Computerized Psychological Treatments for Adult Depression: A Meta-Analysis, 38 Cognitive BeHaviour THERAPY 196, 197 (2009) (examining the effectiveness of internet-based therapy as compared to face-to-face therapy for individuals with depression). See also Vikram Patel, et al., Effectiveness of an Intervention Led by Lay Health Counsellors for Depressive and Anxiety Disorders in Primary Care in Goa, India (MANAS): A Cluster Randomised Controlled Trial, 376 LANCET 2086, 2087-91 (2010) (examining the effectiveness of non-medical counseling being introduced into primary care treatment of patients with anxiety and depression). 
"encouraging people to have time out, to engage, to have sports events, dancing, singing" helps to ensure that people embrace well-being concerns, including such activities not only at work, but also "extending it to their personal lives." ${ }^{385}$

An advocate working in the Americas explained that in her organization, a "monthly space" is set aside for advocates to get to know each other well; this was seen as a corrective, since "capitalism seeks to leave the personal outside for efficiency." ${ }^{386}$ An international advocate also pointed to informal means of support, explaining the value of:

Talking to friends/colleagues who understand your workyou don't need to pay a counselor U.S. $\$ 100$ an hour! When you talk to a friend, that's really helpful. This is happening a lot on the ground. I talk to my friends in different organizations in different countries. Every organizational workplace - even [the] private [sector] ha[s] their own issues. Talk in private and laugh, and feel better about this. Informal ways of supporting one another do exist in the human rights movement. There is resiliency within the movement, and there is solidarity ... Your social group is your counselor! ${ }^{387}$

An advocate working in the Americas said that his organization encourages staff to "have more of a social life and to do things outside of work." 388 This is most effective when the organization's leadership leads the way. ${ }^{389}$ An advocate from MENA concurred, saying that "social life helps a lot," and that even in the worst human rights situations, socializing can provide a "release." 390 Similarly, a South Asia-based advocate explained that human rights advocates turn to each other for support: "You might say, 'this has taken a toll on me, I am disturbed.' Your friend might be able to offer you that emotional support and be understanding even during work." ${ }^{391}$ One expert noted that while human rights advocates "used

\footnotetext{
${ }^{385}$ Interview with Tabitha Netuwa, supra note 40. See also Interview with Simran Sachdev, supra note 138 (discussing how social events among peers created bonds and aided mental health generally); Interview with Marty Huber, supra note 84 (describing their weekly social events as a "way of coming together in a joy that is hard to describe" and noting the importance of humor for the teams' well-being).

${ }^{386}$ Interview with Ana María Hernández Cárdenas, supra note 52; Interview with Miriam Zoila Pérez, supra note 227 (faulting capitalism for the stress of making advocates feel replicable).

${ }^{387}$ Interview with Expert (14 Int'1), supra note 138.

${ }^{388}$ Interview with Luis Fondebrider, supra note 169.

${ }^{389} \mathrm{Id}$.

${ }^{390}$ Interview with Radhya Al-Mutawakel, supra note 77.

${ }^{391}$ Interview with Muna Baig, supra note 65.
} 
to derive strength in the human rights field . . by creating tight-knit groups and communities," this was harder to do when advocates work at a distance, investigating abuses from afar via social media and other open-source material. ${ }^{392}$

While many advocates reported socializing and informal peer support, few reported that their NGOs had any formal peer-to-peer programming. ${ }^{393}$ One group reported facilitating the development of peer support groups among their NGO's community members - the members met monthly to discuss their experiences, an activity which was described as "very emotional and effective and practical." ${ }^{394}$ An advocate working in Africa said that his organization has "open gate discussions" in which staff tell each other about "complex situations" that involve sensitive issues and "tough moments" with clients. ${ }^{395}$ In these discussions, staff "counsel each other, help each other, support each other here and there," but despite these efforts, "some staff are still heart-broken." 396 Some groups also discussed creating "sister circles"- - periodic meetings that aim to "share and deepen issues related to the political and personal life of those within the circles." 397 One organization reported recently fostering peer-to-peer support, in which six students took an active listening workshop and then held office hours for other students to drop in and talk about their experiences one-on-one. ${ }^{398}$ The organization also created a "buddy system" so people working on very difficult issues could work on them together. ${ }^{399}$ Another organization had programming to help people connect to others in different states or regions, facilitating their meetings to discuss wellness issues. ${ }^{400}$

Some advocates discussed the importance of building relationships with more experienced advocates and mentors. ${ }^{401}$ One advocate explained:

\footnotetext{
${ }^{392}$ Interview with Alexa Koenig, supra note 36.

${ }^{393}$ Interview with Ditipriya Ghosh \& Pauline Gomes, supra note 79 (discussing peer support that occurs during staff meetings where mental health issues may be discussed).

${ }^{394}$ Interview with Ram Kumar Bhandari, supra note 35.

${ }^{395}$ Interview with Yona Wanjala, supra note 42.

${ }^{396}$ Id.

${ }^{397}$ Interview with Guacira Cesar de Oliveira, supra note 65. See also Interview with Millicent Auma Otieno, supra note 47; Interview with Arianna Schindle, supra note 69 (noting that the Black Women's Blueprint in the United States have some practices around sister circles - women or feminist identified, including non-binary, individuals "sit together to share and discuss feelings." In addition, "they use a peer based or circle model to reflect on historical trauma and resilience.").

${ }^{398}$ Interview with Andrea Lampros, supra note 36 (also noting that so far, this seems to have been under-utilized).

${ }^{399}$ Interview with Expert (3 Eur.), supra note 114; Interview with Alexa Koenig, supra note 36.

${ }^{400}$ Interview with Gabrielle Jackson, supra note 70.

${ }^{401}$ Interview with Expert (14 Int'l), supra note 138.
} 
"Some of our co-founders are still alive - they have seen and experienced a lot in their careers, and are well known across the region. They can be a great resource - having a conversation with them can be a great help." ${ }^{402}$

Several managers talked about the support that members of their boards provided to staff. One advocate described having "board members who are really actively engaged, in the organization and who really come in when needed, who themselves are veterans in this field and are really empathetic for these issues. They're supportive of me."403

\section{H. MAKING MEANING, AND RECOGNIZING ACHIEVEMENTS AND SUCCESSES}

Some advocates discussed the importance of discussing or highlighting impacts and achievements among staff. ${ }^{404}$ The director of an organization operating in a country experiencing armed conflict explained:

We try to remind [the staff] of the successful stories, the difference we could make in some cases - also being recognized from many international NGOs gives them some support. They might be affected by different armed groups, but they know internationally that people will follow [our] work and this gave them a lot of support. Sometimes it is difficult to explain this to our field researchers. It is easy to talk to people in the center. Field researchers we meet maybe twice in a year-so it is not easy to bring them all to [the capital]. Sometimes we do visits from the center to the field just to support them, and to observe the work, and give them some support. ${ }^{405}$

An advocate working in the Americas further explained why acknowledgement is valuable:

One of the times that I have seen people struggle is when their work is buried and there are certain rock-stars who take credit for the gains that are made in the space. And I think figuring out how to credit everyone from the survivor

\footnotetext{
402 Interview with Muna Baig, supra note 65.

${ }^{403}$ Interview with Advocate (58 U.K.), supra note 74. See also Interview with Gasser AbdelRazek, supra note 80 (describing the "board of super stars involved with the staff"); Interview with Bernard Otieno, Advocate of the High Court of Tanzania \& Executive Director of Himiza Social Justice (Feb. 22, 2018) (explaining that staff have access to board members, one of whom is a professional counselor); Interview with Advocate (7 Int'l), supra note 35 (describing a caring and supportive board which supports the work of senior staff).

${ }^{404}$ Interview with Matthew Smith \& Amy Smith, supra note 108.

${ }^{405}$ Interview with Radhya Al-Mutawakel, supra note 77.
} 
themselves to the frontline worker, and to acknowledge- - I guess that's where I would reframe it - I think it's not credit, but it's being able to articulate the meaning of what they're doing. I think that . . . people feel like they're working their tails off-sacrificing from their personal lives and their professional lives - to try and make a positive impact in the human rights space, but they don't see the impact of their work or they're not cognizant of whether they are having an impact. So one of the things that we've been trying to think about is: how do we instill that sense of meaning and purpose and accomplishment to the people who are giving so much of themselves? So they're finding some personal reward and some personal strength from what's going on. ${ }^{406}$

To acknowledge achievements and "give encouragement and support to the team," one organization used an electronic application that allowed managers to give staff virtual "rewards" for achievements, which culminated in celebration dinners. ${ }^{407}$ Another organization made time during retreats to talk directly about achievements and impact. ${ }^{408}$

A very deliberate approach to acknowledging the work of students was developed by a human rights organization in which many students worked:

Another thing is to acknowledge them in their work. And this is something we've learnt from the research to build resiliency, so students know their work is having an impact. They can see that it ended up in a report to [a well-known $\mathrm{NGO}$ ] or it ended up contributing to a case, or in some way had an effect. So they're not doing this very difficult work without a payoff for them. Even if not acknowledging them as individuals - but acknowledging the team as a group. We're trying to do that a lot to make sure students know their work has meaning. ${ }^{409}$

\footnotetext{
${ }^{406}$ Interview with Alexa Koenig, supra note 36.

${ }^{407}$ Interview with Matthew Smith \& Amy Smith, supra note 108.

${ }^{408} I d$. ("[T] relax and discuss challenges but also impacts and achievements.").

${ }^{409}$ Interview with Andrea Lampros, supra note 36. See also Interview with Alice de Marchi Pereira de Souza, supra note 96.
} 


\section{SHIFTING TOPIC OR TYPE OF WORK}

Advocates told us that shifting the topic or type of work, including taking a break from direct work with witnesses and survivors, can be effective in preventing or responding to burnout or secondary trauma.

An advocate based in the Americas who supervises student investigators trained to analyze sometimes traumatic online material explained that advocates are often drawn to specific countries or focus areas because the work is close to their own experience. ${ }^{410}$ This can be empowering, the advocate explained, but it can also become difficult:

For some members of the team who were U.S. citizens, dealing with stuff this close to home was the most rewarding and strengthening and empowering. For others, it was so personal and so close, they found from a psychosocial perspective, they over-identified . . . they identified so strongly with the people who were experiencing hate crimes and hate speech, which was the nature of the project, that they were really struggling to get through the material. ${ }^{411}$

This kind of experience prompted the creation of a "no questions-asked policy: you can change projects at any time" without needing to provide an explanation. ${ }^{412}$ While this level of flexibility may be hard to achieve in many settings, a number of organizations did stress the importance of finding ways for their staff to change emphasis or focus in light of the emotional toll of some work. ${ }^{413}$ Previous psychological research studies have highlighted the potential benefit of a rotation of duties, which can create an opportunity to have an employee's normal patterns of psychophysiological arousal to return. ${ }^{414}$

One advocate, based in Africa, said that her organization has adopted a system that ensures staff "work rotationally in different areas" in an attempt to "reduce pressure." 415 Another advocate described how staff "in

\footnotetext{
${ }^{410}$ Interview with Alexa Koenig, supra note 36.

${ }^{411} I d$.

${ }^{412} I d$.

${ }^{413}$ Interview with Wadih Al-Asmar, supra note 65 (discussing efforts to reduce workload and limit contact with beneficiaries in case of burnout); Interview with Verónica Cruz Sánchez, supra note 84 (emphasizing the value of allowing for flexibility in what people are working on); Interview with Andrea Lampros, supra note 36 (describing a no questions asked policy permitting volunteers to change the project they're working on).

${ }^{414}$ Amy B. Adler et al., The Impact of Deployment Length and Experience on the Well-being of Male and Female Soldiers, 10 J. OCCUPATIONAL HeALTH PSYCHOL. 121 (2005).

${ }^{415}$ Interview with Millicent Auma Otieno, supra note 47.
} 
cases where they feel it is really draining them mentally were given the choice not to pursue [a case]. They can hand it over to management and we can make a determination on whether we can make referrals." ${ }^{416}$ An organization in which advocates had very stressful fieldwork sought to reduce impact by rotating work responsibilities between time in the office and time in the field. ${ }^{417}$ An advocate working for the rights of intersex persons underscored the importance of stepping back, and described how her organization had come to also realize the importance of "having strong allies and non-intersex people on staff, because we can't be expected to take it all on personally." 418

One advocate stressed the importance of each advocate learning how they are impacted by different kinds of work, so that they can be aware of what to avoid or when to shift work or take a step back:

I think on [the] awareness side, what we've tried to instill in the team is what's going to impact you is different from what impacts other people. So for some people it's seeing children killed. For others it may be beheadings. You don't know until you're in the material. So even in terms of the division of labor - to make sure you're not exposed to the stuff that's particularly challenging [for you] but for someone else who it doesn't affect as much can take that on ... But also making sure that you're aware that what affects you may change not only between people but within yourself from day to day, depending on what your context is and what you're going through in your personal life. So there may be times when, in our own personal lives, when we may be more vulnerable and really don't have the resources and reserves to deal with the trauma and that might be a point of time when it's good to take a break. ${ }^{419}$

The need for a reprieve can come into direct conflict with the pressing nature of human rights work. To address this challenge, an advocate working in MENA explained that when the well-being of a staff member is suffering, the supervisor will:

Try to force the person to step back a little. I reduce their workload and try to isolate them from direct contact with

\footnotetext{
416 Interview with Janet Munywoki, supra note 331. See also Interview with Verónica Cruz Sánchez, supra note 84 (describing how staff were given flexibility on what they wanted to work on).

${ }^{417}$ Interview with Millicent Auma Otieno, supra note 47.

${ }^{418}$ Interview with Kimberly Zieselman, supra note 172.

${ }^{419}$ Interview with Alexa Koenig, supra note 36.
} 
beneficiaries. When you are working on a paper or research it is easier to manage. When you are working with humans who you want to help but you can't, it is more demanding. You have so many pressures on your time. There is conflict between what you want to do and what you can do. ${ }^{420}$

\section{J. TRAUMA-AWARE WORKFLOWS}

Some of the most potentially traumatic elements of human rights work-such as the need to spend long periods of time sifting through graphic images and video from social media feeds - may be mitigated if managed carefully during the period of exposure. As an advocate based in the Americas who is a specialist in open source investigations explained, following guidelines concerning workflow can reduce the possible impacts of this work. ${ }^{421}$ These guidelines include not processing graphic material at night or alone, breaking up exposure into discrete time periods, turning off the sound of traumatic videos, blocking out parts of a graphic image, minimizing the size of a graphic image, and ensuring that the advocate is prepared to review the material. ${ }^{422}$

Developing, disseminating, and following guidelines like these can be especially helpful for new human rights advocates. As this expert explained, it is important to know how to create a "psychosocial resiliency plan" so that advocates can "be aware of who they are as researchers and also individuals and what kind of work they find fulfilling as opposed to draining" or traumatizing. ${ }^{423}$

\section{K. BREAKS AND LEAVE}

Many advocates discussed the importance of breaks, and numerous organizations have various formal or informal break and leave practices and policies focused on enhancing well-being. ${ }^{424}$ Some advocates discussed

\footnotetext{
${ }^{420}$ Interview with Wadih Al-Asmar, supra note 65.

${ }^{421}$ Interview with Alexa Koenig, supra note 36.

422 SAm DubBerley \& Michele Grant, Journalism AND Vicarious Trauma A Guide For JOURNALISTS, EDITORS AND NEWS ORGANISATIONS (2017), https://firstdraftnews.org/wpcontent/uploads/2017/04/vicarioustrauma.pdf. See also Dubberley, Satterthwaite, Knuckey, \& Brown, supra note 238.

${ }^{423}$ Interview with Alexa Koenig, supra note 36.

${ }^{424}$ Interview with Muna Baig, supra note 65 (discussing the importance of leave, but also noting the employees reluctance to take leave); Interview with Pramada Menon, supra note 73 (noting widespread practices of leave among NGOs); Interview with Ajeng Larasati, supra note 35; Interview with Isha Khandeklwal, supra note 44 (allows for sabbaticals); Interview with Janet Munywoki, supra note 331 (offers medical sick leave); Interview with Millicent Auma Otieno,
} 
providing or enabling short breaks during the day or after work, to create space for downtime, socializing, bonding, or community building. ${ }^{425}$ One organization rings a bell at 12:00 P.M. each day for staff to gather together for a 30-minute break outside. ${ }^{426}$ An advocate from the organization explained: "We have been trying it for a year as a measure to prevent the isolation of a large organization - to build solidarity." 427

Some organizations regularly provide longer vacation time at some point during the year. ${ }^{428}$ In addition to regular vacation time, organizations also have various forms of personal or health leave ${ }^{429}$ Some organizations enable longer breaks through sabbatical systems, ${ }^{430}$ extended vacations,${ }^{431}$ or a special medical leave. ${ }^{432}$ Other organizations provide time off in lieu of overtime pay. ${ }^{433}$

Some interviewees noted that it could be difficult to ensure that staff take their breaks. One advocate working in Asia stated:

People don't take leave, even though we try to force them to. People start working virtually; they won't take calls, but they will respond via email to the people calling or seeking.

supra note 47; Interview with Lisa Chamberlain, supra note 54; Interview with Alice de Marchi Pereira de Souza, supra note 96 (describing informal leave policies, like taking a day off on your birthday); Interview with Jean La Rose, Executive Director, Amerindian People Association (June $18,2018)$ (describing paid leave and comp time); Interview with Advocate (55 Int'l), supra note 74; Interview with Advocate (58 U.K.), supra note 74 (describing flexi time); Interview with Phil Lynch, supra note 145; Interview with Kimberly Zieselman, supra note 172 (explaining that employees are given long periods of time off if needed); Interview with Maria LaHood, supra note 96; Interview with Ana María Hernández Cárdenas, supra note 52.

${ }^{425}$ Interview with Matthew Smith \& Amy Smith, supra note 108; Interview with Ajeng Larasati, supra note 35 (explaining that the organization hosted movie or karaoke nights for staff occasionally); Interview with Andrea Lampros, supra note 36 (describing organization's social hours to build community and provide space for relaxation).

${ }^{426}$ Interview with Ana María Hernández Cárdenas, supra note 52.

${ }^{427}$ Id.

428 Interview with Sondos Shabayek, supra note 186 (describing how, every few months, her organization blocks off at least one week so that all staff take leave together).

${ }^{429}$ Interview with Advocate (13 Austl.), supra note 53 (describing personal leave that staff can use for health reasons); Interview with Foromo Frederic Loua, supra note 80 (explaining that advocates can take rest with paid leave for a few days if they are affected).

${ }^{430}$ Interview with Ditipriya Ghosh \& Pauline Gomes, supra note 79 (describing one month leave, which staff have taken for mental health reasons).

${ }^{431}$ Interview with Advocate ( 3 Isr.), supra note 35 (affirming that some advocates could have a one month vacation every few years).

${ }^{432}$ Interview with Advocate (9 S. Korea), supra note 103 (explaining that leave of 1-3 months, started at the organization because people "were at a breaking point." The organization noted that while rest wasn't "ultimately the solution" it does help and "it's the only type of thing that we can think of that can help.").

${ }^{433}$ Interview with Advocate (13 Austl.), supra note 53; Interview with Lisa Chamberlain, supra note 54 . 
Callers have expectations from us; we have our personal expectations as well. ${ }^{434}$

As a result, some advocates discussed the importance of systematic or forced breaks, rather than more ad hoc, informal, or entirely voluntary models. ${ }^{435}$ To ensure that staff actually do take breaks, some organizations utilize mandatory, paid, organization-wide extended breaks ("shut down periods") during the year. One organization in MENA reported closing for two weeks twice a year: "We do this on purpose to give an opportunity for staff to decompress." 436 The management of that organization consciously made leave mandatory to ensure that everyone took it, out of concern that staff would otherwise continue to work. ${ }^{437}$ Another organization in the Americas sought to make breaks easier to take by introducing a "no questions asked break." 438 Some organizations encourage breaks by arranging holidays for staff to take together. ${ }^{439}$ Others stopped allowing staff to continuously roll over their vacation days, as a way of encouraging the use of allotted time-off. ${ }^{440}$ One organization, concerned about staff being online 24 hours per day, seven days per week, began to provide a second, work-only phone to staff so that they could more easily switch off from work when taking leave. ${ }^{441}$

Advocates noted that if organizations arrange staff retreats, it is important to actually include time off for staff and to not work through the entire "retreat." 442 One organization was planning to build an extra day into

\footnotetext{
${ }^{434}$ Interview with Jannat Fazal, supra note 65. See also Interview with Ajeng Larasati, supra note 35 ("We are introducing a policy to encourage people to take leave. You can take paid leave if you need rest, but many people are so dedicated to the work that they do not want to take a break."). 435 Interview with Experts (11 Eur.), supra note 193 (discussing the benefits of "systemically stopping work, forcing work to stop.").

${ }^{436}$ Interview with Wadih Al-Asmar, supra note 65.

${ }^{437}$ Id.

${ }^{438}$ Interview with Alexa Koenig, supra note 36 ("You can take a break from this material at any time.").

${ }^{439}$ Interview with Ajeng Larasati, supra note 35 (explaining that, at the beginning of the year, the organization takes staff to a place they might otherwise not be able to afford, like a beach holiday). See also Interview with Luis Fondebrider, supra note 169 (reporting seeing other organizations in the region offering a paid vacation to the beach once per year).

${ }^{440}$ Interview with Kimberly Zieselman, supra note 171 (" $[\mathrm{N}]$ o longer will we allow people to roll over... vacation time ... we're only allowing people to roll over 5 days. It's encouraging people to use it.").

${ }^{441}$ Interview with Wadih Al-Asmar, supra note 65.

442 Interview with Pramada Menon, supra note 73 ("There has to be a system where retreats are meant for people to come and play.").
} 
staff-wide trainings, dedicating the day to relaxation. ${ }^{443}$ Another organization which has already implemented a similar practice referred to it as the "getting nothing done day." 444

Encouragement of breaks by colleagues and managers is valued by advocates. One advocate noted how colleagues showed support by encouraging each other to take breaks from work. ${ }^{445}$ In another organization, the human resources team has a system of monitoring whether staff are taking leave and contacts staff if they are not. ${ }^{446}$ Others noted the importance of managers suggesting or checking in about staff taking their breaks, particularly where the manager observed a need, or after a difficult event or work period. ${ }^{447}$ One advocate explained why suggestions for even short breaks can be beneficial:

The manager can say, "I see that you have been working so hard on that report on Syria - why don't you just leave early on Friday." This gets people out of the cycle — brings them up from down in the rabbit hole of looking at videos or looking at photos and gets you out into the world. ${ }^{448}$

\section{REMOTE WORKING AND FLEXIBLE HOURS}

Some advocates discussed how their organizations enable remote working or flexible hours, which aids staff in managing their workloads and personal responsibilities and also facilitates working in varied or less-

\footnotetext{
${ }^{443}$ Interview with Sharon Cox, supra note 96 (“'[O]ne of our funders-suggested . . . add[ing] another day to a regional training that could be a mental health day when the attendees could simply lie around for a day ...").

444 Interview with Meerim Ilyas, Senior Program Officer, Urgent Action Fund (June 15, 2018) (explaining how the "getting nothing done day" is "not a retreat, it's [about] doing something luxurious-a nice dinner and museum, a hike, visiting a winery or a chocolate tour. Anything that prevent[s] us from talking about work, and [enables staff to] spend . . time together.").

445 Interview with Sehyek Oh, supra note 112 ("If I feel depressed and under the weather [my colleagues] . . . say, 'Please go and take a break.' I really appreciate it."); Interview with Marty Huber, supra note 84 ("We also try to be very sensible when people are overworked and go through some tough incidents, and ensure that they just take time off.").

${ }^{446}$ Interview with Ditipriya Ghosh \& Pauline Gomes, supra note 79.

${ }^{447}$ Interview with Jannat Fazal, supra note 65 ("If we see someone needs a break we ask them to take a break or half day leave.”); Interview with Ditipriya Ghosh \& Pauline Gomes, supra note 79 (explaining that if supervisors or human resources notice that someone might need some time off, a few days will be suggested). See also Interview with Nancy Tapias Torrado, supra note 165 (describing the option of taking time off after research visits); Interview with Expert (27 Americas), supra note 124 (describing encouragement of breaks after difficult work).

448 Interview with Expert (3 Eur.), supra note 114.
} 
stressful environments. ${ }^{449}$ One advocate discussed the benefits of working away from the office, especially when doing difficult writing:

[W]hen we are doing a report or a proposal, the management or program staff sit together and write together. This shares the load, and builds solidarity-but we have always done this in the office. Soon, we will go away from the office - and go for say, two days - to write the report. ${ }^{450}$

\section{OfFERING INDIVIDUAL Well-BeIng Practices}

A number of advocates said that their organizations facilitate wellbeing practices, including by offering them in the workplace. An international feminist organization has included "yoga, mindfulness exercises, nature walks, and stress-reducing games" at meetings with the aim of providing models for staff to take back to their regional offices. ${ }^{451}$ An advocate based in the Americas explained that her organization has created a "network of allies" who provide well-being support to staff: "We have psychologists and a yoga instructor who give us support. Yoga once per week. Professional psychologists depending on the need. And, finally, we have a massage technician who donates her services to us." ${ }^{452}$

Similarly, advocates based in Brazil said that their organization also provides therapeutic massage to staff. ${ }^{453}$ An advocate in MENA said that some human rights organizations in his region offer yoga, "coaching," and other healthy activities for their staff. ${ }^{454}$ Advocates from Asia and Latin America also said that they and peer NGOs offer yoga to staff (and sometimes staff of associated organizations) on-site. ${ }^{455}$ An organization

\footnotetext{
${ }^{449}$ Interview with Verónica Cruz Sánchez, supra note 84 (describing flexibility in work hours); Interview with Lisa Chamberlain, supra note 54 (explaining that the organization allowed for flexi-time); Interview with Gasser Abdel-Razek, supra note 80 (noting that the office was open from 9:00 A.M. to 9:00 P.M., and that staff could chose to come in any of those hours, or work remotely); Interview with Phil Lynch, supra note 145 (noting lots of flexibility in when and where staff worked from); Interview with Expert (35 MENA), supra note 104 (describing flexible working hours and highlighting their importance); Interview with Mikhail Golichenko, supra note 143 (noting the importance of flexibility in working conditions).

${ }^{450}$ Interview with Sharon Cox, supra note 96.

${ }^{451}$ Interview with Advocate (7 Int'l), supra note 35.

452 Interview with Verónica Cruz Sánchez, supra note 84.

${ }^{453}$ Interview with Renata Trajano, Raúll Santiago, \& Priscila Neri, supra note 43.

454 Interview with Wadih Al-Asmar, supra note 53. See also Interview with Maria Cappello \& Valeria Moscoso, supra note 46 (explaining that the organization offers financial support for reiki and yoga classes).

455 Interview with Tessa de Ryck, supra note 96; Interview with Luis Fondebrider, supra note 169.
} 
based in MENA described how a group of volunteers called "Involved Activism" meets weekly "for meditation and [to] talk about how the activism affects them and what was hard for them." ${ }^{456}$ Other organizations reported recommending meditation to their staff but not offering on-site instruction or space for the practice. ${ }^{457}$

A number of organizations offer physical fitness benefits to staff. One advocate working in Asia explained that:

We have also implemented a fitness benefit because we recognize that mental health has a physical component. Our staff can do yoga, rock climbing or whatever fitness activity they like. Because our work is $24 / 7$ we understand the importance of having those resources to help staff prioritize physical fitness. ${ }^{458}$

Similarly, an advocate working in Africa said:

We've also developed a relationship with the university gym. We pay for memberships if staff want to join. What's happened is that some people joined up, started talking about the great classes, then other people signed up and it spread ... [This also enables] a soft accountability in check-in form. For example, we might ask each other "how is your class going?"459

\section{N. ARt, Spiritual, ANd Religiously Rooted Healing Practices}

A number of participants identified artistic, spiritual, or religiously rooted practices that aimed at individual or collective care and healing. An activist from Brazil emphasized that no matter what practices are adopted, well-being tools need to be designed to be appropriate "within the geographic and cultural realities" of given communities. ${ }^{460}$

An expert based in the Americas explained that indigenous advocacy organizations have established "integrated restorative healing practices," group experiences to deal with stress and trauma that are culturally and spiritually rooted. ${ }^{461}$ Some organizations have identified artists and others

\footnotetext{
${ }^{456}$ Interview with Advocate (3 Isr.), supra note 35.

${ }^{457}$ See Interview with Advocate (23 Cambodia), supra note 46 (describing how trainers motivate activists to take time to relax, exercise regularly and meditate).

${ }^{458}$ Interview with Matthew Smith \& Amy Smith, supra note 108.

${ }^{459}$ Interview with Lisa Chamberlain, supra note 54.

${ }^{460}$ Interview with Renata Trajano, Raúll Santiago, \& Priscila Neri, supra note 43.

${ }^{461}$ Interview with Arianna Schindle, supra note 69.
} 
who can collaborate with advocates to use dance, art, and poetry as healing practices. $^{462}$

Advocates also expressed the importance of religious practices to enhancing well-being. An advocate based in France said that some staff in her organization go to places of worship or engage in spiritual practices which "gives them a sense of nourishment and peace." ${ }^{463}$ Religious and spiritual practices observed by advocates included talking to religious leaders ${ }^{464}$ prayer, ${ }^{465}$ and commencing meetings with silence to create a safe space for people to share. ${ }^{466}$

While often a valuable source of strength, some advocates noted that the ability to engage in religious practices can be impeded by the fact that religion is frequently also a source of persecution, thus making it, in some contexts, "a complicated minefield that you're never to going to talk about." 467

\section{CONCLUSION}

Across the human rights field, conversations about well-being and mental health are increasingly taking place. Among some organizations and within certain parts of the movement, these discussions have long been rigorous and developed, borne of extreme pressure coupled with openings created by the vital energy of feminists, advocates fighting racism and ableism, and LGBTQI organizers. For many organizations and advocates, serious discussions about advocates' well-being are relatively new or are in a period of renewal or particularly intense attention, and advocates, managers, and leaders seek language, concepts, and tools tailored to fit the needs of human rights advocates. The study that is the subject of this Article

\footnotetext{
${ }^{462} \mathrm{Id}$.

${ }^{463}$ Interview with Advocate (60 Fr.), supra note 287.

${ }^{464}$ Interview with Gabrielle Jackson, supra note 70 ("Sometimes people go talk to their religious leaders, and this is part of how people cope."); Interview with Guus van Zwoll, supra note 65 ("Sometimes we support human rights defenders or host organizations in finding someone who has some religious authority to talk and provide support.").

${ }^{465}$ Interview with Tessa de Ryck, supra note 96. See also Interview with Gemma Houldey, supra note 62 (describing having heard "a lot of references to - if you're feeling low you need to pray more . . Religion is a source of comfort, that helps them transcend" adversity); Interview with Simon Ndaula, supra note 106 (noting that some people pray as a means of coping); Interview with Expert (14 Int'l), supra note 138 (noting that one organizational survey found that activists find comfort in religion and that "going to church or a temple to pray" is useful for them).

${ }^{466}$ Interview with Tessa de Ryck, supra note 96 ("So a common practice for Quakers is that they start their meetings with silence, and during this time, they open the floor for anyone who wants to share anything ... creating a safe space for people to share something, preferably not work related.").

${ }^{467}$ Interview with Pramada Menon, supra note 73.
} 
set out to collect information about how human rights advocates perceive well-being issues at the organizational level, their views of challenges to addressing mental health concerns, and their assessments of the extent to which organizations are - or are not-working effectively to advance the well-being and resilience of human rights advocates.

The study also documented key aspects of human rights advocacy and of the human rights field that present significant well-being challenges. Some of these sources of harm and stress - such as exposure to the suffering caused by human rights violations - are built into the very subject matter of the work. For this reason, measures to handle such inherent stressors are mostly aimed at mitigation, reduction of exposure when needed, healing practices, and individual, organizational, and human rights culture reforms to better support advocates as they face injustice and abuse. Other factors causing stress and harm in the human rights field are pervasive and deeply rooted but need not be inherent to human rights practice: the stress and trauma of discrimination and bias within the field itself, extreme overwork, the commodification of human rights advocacy into measurable "outputs," precarious and poor working conditions for many advocates, the stress of poor management, alienating workplace cultures, beliefs about the ineffectiveness or inadequacy of social justice work, and funder pressures and the structure of philanthropy. These causes of harm should be acknowledged and owned; responses should be designed and implemented; and structural changes should be pursued through organizational and collective field-wide efforts.

In order to implement changes to improve well-being, the obstacles that advocates identified as standing between good intentions and positive practices must be removed, reduced, or mitigated. Some of these obstacles are being tackled by human rights organizations: there is increasing attention on the need to seek funding for well-being initiatives, reduce crushing workloads, and provide some education and awareness-raising about well-being. But not enough is being done to change human rights cultures, which too often valorize martyr and savior mentalities and stigmatize well-being concerns. There is also too little attention to poor organizational management and dysfunctional leadership. Little energy has gone into training mental health professionals to work effectively with advocates, and there are too few well-being programs tailored to the needs of human rights advocates. Not enough effort has come from philanthropy, which has the capacity to underwrite organizational transformation, support managers and staff, and use new standards for success. Much more needs to be done to dismantle racism, sexism, ableism, and other forms of discrimination within organizations and movements.

This study documented a wide variety of strategies and practices adopted by human rights organizations seeking to enhance the well-being 
and resilience of advocates. Although many of the practices documented here have not been empirically tested, organizations' own assessments of their importance suggest that many have promise for broader use. Additional research is needed to carefully document, study, and evaluate the benefits of different measures in various settings. Collaborative sharing across organizations, and between movements facing similar challenges, should be supported. Knowledge and experience with health, personnel, and leave policies, human resource practices, training, and peer support programs, and partnerships with wellness and mental health providers could be shared among organizations and advocates through personnel exchanges, conferences, and collaborative leadership projects. Additional manuals, practical guides, and trainings on how to improve well-being would be beneficial. Funding is needed to support organizations that want to make structural changes - including far-reaching transformations aimed at providing advocates with decent conditions of work, safe workplaces, labor rights, family support, and ways to plan for lives of dignity into older age. More attention is needed to organizational resilience and vicarious resilience - the benefits that human rights advocates and organizations reap from working with individuals and communities that resist, persevere, and overcome injustice with dignity and strength. And spaces for respite and healing must be provided to those in greatest need. With concerted attention, human rights organizations can not only reduce harm, stress and trauma, they can advance resilience and protect the joys of purpose-driven work for social justice.

\section{APPENDIX}

\section{A. CASE Study 1: Paving a Feminist Path Toward Well-Being AND CARE: THE INICIATIVA MESOAMERICANA DE MuJERES DEFENSORAS DE DERECHOS HUMANOS (MESOAMERICAN INITIATIVE OF WOMEN HUMAN RIGHTS DEFENDERS) ${ }^{468}$}

The Iniciativa Mesoamericana de Mujeres Defensoras de Derechos Humanos (Mesoamerican Initiative of Women Human Rights Defenders) ("IMD") was established in 2010 as a response to the increasing structural and gender-based violence against women human rights defenders ("WHRD") in Mexico and Central America (El Salvador, Guatemala,

\footnotetext{
468 Interview with Ana María Hernández Cárdenas, Director of Oaxaca Consortium at Mexico, Coordinator of the Strategy of Self-Care, Collective Care \& Healing, Iniciativa Mesoamericana de Mujeres Defensoras de Derechos Humanos (Mesoamerican Initiative of Women Human Rights Defenders) (June 6, 2018); Interview with Ana María Hernández Cárdenas, supra note 52.
} 
Honduras, and Nicaragua). In a short span of time, this collective-made up of human rights organizations and defenders - successfully brought attention to the issue of self-care, safety, and healing among WHRDs. Important steps have followed, including the appointment of a "Coordinator of the Strategy of Self-Care, Collective Care and Healing"; a role occupied by Ana María Hernández Cárdenas, ${ }^{469}$ who was interviewed for this case study.

Working exclusively with WHRDs, IMD built a feminist perspective into the very fabric of its operations, beginning with the recognition that WHRDs are doubly attacked: they face gender-based violence, and they are targeted for their human rights work. IMD has developed holistic strategies of protection against violence, promoting both self and collective care and healing across the physical, emotional, mental, and spiritual dimensions.

Hernández Cárdenas explained the motivation that guided IMD toward these approaches:

After a few years of working in this field, I realized that it is not only the transformation of the world around me that matters. It is more than that-it is my personal transformation as well ... The struggle is not just what we dream for others, but also how we live our lives ... The powers that we face seek to undermine the action of our [human rights] movements. When we invest time, actions, funds, and energy to take care also of ourselves, we strengthen our action to face those powers. ${ }^{470}$

\section{Rising to the Challenge: Key Responses}

Recognizing that investment in self and collective care improves the overall well-being of defenders, as well as the effectiveness of their work, IMD has deployed a wide range of actions including the following:

- "Casa La Serena": A house and retreat center that serves women from the network of human rights organizations across the five countries in which IMD works. Retreats involve five defenders staying together for ten days. The

\footnotetext{
469 Ana María Hernández Cárdenas is a member of the management team and founder of Consortium for Parliamentary Dialogue and Equity Oaxaca, a feminist women's human rights organization in Mexico. She is also the general coordinator of Casa La Serena and is responsible for the self-care strategy, collective care and healing of the Iniciativa Mesoamericana de Mujeres Defensoras de Derechos Humanos.

${ }^{470}$ Interview with Ana María Hernández Cárdenas, supra note 52.
} 
retreat includes psychotherapy, medical services, nutritional care, creativity-enhancing activities, and time for reflection and re-orientation toward healthy activism. Activists leave the retreat with an individualized six-month support care plan. Self-care groups are also set up in the five countries to monitor the effective implementation of the activists' plans.

- Dedicated funding for care initiatives: IMD financially supports campaigns that seek to promote self and collective care among WHRDs.

- Education, training, and resource development: IMD invests in healthy activism through workshops and meetings that disseminate IMD's learnings and action plans to protect WHRDs from violence. It also interacts with its peers and counterparts in other countries, sharing knowledge, and publishing its findings in the form of testimonial and collective and self-care books. These books include inputs from human rights defenders from all continents.

- Specific budgetary allocation for "care": IMD recommends to human rights organizations that it works with to allocate $10 \%$ of all project budgets for the "collective and self-care" of defenders within those organizations. IMD also encourages those organizations to incorporate self-care into their funding proposals to potential donors. This is because IMD believes that selfcare is necessary to sustain the movement. As an example of an organization that has adopted this budgetary policy, Hernández Cárdenas cited Consorcio Oaxaca, a feminist organization that she manages as part of IMD.

- Investing in the well-being of defenders: IMD recommends a wide range of efforts that can yield positive results when implemented collectively by the various human rights organizations within the collective-such as upholding labor rights, employment benefits and holidays, celebrating different rituals and practices for individuals' well-being, spending resources toward nutritious food and clean drinking water, building solidarity within organizations, etc. These measures should be part of a self 
and collective care plan and healing process paid through the organization's expenses.

Looking ahead: What are key lessons learned from IMD?

- Recognizing the problem: The first battle is the recognition that mental health, well-being, and the collective and self-care of human rights defenders is key to making the larger human rights movement sustainable and effective.

- There is no one-size-fits-all model: Each case is an experience in itself, and different activists need different measures to strengthen their well-being and improve their mental health.

- Creating a culture of prevention and early attention: The prevalent culture is one of responsiveness, rather than prevention. There is a need to shift focus and incorporate responses to challenges of mental health into the realm of protection. Such precautionary measures should ideally be comprehensive and extend to the defenders' families as well so as to create a good environment for healing.

- The power of networks and collaboration: Collaborative efforts help to strengthen processes and make them more powerful. Increased engagement and dialogue can also go a long way in generating a practice of reflection/introspection and encouraging more NGOs to adopt sustainable practices for dealing with mental health.

- Enhanced dialogue, research, and advocacy: There is a greater need to engage with different stakeholders-donors, NGOs and civil society organizations working at the grassroots level, human rights defenders, and the larger community. Special care should be taken to sensitize men and build awareness about inter-sectional issues that affect WHRDs. These efforts will also help lay the groundwork for developing public policies that include elements of self and collective care and healing to improve protection mechanisms for human rights defenders. 
B. CASE STUdy 2: From CRISIS TO LEADERSHIP, CONVERSATIONS, AND FUNDING: THE EGYPTIAN INITIATIVE FOR PERSONAL RIGHTS ${ }^{471}$

Gassar Abdel-Razek, the Executive Director of the Egyptian Initiative for Personal Rights ("EIPR"), traced EIPR's current focus on advocate well-being to a mental health crisis that emerged following the 2011 Egyptian Revolution. EIPR is among Egypt's most prominent human rights organizations, and specializes in research, advocacy and litigation to advance civil liberties, criminal justice and economic and social rights.

During and after the Revolution, the Egyptian state cracked down on activists, and advocates witnessed horrific rights violations committed against fellow activists. But advocates often felt they had no right to feel emotionally impacted by harms committed against others and which they had personally escaped. Activists often felt "privileged" to have survived the revolution, and some had difficulty accepting payment for their work in fighting for justice, which they believe should be undertaken voluntarily. These activists tend to see the discomfort of human rights work as something that they should ignore and abide. The culture of guilt and deflection began to change when day-to-day life became so difficult for so many that it felt impossible to ignore the stress.

According to Abdel-Razek and EIPR researcher Yara Sallam, the barbarity of the Egyptian government's response to the January 25, 2011 revolution created space for dialogue about the well-being of human rights advocates. The daily exposure to violence became so unbearable that advocates were compelled to speak up. These well-being conversations started small and informal but, over time, the need to formalize a system of support became apparent. From a managerial perspective, conversations started because advocates' well-being concerns - which manifested as sleep deprivation, poor appetite and burnout-were too severe to be neglected. Managers at EIPR decided to seize the opportunity and organized group therapy sessions with staff, led by a psychologist familiar with the human rights field.

Since then, Abdel-Razek has taken the lead on further initiatives to advance staff well-being at EIPR. With regard to mental health, Sallam said that EIPR is the most progressive organization she has seen, and worked for, in Egypt. The organization now boasts a wide range of policies and

\footnotetext{
471 This case study is based on interviews with EIPR leadership and staff. See Interview with Gasser Abdel-Razak, supra note 80; Interview with Gasser Abdel-Razak, Executive Director, Egyptian Initiative for Personal Rights \& Yara Sallam, Regional \& International Human Rights Mechanisms Officer, Egyptian Initiative for Personal Rights (October 11, 2018).
} 
programs to support mental well-being, including policies against workplace discrimination and sexual harassment. For instance, flexible working hours and the option to work from home allow advocates to work and rest at their own pace. Competitive salaries and medical insurance give staff a sense of financial security and the comfort of feeling prepared for emergencies. Parental leave is provided so that advocates can commit time to their family and receive support from outside the workplace. After the initial three months of maternity leave, new mothers at EIPR can work a regular thirty-five hour week from home for the remainder of the year while enjoying a full salary and only attending the office for meetings. Paternity leave is offered as well, although it does not exist under Egyptian law. In addition, advocates have access to psychological support through up to six sessions of free therapy if desired. From 2019 onwards, anyone who has been working at EIPR for seven continuous years will be entitled to three months paid sabbatical leave.

When asked what lessons Sallam has learned from EIPR that she would pass on to other organizations, she emphasized that it is crucial not to look for ready-made answers. Instead, it is essential to respond to the people in front of you. For Sallam, this means asking what kind of support each employee needs and finding ways to meaningfully respond.

Abdel-Razek explained that as a leader, the most important thing is that his employees are valued as people and that management supports them when they are experiencing emotional difficulties. He dedicates a lot of time to building a sense of community within EIPR and to ensuring that the work environment is as positive as possible. Abdel-Razek acknowledged the risk of some staff members abusing the system, but believes it is a risk worth taking. EIPR organizes annual retreats where staff can relax together outside of work. And every week, each Thursday morning, staff gather in the office kitchen and cook breakfast together, with Abdel-Razek often playing the role of head chef. He explained that when employees realize that management values them like this, it changes the dynamics of the organization for the better. Abdel-Razek acknowledged that one could run an NGO like a corporation, focusing only on output, and perhaps be very successful. But, he said, this would be "ethically wrong." He believes that, as a leading human rights organization, EIPR has a duty to practice what they preach. He noted that donors always seem to want to invest more money into projects, but rarely people. As a large national NGO, and one of Egypt's best funded human rights groups, EIPR has more financial freedom to push prospective donors on these issues and to insist on core fundingas opposed to project-based funding - which allows them to spend more money on employee benefits and well-being programs. 


\section{Case Study 3: Fostering Holistic, Collaborative, And SUSTAINABLE WELL-BEING: WITNESS ${ }^{472}$}

WITNESS is a Brooklyn-based organization with a global staff network that supports human rights activists all over the world to use the power of video and technology to protect and defend human rights. WITNESS does this by collaborating closely with activists, particularly vulnerable and marginalized groups, and training them on how to use video and other technology safely, ethically, and effectively. Working alongside both local communities and technology giants, WITNESS fills critical gaps in the use of video and technology for human rights, ensuring that videos can be trusted and verified; that evidentiary videos can be found amidst mass volume; that activists can be safer and manage risks; that movements and groups can use visual storytelling in strategic and impactful ways; and that new and existing technologies can enable greater citizen participation, not stand in the way of it. The organization works on a broad spectrum of human rights abuses including state violence, environmental crimes and violations of freedom of expression.

Yvette Alberdingk-Thijm, Executive Director of WITNESS, acknowledged that staff and collaborators have suffered physical and mental health consequences related to their work. This is "partially because [they] are on a daily basis confronted with human rights crimes and human rights abuses and violations, both directly and vicariously, particularly though visual material." The impact of this visual material is compounded by increasing threats to the safety, dignity and security of individual activists in the team and with whom WITNESS works. At a broader, systemic level, WITNESS staff and collaborators are subject to pressures experienced by the organization and the human rights ecosystem as a whole, including physical and security threats as well as structural threats, internal threats concerning funding models, and systems' threats created by technology platforms. In her decade with the organization, AlberdingkThijm has never seen higher levels of burnout as she sees today. She attributes this to rapid changes in the human rights landscape, fuelled in part by the effects of media and digital media.

\section{Obstacles to Sustainable Practice Within the Human Rights Field}

Alberdingk-Thijm identified the narrative of human rights work as a core obstacle to the mental well-being of advocates. To illustrate, she cited

\footnotetext{
472 Interview with Yvette Alberdingk-Thijm, supra note 92.
} 
the Universal Declaration of Human Rights and explained that, while a phenomenal aspiration, this unachievable standard inevitably leads to feelings of failure among activists. She suggested that reframing the objective of activism to focus on how "we are all in this together doing our collective part, incrementally, to create a just world" could help to address the negative perceptions of self-efficacy within the movement.

Further, the roles attributed to different players in the human rights field are also described as a narrative problem. Alberdingk-Thijm said that the "old school model comprised of evil states, NGOs who will fix the world, and the 'poor people' who do not have a voice and need our help" sets advocates up for failure, leads to bad collaboration, and reinforces power imbalances. To combat this, she advocates for a more holistic view of the human rights ecosystem which recognizes a broad spectrum of people who are collaborating across enormous divides to fight for justice. Systemic human rights violations now involve a more diverse set of increasingly sophisticated bad actors, including corporations, governments, and individuals.

Another problem that Alberdingk-Thijm highlighted is the existing model of predominantly funder-driven human rights work, which does not necessarily prioritize mental health support. She explained that projects should not be funded unless there is an organizational structure in place to support the staff. This should encompass a broad view of sustainable philanthropic support, which includes mental health support, digital safety and security practices, comprehensive benefits including health insurance, and peer support mechanisms. She suggested that some funders formulate outcome expectations that undermine, instead of help, a healthy understanding of social impact. She emphasized that funders have an active responsibility to "do no harm" and this includes providing sufficient funding for programs to be executed sustainably. To do anything else, she said, would be irresponsible.

WITNESS Creates Space for Holistic, Collaborative, and Sustainable Human Rights Work

The impacts of traumatic videos on WITNESS' staff were recognized before Alberdingk-Thijm's time and, as a result, she said that the organization has long taken a holistic approach to mental well-being and sustainable practices. Because the organization works so collaboratively, its model facilitates a lot of listening and talking about dignity and respect. This, in turn, fosters an organizational ethos centered around creating space 
to collaborate for impact, instead of a "let me solve your problems" mentality.

So, What is WITNESS Doing to Improve the Mental Health of Its Employees?

Alberdingk-Thijm recognized that her organization and the spaces it collaborates in are not devoid of challenges to sustainable human rights practices. At the organizational level, the importance of culture and language is recognized. Alberdingk-Thijm actively promotes mental health dialogue by talking openly and regularly about these challenges when times are hard. Critically, the organization also fosters a culture that never victimizes or pathologizes mental health concerns. While recognizing that everyone comes with their own histories, "we start from the assumption that everyone is human so, by definition, this work will affect you." Accordingly, the organization constantly debunks the superhero myth and tries to avoid rewarding unsustainable work practices. To AlberdingkThijm, there are no tireless activists - all "people have to sleep."

At the leadership level, mental health and sustainability awareness is incorporated into supervisor training and staff evaluations; supervisors are asked whether they are raising these issues with staff and dealing with them appropriately. WITNESS creates spaces for open conversations for learning and sharing through weekly staff meetings, program meetings and a quarterly "share" meeting where staff discuss topics regarding stress and sustainability. In particular, one tool that Alberdingk-Thijm has found to be effective in helping staff feel connected is a secure group chat where staff share updates, as well as photos about their lives and offer each other support.

WITNESS has integrated awareness of capacity restraints on mental health and sustainability into work planning through the process of goal setting and defining impacts and successes. Although Alberdingk-Thijm admitted that this is an ongoing challenge to address, when creating work plans, staff consider workloads and the allocation of resources within the organization. On a more structural level, WITNESS tries to be accommodating in understanding what staff need to work effectively. Many staff work part-time, flexible hours, or remotely from wherever they feel comfortable and safe. For those working in isolated locations, WITNESS utilizes the support of its collaborative network and considers how to house staff with other groups.

Alberdingk-Thijm emphasized that mental health is affected by a much broader spectrum of factors that influence organizational health and 
sustainable work culture. Currently, the organization is reviewing remuneration packages to ensure staff are paid appropriately. Employees at WITNESS are given comprehensive benefits and leave entitlements including compensatory time in lieu of overtime pay and access to "reading days" to take a step back from the day-to-day. All employees are provided training on vicarious trauma, including interns and consultants. In recognition that safety and security threats are deeply connected to resilience, WITNESS updates its digital safety and security practices and regularly and shares these practices with its community partners.

While many of these measures, such as flex time and relocation policies, are recorded in written policies, WITNESS cares more about the "lived reality of the team." In other words, it values practice over policy. Having said this, Alberdingk-Thijm does see the value in documenting organizational policies to facilitate knowledge sharing within the movement and this is her goal for 2019 .

At the movement level, Alberdingk-Thijm engages her peer Executive Directors at other organizations on mental health issues. Presently she does this through panel discussions at conferences and, in the future, she hopes to establish a peer support community of human rights practitioners to share best practices for enhancing sustainable practice, well-being and resilience.

Despite the organization's many admirable initiatives, AlberdingkThijm reiterated that WITNESS is far from perfect and still has much room for improvement. But having a leadership that puts mental well-being on the agenda provides a solid foundation for progress. Alberdingk-Thijm warned against making mental well-being a "project" because it is not something you can simply hire a consultant to "fix." Rather, she recommended making sustainability an integral part of the organization's work: "it should be a thread in everything you do." When feeling overwhelmed by the workload, Alberdingk-Thijm's parting reminder is to "stop and breathe and plan" and always take the time to celebrate wins.

\section{Case Study 4: Balancing Well-Being Practice With Excessive WORKLOADS: FRIDA | THE YOUNG FEMINIST FUND ${ }^{473}$}

Through supporting young feminist organizers and creating new cultures of collective leadership, FRIDA | The Young Feminist Fund ("FRIDA") provides young women, girls, trans, and intersex activists the resources they need to amplify their impacts in their own communities. FRIDA comprises a group of young feminists working all over the world

${ }^{473}$ Interview with Ruby Johnson, Co-Executive Director, FRIDA (Oct. 10, 2018). 
from virtual offices. According to Ruby Johnson, FRIDA's Co-Executive Director, the organization quickly recognized the need to prioritize wellbeing because staff who are geographically isolated and separated from colleagues are prone to overworking and developing unhealthy work practices. To cope with the realities of burnout, FRIDA has adopted several measures that aim to cultivate an organizational culture where people celebrate holistic security, which includes self-care, collective-care, and digital and physical security.

Firstly, FRIDA strongly encourages informal personal interactions within its community. Well-being check-ins are put on the agenda for staff meetings and staff are encouraged to share things about their lives including photos, GIFs and songs. This encourages advocates to be creative in expressing how they feel, what they are experiencing, and how this relates to their work. In addition, FRIDA has a channel of communication where staff share resources on well-being and mental health.

Secondly, FRIDA created a "happiness manifestx" affirmation of the things staff need to be happy, to support each other, and to be well in their work. While a work in progress, this documents individual commitments such as not working too many hours, taking email off phones when on holiday, eating well, and taking breaks. But it also includes collective and organizational commitments such as "how we work as a team and how we make a safe space in the organization to talk about when you're not okay." It evolved from a workshop where staff began writing down commitments on post-its, sticking them onto the wall and then having staff sign the wall. This creative process led to a "collective document" that is not "static" but "really alive" and constantly evolving to reflect the needs of FRIDA's staff. According to Johnson, it goes beyond a mere recording of policies and serves as FRIDA's documented commitment to well-being. It has also been converted into a "beautiful illustrated version" which is available online. ${ }^{475}$

In 2018, FRIDA established a "communities and culture" team to foster an environment where staff think actively about mental health and well-being, as well as supporting the connections of a strong community. The two staff on this team, along with FRIDA's leadership, are responsible for co-creating and putting policies into practice to "make real" FRIDA's commitment to well-being "so that it goes beyond written documents."

\footnotetext{
${ }^{474}$ FRIDA uses the term "manifestx" rather than "manifesto", rejecting the gendered nature of "manifesto" in Romance languages, and instead recognizing the importance of inclusivity.

${ }^{475}$ Happiness Manifestx, FRIDA, https://youngfeministfund.org/home/happiness-manifestx/ (last visited May 12, 2019).
} 
Within this team, there is a "holistic security working group" which considers well-being issues not just among staff but also in relation to grantees, partners, the advisory, and the broader community of advocates that FRIDA supports.

Within its formal human resources policies, FRIDA is working to strengthen language and resource allocation devoted to well-being and collective care. For instance, this includes encouraging staff to take time off or utilize "mental health days" when needed to protect their well-being. FRIDA has sought to debunk the perception that taking breaks is taboo and has reframed taking time out as a means of giving back by prioritizing selfcare. FRIDA links professional development and leave to well-being in recognition that taking time to access coaching or attend a workshop not only expands one's skill-base but also enhances well-being. This is because happiness and job satisfaction are often tied to learning opportunities. In addition, staff are able to use their health benefits to claim reimbursements for more holistic health needs, such as therapy, acupuncture and holistic healthcare amongst other things. Since FRIDA works with female advocates, the organization has developed practices to provide mothers with the flexibility to bring their children to work meetings if needed. FRIDA is working to strengthen its care practices by ensuring these practices are reflected in policies. When FRIDA grew financially, it revised its salary scales to promote fairer wages in recognition that "people having enough money to live [is] an important part of their well-being and mental health." Given recent organizational growth, FRIDA hopes to repeat this process during upcoming salary reviews which take place periodically.

In 2013, FRIDA adopted a shared leadership model which Johnson has personally benefited from. She finds that having someone to learn and share with in a safe space is "absolutely critical" to her role: "I actually don't think this is a job that one person can do." Johnson explains that co-leadership provides an inbuilt support mechanism around well-being which provides "dual mentoring support." FRIDA has sought to replicate this model across the organization by having a "co-chair model" on the board and also two people at the same level in various teams. This provides staff the "support mechanism of another person doing a similar role to them where they can learn together safely and give each other feedback."

In its capacity as a funder, FRIDA believes it should lead by example. FRIDA provides funding to organizations to support their work on collective care and well-being. Further, FRIDA's commitment to collective leadership is reflected in its choice of grantees, with many organizations funded by FRIDA having either co-leadership, decentralized or entirely flat structures. As a donor itself, Johnson utilizes FRIDA's opportunity to open 
the well-being conversation to fellow donors. For instance, at a human rights funders' network event, FRIDA co-led a session with Urgent Action Fund Latin America on collective care and how funders can play a role in supporting organizations and activists who prioritize these issues.

According to Johnson, FRIDA's commitment to well-being is shared from the leadership level to the board, and is reflected in its documentation and public communications. However, going forward, FRIDA hopes to improve uptake of the well-being opportunities and benefits that can be claimed and accessed through the organization. Johnson hopes to do this by making FRIDA's support policies more open and transparent so that staff can better utilize the resources that are readily available to them.

Critically, Johnson identified the biggest challenge as striking a balance between how to practice the values and engage in meaningful conversations about collective care, sustainability and well-being without generating excessive workloads. She highlighted that, ironically, taking the opportunity to present on collective care, talk in well-being spaces, and even participate in this interview generates more work: "That's the biggest contradiction with all of this, everything generates more things to do." This tension is said to be reflective of the human rights sector at large because everyone is "always wanting to do more and more," and pushing to "produce things, spark new collaborations and be visible." This is because when you are passionate about your work, it is challenging to refrain from doing more. Johnson explained that, "Ultimately it seems it requires a reprioritization of what is important and a practice of truly placing collective care and well-being at the heart of your organization and all that you do." Despite the challenges in practicing well-being values, FRIDA recognizes that it is only at the beginning of this journey and remains dedicated to a constant process of "learning and unlearning," reflecting, and trying again the next day.

\section{E. CASE Study 5: CREATING AN ORGANizATIONAL CUlture that VALUES WELL-BEING: THE ASSOCIATION FOR WOMEN'S RIGHTS IN DEVELOPMENT ${ }^{476}$}

The Association for Women's Rights in Development (“AWID") is an international, feminist, membership organization that works to support feminist, women's rights and gender justice movements to thrive. It seeks to be a driving force in challenging systems of oppression, and in cocreating feminist realities. With partners and members in over 164

\footnotetext{
${ }^{476}$ Interview with Cindy Clark \& Shareen Gokal, supra note 69.
} 
countries, AWID advances its mission through collaborative advocacy and knowledge building, and holding convenings to connect advocates globally and strengthen solidarity. Among the 39 staff members working virtually across 17 countries are Cindy Clark, AWID's Co-Executive Director, and Shareen Gokal, AWID's Director of Special Projects.

When asked what motivated AWID's approach to well-being, Clark said: "to see so many wonderful, amazing activists impacted, we realized we have to do something about it." The cultural shift within AWID has been credited to a number of factors. Firstly, AWID's engagement with women human rights defenders, including their role as one of the founding organizations of the Mesoamerican Women Human Rights Defenders Initiative ("IMD"), ${ }^{477}$ deepened their thinking on self-care and well-being. Particularly important has been the framework of holistic protection that IMD developed, which centers a collective approach to security and protection, with strong attention to self-care and well-being as a core element in protection for human rights defenders. Secondly, a member of staff who had particular insight into mental health issues played a significant role as an internal champion to destigmatize mental health and make it a part of normal life within the organization. By sharing her own personal challenges, this encouraged others to do the same. Thirdly, AWID hired a new Human Resources ("HR") Manager who has transformed the organizational response to mental health concerns by introducing new practices, promoting open communication, and providing greater consistency and support for managers and staff.

According to Gokal, leadership has played a key role in shifting the organizational tone at AWID. Among staff, AWID's shared or distributed leadership model provides collaborative support. This can happen through role-sharing (as in AWID's current Co-Executive Director model), or through the project team structure which de-centralizes project leadership. Between managers and their staff, Gokal emphasizes the importance of "modelling": "If [managers] set the tone where all work is considered urgent, then there isn't room for true staff wellness and it adds to the stress and pressure staff may be feeling." On the other hand, if leadership encourages staff to take a break or fosters organizational practices such as "no meeting days" to give staff uninterrupted time to get work done, this can have a significant impact on well-being. For Gokal, it's all about leaders

\footnotetext{
${ }^{477}$ Another organization that was interviewed for the purposes of this study. See "Case Study 1: Paving a Feminist Path Toward Well-Being and Care: The Iniciativa Mesoamericana de Mujeres Defensoras de Derechos Humanos (Mesoamerican Initiative of Women Human Rights Defenders)," supra pp. 539-42.
} 
"walking the talk" so that staff are treated as "more than just the products of their work."

With the support of AWID's leadership team, the staff champion rallied an internal working group on "being well at AWID," which developed a preliminary assessment and recommendations to strengthen both staff and organizational attention to well-being. The assessment drew from select interviews and results from AWID's annual confidential staff survey, intended to take the pulse of staff concerning their experience in the organization. Factors identified as having a negative impact on well-being included: a sense of unmanageable workload; the emotionally draining nature of the work for some staff; unclear expectations; and challenges associated with working as a geographically dispersed, "virtual" organization such as communication breakdowns, feelings of isolation and inadequate trust across the organization. The assessment was shared during staff calls and recommendations were gathered to support ways of working that could address these challenges.

As a result, AWID adopted a number of measures to manage staff stress and support well-being. AWID strengthened work planning systems and introduced new tools for project management and information sharing across the organization. Further, AWID's employee handbook includes policies which are intended to support well-being, such as sick leave explicitly including mental health care leave. Rather than a health benefit "reimbursement" which had to be justified and enjoyed uneven uptake across staff, AWID now provides a health promotion "contribution" to all staff at the beginning of each year to use in any manner that staff see fit to support their wellness. As a virtual organization, for those who need more interaction, AWID supports staff to find a like-minded organization that they can share space with or covers the cost to hire a desk in shared office spaces. Recognizing that increasing security risks for human rights defenders intersect with mental health challenges, AWID developed an integrated protection and security plan, building on guidelines shared by various human rights organizations. In addition, the HR Manager uses individual risk assessments and security plans to provide personalized support to staff.

While the organizational culture has improved, Clark says that AWID can still do more. The challenge remains, not in the creation and understanding of well-being policies, but in their implementation and practice - this is where the new HR manager is helping by providing clear and consistent support to managers and staff. According to Clark, there are still moments of extreme demand on AWID staff, and the organization is still honing mechanisms to support staff through such intensity. Further, 
sometimes even well-intended and generally celebrated acts like a promotion might in fact undermine staff well-being. For instance, promoting staff without providing the necessary support to deal with the added pressures of the new role can cause harm. AWID is working to be more mindful of these issues and also seeking to strengthen mental health awareness and education. Gokal highlighted the need to equip staff with the ability to recognize warning signs, not only in others but also themselves. Although mental health concerns are not swept under the rug, the stigma has not completely disappeared.

According to the latest organizational survey, just over half the staff feel that AWID either "greatly" or "completely" pays attention to their wellness, holistic protection and security. When asked to share advice for other organizations, Gokal felt that one of AWID's key learnings was to avoid imposing "impossible workloads" which cause unreasonable stress and burnout. Instead, she emphasized the need for "realistic work planning" that leaves room for the unexpected and "recognizes that we don't always work at $100 \%$ capacity." When faced with conflicting priorities, Gokal insisted that sometimes it is appropriate to prioritize self-care instead of meeting a deadline. However, for staff to feel like they can exercise this judgment and engage in sustainable work practices requires a cultural shift within human rights organizations.

Recently, AWID commenced a bold experiment called "Wellness Fridays." To support wellness and sustainability, full-time staff can elect to work their 35 hour week in four days instead of five. Staff are encouraged to use their "Wellness Friday" to do anything that will increase their wellness, such as: visit health practitioners; attend a class or creative workshop; exercise; sleep; spend time with loved ones; or read a book that they haven't had time for. AWID offers this as an election-not a mandatory requirement - in recognition that not all staff are able to work increased hours on certain days due to, for instance, child-care obligations. However, all staff are asked to adhere to a "no-call" policy on Fridays and to limit internal emails on Fridays to support the inbox wellness of those with a reduced work week. Throughout 2019, AWID's HR department will collect feedback through staff surveys to monitor whether "Wellness Fridays" is increasing wellbeing for staff and maintaining the sustainability of the organization. In rolling out this program, Clark describes it as AWID's attempt to "explore new ways of working which can improve our lives and the way we work." This creative experiment serves as an innovative example for other organizations seeking to foster a "healthy, well and sustainable work week." 